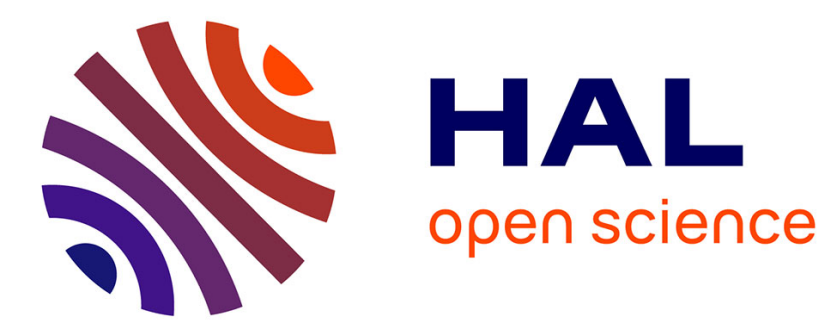

\title{
Nanomedicine-Based Approaches for mRNA Delivery
}

Satoshi Uchida, Federico Perche, Chantal Pichon, Horacio Cabral

\section{To cite this version:}

Satoshi Uchida, Federico Perche, Chantal Pichon, Horacio Cabral. Nanomedicine-Based Approaches for mRNA Delivery. Molecular Pharmaceutics, 2020, 17 (10), pp.3654 - 3684. 10.1021/acs.molpharmaceut.0c00618 . hal-02995814

\section{HAL Id: hal-02995814 https://hal.science/hal-02995814}

Submitted on 9 Nov 2020

HAL is a multi-disciplinary open access archive for the deposit and dissemination of scientific research documents, whether they are published or not. The documents may come from teaching and research institutions in France or abroad, or from public or private research centers.
L'archive ouverte pluridisciplinaire HAL, est destinée au dépôt et à la diffusion de documents scientifiques de niveau recherche, publiés ou non, émanant des établissements d'enseignement et de recherche français ou étrangers, des laboratoires publics ou privés. 
Subscriber access provided by bibCNRS INSB

\title{
Review
}

\section{Nanomedicine-based approaches for mRNA delivery}

\author{
Satoshi Uchida, Federico Perche, Chantal Pichon, and Horacio Cabral
}

Mol. Pharmaceutics, Just Accepted Manuscript • DOI: 10.1021/acs.molpharmaceut.0c00618 • Publication Date (Web): 26 Aug 2020

Downloaded from pubs.acs.org on September 2, 2020

\section{Just Accepted}

"Just Accepted" manuscripts have been peer-reviewed and accepted for publication. They are posted online prior to technical editing, formatting for publication and author proofing. The American Chemical Society provides "Just Accepted" as a service to the research community to expedite the dissemination of scientific material as soon as possible after acceptance. "Just Accepted" manuscripts appear in full in PDF format accompanied by an HTML abstract. "Just Accepted" manuscripts have been fully peer reviewed, but should not be considered the official version of record. They are citable by the Digital Object Identifier (DOI®). "Just Accepted" is an optional service offered to authors. Therefore, the "Just Accepted" Web site may not include all articles that will be published in the journal. After a manuscript is technically edited and formatted, it will be removed from the "Just Accepted" Web site and published as an ASAP article. Note that technical editing may introduce minor changes to the manuscript text and/or graphics which could affect content, and all legal disclaimers and ethical guidelines that apply to the journal pertain. ACS cannot be held responsible for errors or consequences arising from the use of information contained in these "Just Accepted" manuscripts. 
$4{ }^{1}$ Department of Bioengineering, Graduate School of Engineering, The University of Tokyo, 7-3-1 Hongo, 5 Bunkyo-ku, Tokyo 113-8656, Japan.

6 Innovation Center of NanoMedicine, Kawasaki Institute of Industrial Promotion, 3-25-14, Tonomachi, 7 Kawasaki-ku, Kawasaki 210-0821, Japan.

$8{ }^{3}$ Centre de Biophysique Moléculaire, UPR4301 CNRS Rue Charles Sadron Orléans, Orléans Cedex 02, 9 France.

$10{ }^{4}$ University of Orleans, Faculty of Sciences and techniques, 45071 Orléans, France

11

$12 *$ Corresponding author

13 Horacio Cabral, $\mathrm{PhD}$

14 horacio@bmw.t.u-tokyo.ac.jp
15

16

\section{Abstract}

18 Messenger RNA (mRNA) has immense potential for developing a wide range of therapies, including 19 immunotherapy and protein replacement. As mRNA presents no risk of integration into the host genome 20 and does not require nuclear entry for transfection, which allows protein production even in non-dividing 21 cells, mRNA-based approaches can be envisioned as safe and practical therapeutic strategies. 22 Nevertheless, mRNA presents unfavorable characteristics, such as large size, immunogenicity, limited 23 cellular uptake and sensitivity to enzymatic degradation, which hinder its use as therapeutic agent. While 24 mRNA stability and immunogenicity have been ameliorated by direct modifications on the mRNA 
1 structure, further improvements in mRNA delivery are still needed for promoting its activity in biological 2 settings. In this regard, nanomedicine has shown the ability for spatiotemporally controlling the function 3 of a myriad of bioactive agents in vivo. Direct engineering of nanomedicine structures for loading, 4 protecting and releasing mRNA, and navigating in biological environments, can then be applied for 5 promoting mRNA translation toward the development of effective treatments. Here, we review recent 6 approaches aimed at enhancing mRNA function and its delivery through nanomedicines, with particular 7 emphasis on their applications and eventual clinical translation.

\section{Keywords}

10 mRNA delivery; mRNA engineering; Nanomedicine; mRNA therapeutics; Clinical translation

11

\section{1. Introduction}

Messenger RNA (mRNA) mediates the translation of genetic information from genes into proteins. Delivering exogenous mRNA into cells allows to transiently produce proteins in a precise manner. Such mRNA-mediated transfection offers an attractive alternative to plasmid DNA (pDNA)based gene therapy by expressing proteins even in non-dividing and hard to transfect cells without the risks of genomic integration. ${ }^{1}$ Moreover, while pDNA needs to be delivered inside the nucleus of targeted cells, the access of mRNA to the cytosol and the subsequent engagement with the translation machinery of the cells are sufficient to obtain the proteins of interest. The mRNA delivered inside the cells can also last for several days, which is convenient for developing efficient therapeutic strategies, as well as commercially viable approaches. On the other hand, mRNA presents inherent limitations for being used as a stand-alone drug, including fast degradation by nucleases, limited cellular uptake, and immunogenicity. ${ }^{2}$ While the immunogenic signals triggered by mRNA could be exploited for vaccination or immunotherapy applications, ${ }^{3}$ major efforts have been dedicated to reduce mRNA immunogenicity 
1 and improve the stability of the molecule by either chemical modification or by RNA architectonics, 2 aiming at increasing the significance of mRNA as a therapeutic agent. Nevertheless, mRNA is still 3 susceptible to degradation and the cellular uptake of naked mRNA should be improve for eliciting 4 adequate amounts of proteins. Thus, the development of safe carrier systems capable of intracellular 5 delivery of intact mRNA molecules is fundamental for progressing into effective treatments.
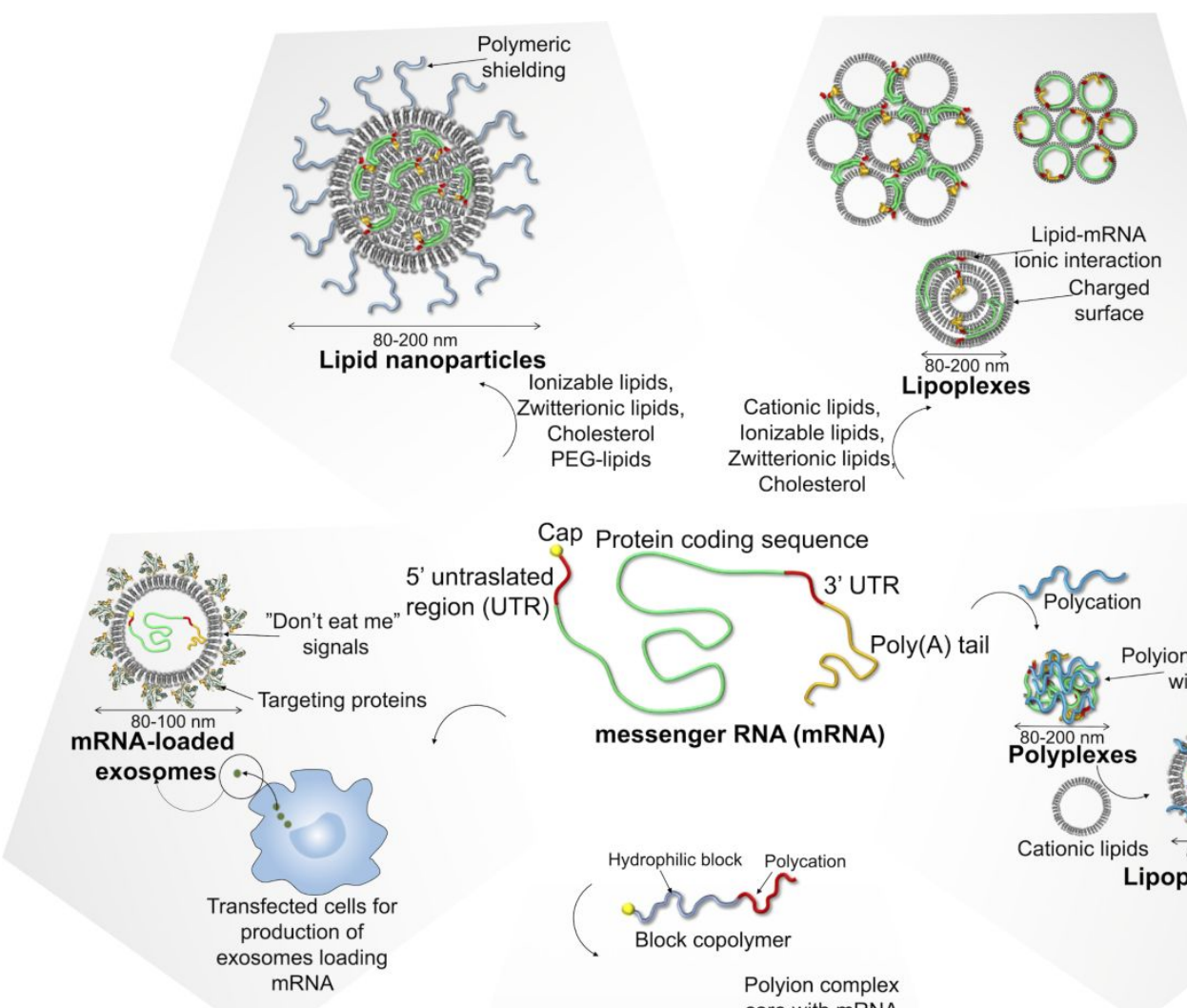

Cap Protein coding sequence
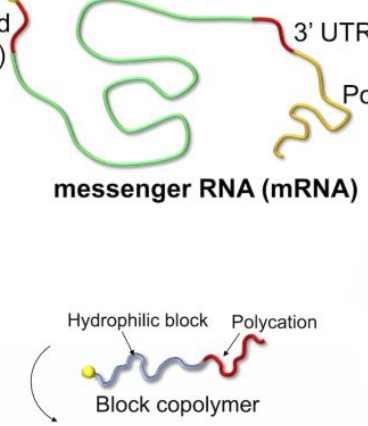

messenger RNA (mRNA)

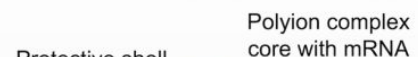

8 Figure 1. Nanomedicine approaches for mRNA delivery. Various platforms are under intense research

9 and development for the delivery of mRNA based on their unique ability to promote navigation in

10 biological environments, intracellular delivery and engagement with the translation machinery of cells. 
A wide range of nano-scaled carriers are under intense investigation for developing mRNA

3 delivery systems. ${ }^{1}$ Viral vectors, which have been extremely useful for delivering other nucleic acids, 4 have been among the first carriers to be considered for developing mRNA delivery systems. ${ }^{4}$ 5 Nevertheless, viral carriers present intrinsic limitations, such as small packing size, immunogenicity, 6 cytotoxicity and complex production processes, ${ }^{5}$ which have spurred the development of safe and 7 effective non-viral vehicles. ${ }^{6,7}$ These non-viral vehicles can benefit from a myriad of biocompatible 8 synthetic and natural materials for attaining specific physicochemical and functional features directed to 9 develop mRNA-loaded nanomedicines with improved mRNA bioavailability, targeting to specific 10 tissues and cells, and enhanced cellular uptake and intracellular release of mRNA molecules (Figure 1). 11 Thus, various non-viral strategies have achieved major breakthroughs in the in vivo delivery of mRNA, 12 as well as in the clinical translation of mRNA-based therapies. ${ }^{1,6,7}$

13 Here, we present the recent progress in mRNA-loaded nanomedicine toward innovating 14 vaccination, immunotherapy, treatment of genetic disorders and protein replacement approaches. We 15 have focused on the different non-viral strategies with emphasis on the employed materials and the 16 advantages offered by each approach. Moreover, the mRNA modification methods are also reviewed, 17 highlighting opportunities for synergistically enhancing nanomedicine efficiency. Finally, the trends in 18 the application of mRNA-loaded nanomedicines and their future perspectives are discussed.

\section{2. Engineering mRNA for enhanced function}

21 mRNA modification by approaches that enhance the stability and promote its function have 22 been considered for improving mRNA biological activity, as well as reducing immunogenicity issues. 23 Notably, these modification methods do not affect the main structural features of mRNA, i.e. being a 24 negatively-charged macromolecule, which provides opportunities for developing orthogonal cooperative 
1 approaches in combination with nanomedicine with potential for synergistic enhancement of mRNA 2 function. We have categorized these methods as chemical modifications of mRNA, introduction of self3 replication functions to mRNA sequences, stabilization through RNA architectonics and circularization 4 of RNA. In the following sections, we review each of these approaches.

\section{2.1. Chemical modifications of mRNA}

Chemical modification of mRNA structure is an effective way for promoting mRNAs that are more resistant to enzymatic degradation than their native counterparts, as well as mRNAs with decreased immunogenicity. Major strategies have focused on the introduction of a m7G 5'-Cap structure ${ }^{8,}$, modifications through poly(A) tails ${ }^{10,11}$, incorporation of untranslated regions (UTRs) ${ }^{12,13}$, and insertion 11 of modified nucleotides ${ }^{11}$ to the structure of mRNA (Figure 1). In the following sections, we summarize 12 the advantages provided by these features.

\section{2.1.1. 5'-Cap structure}

During maturation of primary transcripts, a cap is added at the 5 ' extremity of pre-mRNA. ${ }^{14}$ 16 This step occurs very early, before the addition of the first 30 nucleotides. The $5^{\prime}$-cap consists of an 17 inverted 7-methylguanosine connected to the rest of the eukaryotic mRNA via a 5'-5' triphosphate bridge 18 (m7GpppN, Cap 0). Besides Cap 0, the cap can be further modified by methylation at the 2'-O position 19 of the +1 ribonucleotide (m7GpppNm, Cap 1) or the +2 ribonucleotide (m7GpppNmNm, Cap 2), 20 respectively. ${ }^{15}$ This methylation is necessary to distinguish self from viral RNA. ${ }^{16}$ The presence of the 21 cap is first required for RNA export from the nucleus after binding to the cap binding complex. ${ }^{17}$ Once 22 in the cytoplasm, the cap is required for initiation of translation and protection against nuclease 23 degradation. ${ }^{18,19}$ Accordingly, cap analogs are incorporated in synthetic mRNA by 2 strategies: post24 transcriptional capping or co-transcriptional capping. ${ }^{17}$ In post-transcriptional capping, capping enzymes 
1 from RNA viruses (mostly Vaccinia) are used to produce cap1-capped mRNA using GMP. Although 2 very effective, this strategy requires the expensive production and purification of capping enzymes and 3 is limited to existing natural cap structures. ${ }^{17,20}$

In co-transcriptional capping, chemical cap analogs are incorporated during transcription. This 5 allows optimization of chemical analogs, a work well covered by Jemielity's group, as reviewed 6 elsewhere. ${ }^{8}$ During transcription, the $\mathrm{m} 7 \mathrm{G}$ cap analog can be incorporated either in correct orientation 7 with the methylated guanosine in $5^{\prime}\left(\mathrm{m}^{7} \mathrm{GpppGpN}\right)$ or inverted orientation $\left(\mathrm{Gpppm}^{7} \mathrm{GpN}\right)$, with a sharp 8 decrease in translation efficiency of mRNA with inverted cap. ${ }^{21}$

The ARCA (Anti Reverse Cap Analog) has been developed for obliged incorporation in the correct orientation. ${ }^{22}$ In this analog, the hydroxyls of the ribose have been substituted by $\mathrm{OCH}_{3}$, this stops 11 elongation in the incorrect orientation as it prevents bonds between nucleotides. ARCA-capped mRNAs cleave the triphosphate bond. Analogs with the second phosphate replaced by an heteroatom have been

have 1.8-fold higher translation efficiency over uncapped- or m7G-capped mRNAs. ${ }^{23}$

Chemical cap analogs aimed at decreasing cleavage by Dcp1/2 decapping enzymes which developed: either carbon $^{24}$ or nitrogen ${ }^{25}$. Bridging oxygens have also been substituted with dihalogenmethylenebisphosphonate, and were superior to phosphate substitution both in terms of resistance towards hydrolysis and translation. ${ }^{26}$

Analogs combining ARCA and phosphorothioated riboses have also been developed ( $\beta$-SARCA analogs). ${ }^{9,} 27$ Such analogs allowed 3-fold higher expression in vivo in mice over ARCA-capped mRNA resulting in superior immune response induction. ${ }^{28}$ Increased translation of $\beta$-S-ARCA-capped mRNA was related to increased affinity for the cap-binding translation initiation factor eIF4E and increased resistance to Dcp2 or Dcps degradation over ARCA or m7G caps. ${ }^{9}, 27,29$

A further refinement in cap design has been to optimize the first transcribed nucleotide. Indeed, 24 mammalian mRNA can be capped with cap1/cap2 with different first nucleotide (A,G,C,U). ${ }^{30}$ Sirkoski 
1 et al. compared the translation efficiency of in vitro transcribed and HPLC-purified mRNA harboring 2 caps with different first nucleotides. ${ }^{31}$ They synthetized trinucleotides cap analogs m7GpppNpG where $3 \mathrm{~N}$ is the unmethylated or methylated nucleotide and, used them for co-transcriptional capping. They 4 reported that guanine as the first transcribed nucleotide led to the lowest expression in JAWSII murine 5 dendritic cells: 20 -fold lower expression of $\mathrm{m} 7 \mathrm{GpppGpG}$ cap compared to m7GpppApG cap. This was 6 not due to increased affinity for eIF4E nor increased resistance to decapping enzymes and is in agreement 7 with the abundance of adenosine as first nucleotide in human cell lines. ${ }^{30}$

One of the drawbacks of co-transcriptional capping is that, due to competition with GTP, not 9 all cap analogs are incorporated alongside transcription and, the efficiency of capping is around 8010 11 12 2.1.2 Poly(A) tail

Another step of pre-mRNA maturation occurs after release from the RNA polymerase II. ${ }^{14}$ At 14 the $3^{\prime}$ extremity, pre-mRNA is cleaved at 20 nucleotides after a consensus polyadenylation sequence 15 (AAUAAA). ${ }^{34}$ After cleavage, the polyA polymerase binds to the pre-mRNA and adds a 100 to 250 adenosines polyA tail. The presence of the poly(A) tail is required for translation and for protection against degradation. ${ }^{1}$

Polyadenylation of synthetic mRNA can be achieved either by enzymatic polyadenylation of capped mRNA or by cloning a poly(T) sequence in the plasmid template. ${ }^{35}$ However, enzymatic polyadenylation yields mRNAs with profound differences in poly(A) lengths resulting in a mixture of mRNAs critically affecting reproducibility and purity of mRNA. ${ }^{35,36}$

Electroporation of dendritic cells and cancer cells with mRNAs of different poly(A) lengths $23(0,16,42,51$ or $120 \mathrm{~A})$ demonstrated the requirement of a poly(A) tail for in cellulo translation and a 24 critical impact of poly(A) length on translation efficiency. ${ }^{35} \mathrm{GFP}-120 \mathrm{~A}$ mRNA resulted in a 4-fold higher 
1 transcript level over 51A or 42A mRNA $24 \mathrm{~h}$ after electroporation. Increased transcript levels were 2 correlated with higher GFP protein levels. On the contrary, transcript and protein levels were negligible 3 after electroporation of untailed mRNA or mRNA with 16A. Following studies confirmed that the 4 optimal length of the tail is between $120 \mathrm{~A}$ and $150 \mathrm{~A}$, and that is should not be masked by additional 5 bases. ${ }^{37-41}$

\section{2.1.3. Untranslated regions}

$5^{\prime}$ and $3^{\prime}$ UTRs regulate both translation and stability of mRNA. ${ }^{14}$ Therefore a strategy to

9 increase translation efficiency and half-life of synthetic mRNA is to include UTRs sequences from stable and highly translated mRNA such as beta-globin, albumin, complement factor 3 (C3) and cytochrome $11 \mathrm{p} 4502 \mathrm{E} 1$ (CYP2E1). ${ }^{12,13}$ The $5^{\prime}$ UTR plays a critical role in the initiation of translation as it controls both 12 mRNA scanning and the selection of the initiation codon. ${ }^{42}$ Because of this role, highly structured $5^{\prime}$ 13 UTR regions are avoided and more research has been focused on 3' UTRs. 3' UTRs derived from $\alpha$ - or $14 \quad \beta$-globin, which have long half-lives in erythrocytes (enucleated cells) are the most frequently used for 15 mRNA, ${ }^{10,} 43$ particularly when two 2 sequential $\beta$-globin $3^{\prime}$ UTRs are fused head to tail. ${ }^{35}$ Since 16 homologous double UTR (dUTRs) are unstable and prone to recombination, heterologous dUTRs are 17 preferred. ${ }^{44}, 45$ Sahin's group used a SELEX (Systematic Evolution of Ligands by Exponential 18 enrichment) to identify best dUTRs for vaccination and cell reprogramming. ${ }^{45}$ They tested 64 19 combinations of dUTRs. The two best dUTRs identified were mtRNR1 (mitochondrially encoded 12S 20 rRNA) / $\beta$-globin and mtRNR1/ AES (Amino Enhancer of Split) with both 1.89-fold mRNA half-life 21 over double $\beta$-globin UTR in human dendritic cells (hDCs). Superior half-life was mirrored with 22 decreased miRNA binding. mtRNR1/AES dUTR also improved mRNA translation in hDCs by 1.6-fold 23 over double $\beta$-globin UTR. The intravenous injection of luciferase mRNA lipoplexes in mice revealed a 
13 -fold higher expression of mtRNR1/AES dUTR over double $\beta$-globin UTR, which resulted in superior 2 induction of antigen-specific $\mathrm{T}$ cells. For the reprogramming of human foreskin fibroblasts, the 3 AES/mtRNR1 dUTR was the best demonstrating a cell type specificity for optimal dUTR. Recently, 4 Asrani et al. evaluated a library of 10 variants of 5' and 3' UTRs in their ability to improve arginase 1 5 mRNA expression. ${ }^{12}$ They reported higher dependence of mRNA translation on $5^{\prime}$ UTR sequence relative 6 to $3^{\prime}$ UTR variants. Moreover, improved protein production was associated with increased protein 7 translation efficiency, and not to an improved mRNA stability. UTR sequences from C3 and CYP2E1 8 were found to be the most efficient.

Besides optimization of $5^{\prime}$ UTR and $3^{\prime}$ UTR regions, sequence engineering of the coding 10 sequence is also required for maximal expression. ${ }^{46}$ Whereas AU-rich motifs are prone to exosome11 mediated degradation of mRNA, GC-rich mRNAs have increased expression. ${ }^{47-49}$ Accordingly, mRNA 12 sequences have been optimized to be GC-rich. ${ }^{50-52}$

\subsubsection{Modified nucleotides}

The first generation of synthetic mRNA lacked the diversity of natural nucleotides present in mammalian mRNA with natural modified nucleotides such as pseudouridine $(\Psi), 5$-methylcytidine (5meC), N6-Methyladenosine (m6A), 5-methyluridine (m5U), or 2-thiouridine $\left(\mathrm{S}^{2} \mathrm{U}\right) .{ }^{11,53}$ This led to recognition of mRNA as foreign mRNA by intracellular sensors, such as Toll Like Receptors (TLRs) 7 and 8 , resulting in the induction of type I interferon (INF $\alpha / \beta)$ expression and associated anti-viral responses. These signals resulted in mRNA translation suppression and degradation, and even host cell apoptosis. ${ }^{54,55}$

Incorporation of $\Psi$ is the most frequent modification of synthetic mRNA. ${ }^{56} \Psi$-modified mRNA 23 resists RNase degradation ${ }^{57}$ and lacks TLR activation ${ }^{54}$ resulting in improved translation in cell lysates 24 and cultured cells. ${ }^{58,59}$ Then, combination of modifications have been preferred to mirror the diversity 
1 of natural mRNA. Andries et al. reported that mRNA harboring both $\mathrm{N}$ methyl $\Psi(\mathrm{m} 1 \Psi)$ and $\mathrm{m} 5 \mathrm{C}$

2 outperformed mRNA with single $\Psi$ modification or m5C and $\Psi$ modifications in several cell lines and 3 in vivo. ${ }^{60}$ Notably, they showed that after intramuscular or intradermal injection of luciferase mRNA 4 lipoplexes, $\mathrm{m} 1 \Psi$-mRNA yielded 13-fold higher expression over $\Psi$-mRNA and 4-fold higher expression 5 over $\mathrm{m} 5 \mathrm{C} / \Psi$ - or $\mathrm{m} 5 \mathrm{C} / \mathrm{m} 1 \Psi$-modified mRNA suggesting $\mathrm{m} 1 \Psi$ as a new standard for chemically 6 modified mRNA.

7 Importantly, the incorporation of modified nucleotides is cell-type and mRNA sequence8 dependent, requesting application-based screening of modifications. ${ }^{61-63}$ For instance, Li et al., re- ported 9 that, in THP-1 macrophages, $5 \mathrm{meC} / \Psi$ modified Fluc mRNA resulted in significantly higher Fluc 10 expression, while $5 \mathrm{meC} / \Psi$ modified eGFP mRNA resulted in a decreased GFP expression; $\mathrm{m} 1 \Psi$ 11 modified Fluc in THP-1 cells generated 8-fold more Fluc than that in hepatocellular carcinoma Hep 3B 12 cells. $^{62}$

\section{2.2. Self-amplifying $R N A$}

Another approach to increase the activity of mRNA comes from mimicry of RNA viruses. Indeed, RNA viruses need to replicate their genome in the host cell for virion production. ${ }^{64}$ Accordingly, researchers have used strategies derived from RNA viruses for vaccination as early as $1999 .{ }^{65}$ These RNA with self-amplification capacity are called self-amplifying RNA (saRNA) or replicons. ${ }^{64,}$ 66, 67 In most studies, saRNA are derived from alphaviruses. ${ }^{39,65,66,68-72} \mathrm{In}$ alphaviruses, on part of the genome codes for non-structural proteins which assemble to form the RNA-dependent RNA polymerase (replicase), the other part for structural proteins (capsid and envelope proteins). ${ }^{73}$ After infection, replicase is expressed from the positive strand RNA genome to synthetize the minus RNA strand, which serves as template to amplify the genomic RNA and, for subgenomic RNA synthesis (Figure 2). It is 
1 important to notice that saRNA is amplified after a first round of translation to assemble the replicase, 2 highlighting similar bottlenecks for the early steps of mRNA and saRNA transfection. ${ }^{74,75}$

\section{Self-amplifying RNA replication and translation}

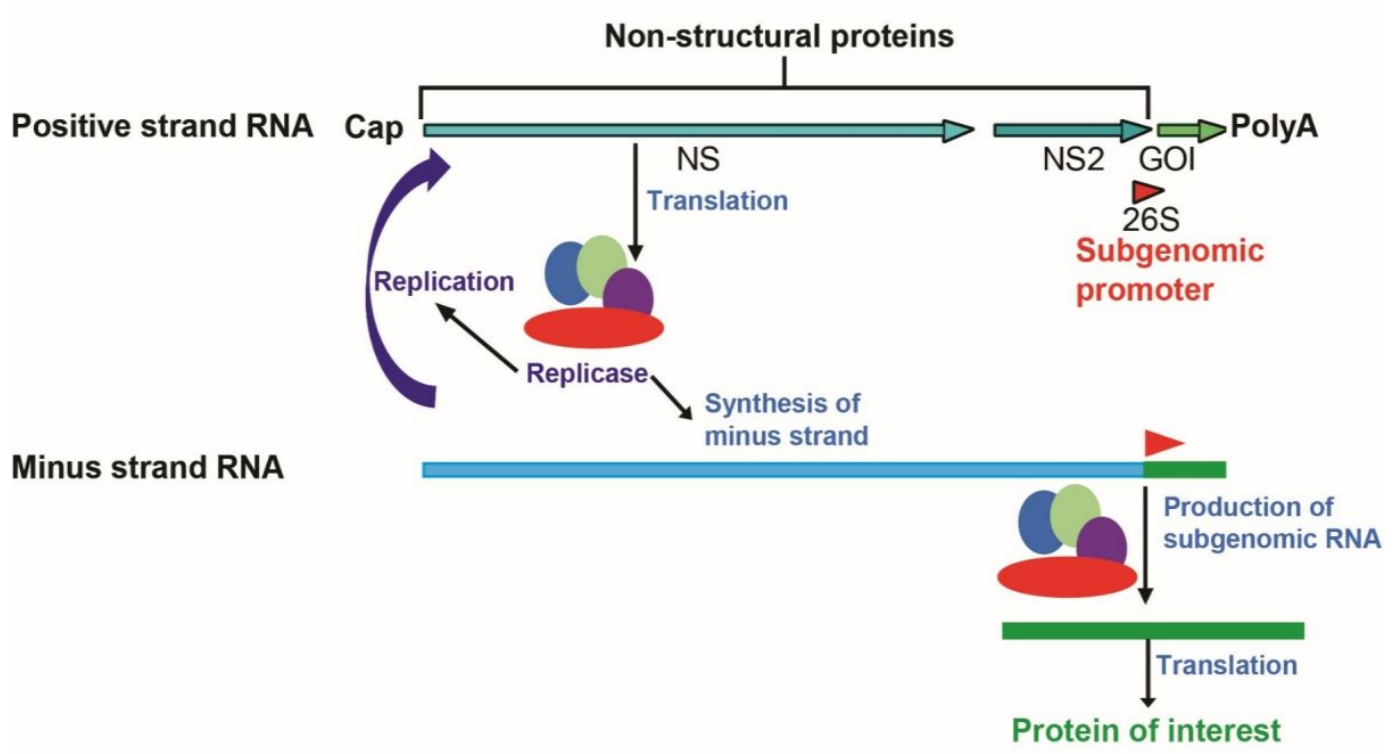

5 Figure 2. Replication and translation of saRNA. Early after infection the non-structural proteins (NS)

6 are translated and self-assemble to form the replicase. The replicase both amplifies the genome and 7 synthetizes the minus strand RNA. Finally, the replicase translated subgenomic RNA which contains 8 virulence genes allowing production of virions. In synthetic saRNA virulence genes (e.g. capsid) are 9 replaced by the gene of interest. The figure is based on information from a reference ${ }^{73}$.

\section{2.3. Circular RNA}

12 Another solution to face the degradation of RNA by exonucleases is the circularization of 13 RNA. ${ }^{76-79}$ This strategy was inspired by the endogenous circular RNA with covalently linked ends found 14 in viruses ${ }^{80}$, archaea ${ }^{81}$, all eukaryotes ${ }^{82}$ among which humans. ${ }^{83}$ CircRNA is formed by the pre-mRNA 15 splicing machinery from introns ${ }^{84,85}$ or from exons ${ }^{71,86}$ and its biogenesis is regulated by several factors 16 87. circRNA is generated by back-splicing to join a splice donor to an upstream splice acceptor (Figure 

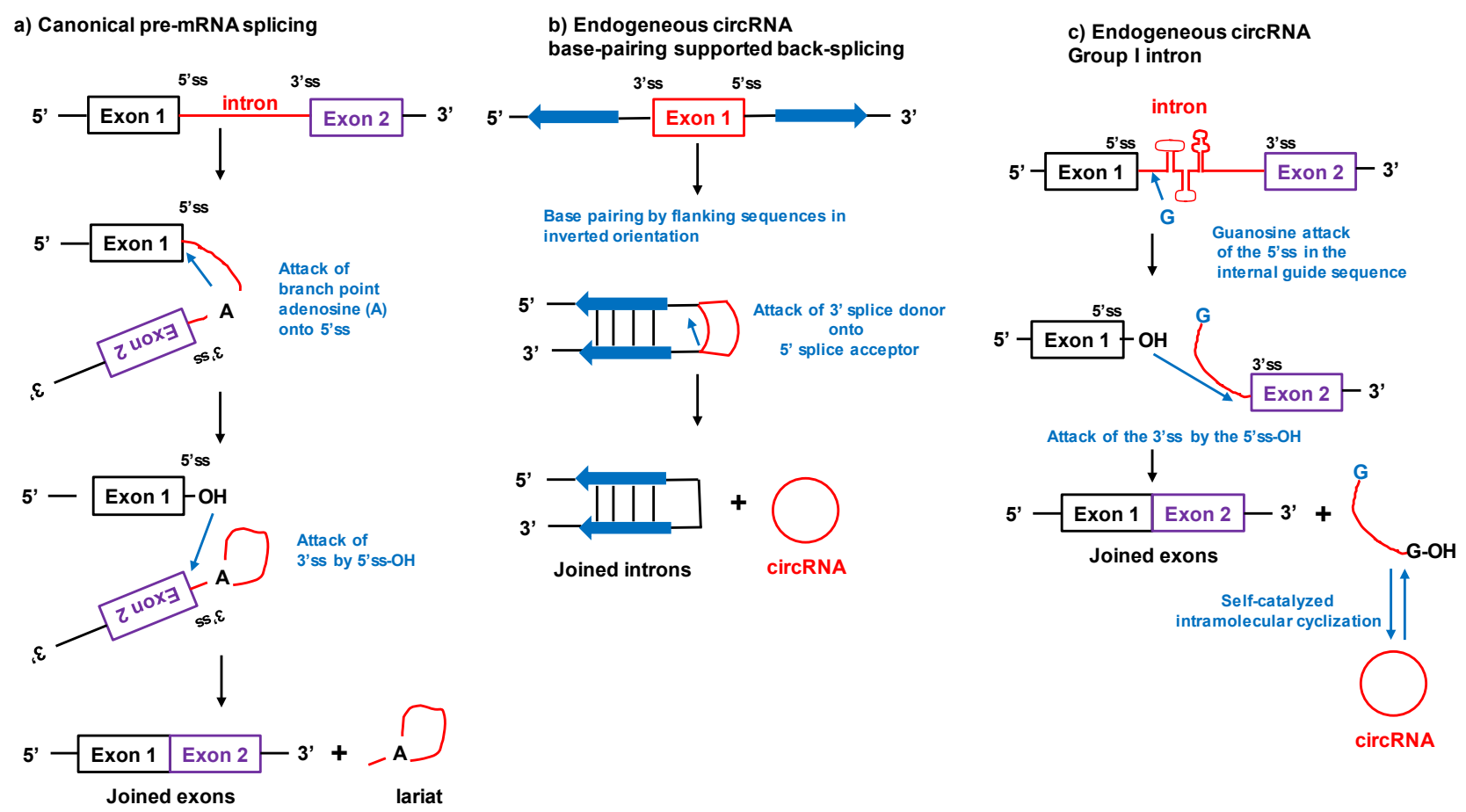

Figure 3. Canonical splicing, back-splicing and self-splicing. A. For pre-mRNA, the spliceosome 5 binds to 5' and 3' splice sites (5'ss and 3'ss). The then 2'OH of a 3'ss branchpoint nucleotide performs 6 a nucleophilic attack on the first nucleotide of the 5'ss. This results in the formation of an exon1-3'OH 7 and a lariat intermediate-exon2. Finally, 5'ss-OH attack of exon 2 3'ss joins exons and releases a lariat. 8 B. In back-splicing, 5'ss and 3'ss are in reverse orientation. As back-splicing is not sterically favorable, 9 it is supported by complementary base pairing of flanking exons which juxtaposes 5'ss and 3'ss. Then 103 'ss attack of the 5'ss splice acceptor joins the two introns and releases circRNA. C. An exogenous 11 guanosine $(\mathrm{G})$ attacks the 5'ss separating exon1 5'ss-OH from G-intron 3'ss-exon2. The, 5'ss attack of 12 the 3'ss results in exon joining and release of a linear intron. Group I introns possess a 3' terminal G and 13 this 3'G-OH performs a self-catalyzed nucleophilic attack close to the exogenous $\mathrm{G}$ resulting in the 14 formation of circRNA. The figures are based on information from references ${ }^{87-91}$.

For pre-mRNA canonical splicing, the spliceosome recognizes consensus intron/exon 17 boundary sites: $5^{\prime}$ splice site $\left(5^{\prime} \mathrm{ss}\right)$ and $3^{\prime}$ splice site (3'ss) to remove introns in two steps: 1$)$ formation 
1 of a free hydroxyl at the $5^{\prime} \mathrm{ss}, 2$ ) attack of the 3 'ss by the 5 'ss-OH resulting in exon joining and an excised 2 lariat (Figure 3A) ${ }^{89}$

Endogenous circRNA is generated when splicing occurs not between 5'ss of exon 1 and 3'ss

13 performs a nucleophilic attach on the 5'ss phosphate resulting in covalent linkage of $\mathrm{G}$ to the end of the 14 intron and generation of a reactive $\mathrm{OH}$ on the $5^{\prime} \mathrm{ss} .{ }^{88,90}$ The site of $\mathrm{G}$ attack is defined by an internal guide 15 sequence present in a duplex formed between the last nt of the 5'ss and the first nt of the intron. The 16 second step involves attack of the 3 'ss by the 5'ss-OH. This ligates the $5^{\prime}$ and $3^{\prime}$ exons and releases a 17 linear intron. Finally, the linear intron undergoes a self-catalyzed intramolecular cyclization reaction 18 (Figure 3C)..$^{96}$

19 CircRNA is resistant to exonucleases and highly stable with a median half-life of $24 \mathrm{~h} .{ }^{97}$ Due 20 to the low efficiency of back-splicing ${ }^{93}$, most circRNA have been categorized as side products of pre21 mRNA splicing ${ }^{98}$ or miRNA sponges. ${ }^{95}$ Only few circRNA have been proven to bind and regulate 22 specific miRNA $95,99,100$ or express proteins. ${ }^{101,102}$

23 Progression of RNA therapeutics in preclinical and clinical studies ${ }^{103,104}$ supported the demand 24 for circRNA to benefit from its enhanced stability. ${ }^{76-79,} 105$ Synthetic circRNA is prepared by 
1 intramolecular ligation of a linear precursor followed by elimination of linear RNA using RNAse R 2 (RNA circularization strategies reviewed in ${ }^{90,92}$ ). Use of exogeneous circRNA for protein expression in 3 mammalian cells is recent (2018). ${ }^{78}$ Authors used a permutated intron-exon method for RNA 4 circularization. This strategy had been applied in 1994 for circRNA production in yeast and bacteria 5 using group I intron of phage T4. ${ }^{106}$ Wesselhoeft et al used the group I intron in the thymidylate synthase 6 gene of the T4 phage. ${ }^{78}$ They took advantage of exon-joining by Group I introns and inserted a cassette 7 between 5'ss and 3'ss. Their construct contains 5' and 3' introns. They permuted 5'ss and 3'ss on both 8 sides of the cassette to circularize the insert between splicing sites by group I intron mediated exon 9 joining. The cassette contains an EMCV IRES (encephalomyocarditis virus internal ribosomal entry site) 10 for cap-independent translation followed y Gaussia luciferase with a 3'ss in 5' and a 5'ss in 3' (Figure 4). 11 Contrary to group I introns where intron is between two exons, in their construct the 5'ss and 3'ss are 12 separated by the inserted cassette, a distance unfavorable to group I intron self-splicing. Accordingly, 13 authors added homology arms (in green in Figure 4) in $5^{\prime}$ and $3^{\prime}$ to bring introns closer to 5'ss and 3'ss. 14 Using this strategy, they reported circularization of RNA up to 5, $000 \mathrm{nt}$ with close to $100 \%$ 15 circularization efficiency. 


\section{Group I intron and base-pairing inspired production of synthetic circRNA}

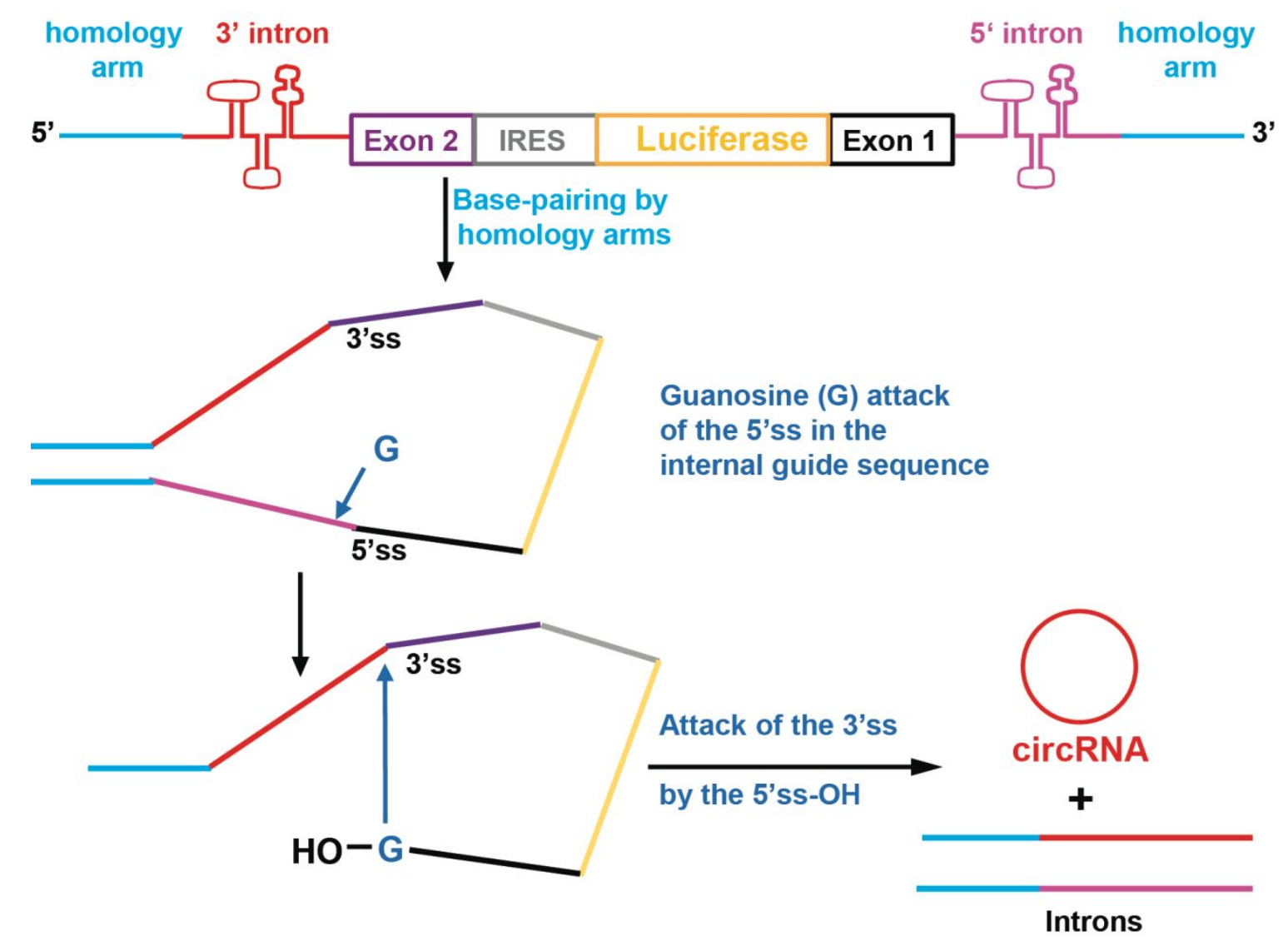

2 Figure 4. Production of exogeneous circRNA by a Group I intron-based strategy. The I intron-based 3 strategy, the 3'ss and 5'ss are too far from each other to allow splicing. Thus, homology arms are added 4 on both sides to bring the two splicing sites closer. Exogenous G attack of the 5'ss releases the 5' intron5 homology arm and produces an exon1-OH. This is followed by 5'ss-OH attack of the 3'ss to form a 6 circRNA and release the 3'intron-homology arm. The figures are based on information from a reference $7 \quad 78$. 8

9 Transfection of human cancer cells (HEK293) with circRNA complexed with Lipofectamine 10 Messenger Max (Invitrogen) resulted in 8-fold more luciferase expression over unmodified luciferase 11 mRNA and $50 \%$ more than nucleoside-modified mRNA. This was accompanied with a doubling of 12 luciferase production half-life reaching $80 \mathrm{~h}$ compared to $40 \mathrm{~h}$ for linear mRNA. Two critical 13 improvements of linear mRNA: HPLC purification and incorporation of modified nucleotides ${ }^{107}$ have 
1 also been applied to circRNA and further enhanced its translation and decreased its immunogenicity. ${ }^{76 \text {, }}$

$2{ }^{78}$ Circularization of RNA followed by HPLC purification reduces TLR and RIG-1 sensing. ${ }^{78}$ Concerning

3 incorporation of modified nucleotides it appears that the circRNA production method needs to be adapted 4 as replacement of uridine by methyl pseudo uridine or replacement of adenosine by N-methyl adenosine 5 greatly decreased splicing efficiency. ${ }^{79}$

Along with the stabilization against exonuclease, RNA circularization strategy has a potential 7 to improve the efficiency of protein production. Among the three protein translational processes, 8 initiation, elongation and termination, initiation is the rate-limiting phase. In circular RNA without stop 9 codon, ribosomes continue translation with low frequency of detachment from RNA, thereby skipping 10 rate-limiting re-initiation step. Indeed, circular RNA without stop codon improved the efficiency of 11 protein production compared to linear mRNA and circular RNA with stop codon in cell-free translational system from E. Coli, and also in human cells. ${ }^{108,109}$ For application of this strategy to mRNA therapeutics, 13 additional mechanism is needed to post-translationally cleave large protein translated from circular RNA 14 without stop codon for obtaining intended protein.

\section{4. $m R N A$ engineering with $R N A$ architectonics}

While chemical methods have provided improved translational activity and decreased mRNA 18 immunogenicity, ${ }^{54,58,60,110}$ only a few types of modified nucleosides allow to preserve mRNA 19 translational activity, and even widely used modified nucleoside species induce negative effect on 20 translational processes, depending on their introduction ratio and target cell types (see Section 2.1.4 for 21 detail). ${ }^{61,62}$ Thus, other approaches are needed to expand the options of mRNA engineering. 
A
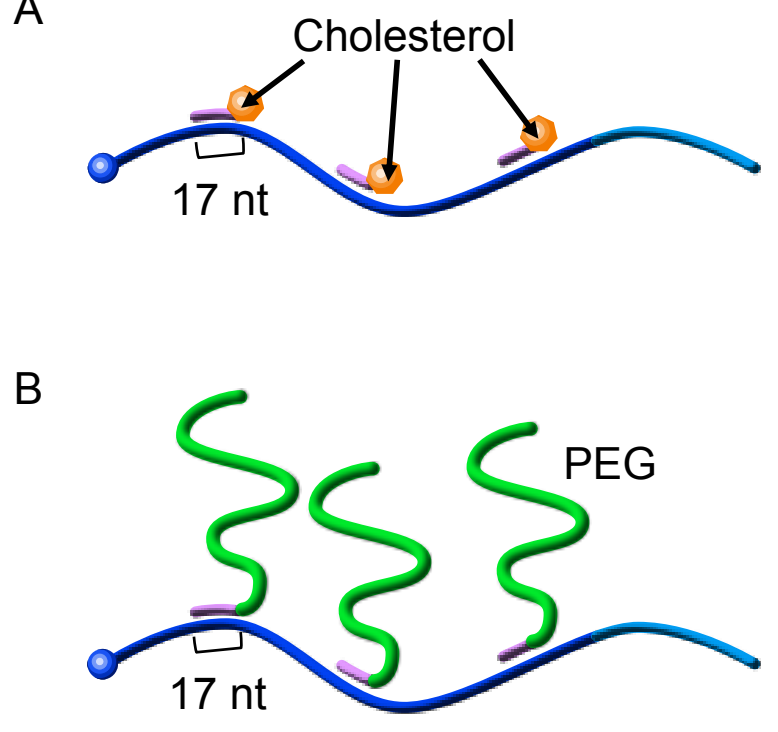
4 vaccination. ${ }^{114}$ 5

C RNA linkers

2 Figure 5. mRNA engineering with RNA architectonics. A, B. Introduction of (A) cholesterol 3 moieties, ${ }^{111}$ and (B) PEG. ${ }^{112}$ C. mRNA nanoassemblies. ${ }^{113}$ D. mRNA hybridized with poly U for mRNA

We proposed an original approach of mRNA architecnics for introducing various functional 7 moieties to mRNA, through hybridization of mRNA with functionalized RNA oligonucleotides 8 (OligoRNAs) (Figure 5). Although formation of double stranded RNA structure resulting from 9 OligoRNA hybridization may impair mRNA translational processes and increase mRNA 10 immunogenicity, these unfavorable outcomes were successfully avoided by limiting OligoRNA 11 hybridization length to $17 \mathrm{nt} .{ }^{111}$ This finding motivated us to functionalize mRNA carriers, such as 12 polymeric micelles (PMs) and lipid nanoparticles (LNPs), using OligoRNAs introduced with functional 13 moieties. For structural stabilization of PMs, OligoRNAs introduced with hydrophobic cholesterol 14 (Chol) moiety (Chol-OligoRNAs) was hybridized to mRNA (Figure 5A), and then resulting mRNA was 15 mixed with $\omega$-cholesteryl poly(ethylene glycol) (PEG)-polycation block copolymers to prepare PMs (see 16 Section 3.5 for detail about PMs). Hybridization of just one or a few Chol-OligoRNAs provided drastic 
1 effect on tightening mRNA structure in PM core, presumably through stacking between Chol moieties 2 on mRNA and those on the block copolymers. As a result, PMs became stabilized against nuclease 3 attacks and polyion exchange reaction. Eventually, the stabilized PMs showed efficient mRNA 4 introduction in mouse lung with minimal toxicological responses, after intratracheal administration, 5 demonstrating in vivo utility of Chol-OligoRNA hybridization strategy.

The hybridization-based mRNA engineering approach is versatile to improve bioavailability 7 of other types of carriers, such as LNPs (see Section 3.1 for detail about PMs). Although mRNA LNPs 8 have demonstrated their high potential especially in delivery to the liver and the spleen, ${ }^{115-117}$ arduous 9 processes, including the use of microfluidics, are needed for mRNA preparation, especially for

preventing LNP aggregation after the mixture of cationic lipids with mRNA. ${ }^{118}$ To tackle this issue, we developed a simple and robust strategy through hybridization of mRNA with PEGylated OligoRNAs (Figure 5B). ${ }^{119}$ This strategy allowed to prevent aggregation after mixing mRNA with commonly used 13 LNPs, including lipofectamine LTX and DOTAP/Chol liposomes, with minimal influence on mRNA 14 translational activity. The PEGylated LNPs thus prepared exhibited high structural stability even in 15 physiological environment, without forming aggregates in mouse blood circulation, while unPEGylated 16 LNPs formed several micrometer-sized aggregates in blood, and caused lung embolism.

18 its nuclease stability. Growing field of RNA nanotechnology revealed that nuclease attack to RNA is 19 weakened by structuring RNA, presumably through steric hindrance, and this strategy was applied to 20 siRNA delivery. ${ }^{120,121}$ Meanwhile, precise sequence designing is needed to obtain intended base-pairing 21 for structuring RNA. This issue hampers direct application of this technology to the delivery of mRNA, 22 which possesses limited sequence flexibility with fixed structure containing a $5^{\prime}$-cap, $5^{\prime}$ - and $3^{\prime}$ 23 untranslated regions, a coding region, and a poly-A tail. To prepare structured mRNA possessing all of 24 these endogenous mRNA components without sequence optimization, we crosslinked mRNA strands 
1 using linker OligoRNAs, which possess two complementary arms for hybridization (Figure 5C). ${ }^{122}$ Each 2 mRNA nanoassembly thus prepared was comprised of 7.7 strands of mRNA on average, with average 3 size below $100 \mathrm{~nm}$, and the nanoassemblies exhibited around 100-fold increase in nuclease stability 4 compared to naïve mRNA, with preserved translational activity. Intriguingly, this result suggests that nanoassemblies remained accessible to translational factors, although the recognition by nucleases is 6 effectively weakened presumably through steric hinderance. In mechanistic analysis, nanoassemblies 7 from mRNA with $5^{\prime}$ cap were selectively dissociated in the environment mimicking intracellular space, 8 while those from mRNA without 5' cap failed to dissociate. This result suggests that translational factors 9 recognize $5^{\prime}$ cap in nanoassemblies to trigger translation, and then nanoassemblies dissociate through

translation. Similar unwinding mechanism might contribute to protein translation from mRNA hybridized with Chol-OligoRNAs or PEG-OligoRNAs. Nanoassemblies exhibited efficient mRNA introduction to mouse brain, demonstrating their in vivo utility. Rolling circle transcription of plasmid DNA, a widely-used method, can also provide structured RNA with protein expressing capability, and this approach resulted in improvement of RNA nuclease stability, ${ }^{123}$ which is consistent with our finding of mRNA nanoassemblies. However, protein translation from RNA prepared by rolling circle methods 17 relies on an internal ribosomal entry site, which tends to yield a much lower level of translational 18 efficiency compared to cap-dependent translation. ${ }^{124}$ Other strategies to improve mRNA nuclease 19 stability includes the preparation of long double stranded structure in mRNA by hybridizing long 20 antisense strand. ${ }^{125}$ Although this strategy was effective in facilitating mRNA delivery to the liver after 21 hydrodynamic injection, its versatility is unclear, because long RNA hybridization to mRNA resulted in 22 impaired translational activity and enhanced mRNA immunogenicity. ${ }^{111,114}$ 
1 OligoRNA to protein coding region led to the decrease in translational activity. ${ }^{111}$ Meanwhile, mRNA 2 hybridized with $120 \mathrm{nt}$ poly U (mRNA:pU) induced strong innate immune responses, especially when 3 the poly $U$ strand possesses triphosphate structure at its $5^{\prime}$ end, which is a substrate of an innate immune 4 receptor, retinoic acid-inducible gene (RIG)-I. ${ }^{126,127}$ We utilized these unique properties of mRNA:pU, 5 preserved translational activity and enhanced immunogenicity, for mRNA vaccine, to obtain antigen 6 expression and immunostimulatory adjuvant function simultaneously (Figure 5D). After introduction to 7 cultured mouse and human dendritic cells, mRNA:pU induced enhanced expression of dendritic 8 activation markers, CD86 and CD40, compared to naïve mRNA. Mechanistic analyses indicate the 9 involvement of RIG-I and Toll-like receptor (TLR)-3 for the immunostimulation by mRNA:pU. 10 Eventually, in mouse vaccination experiment using a model antigen, ovalbumin (OVA), mRNA:pU 11 formulation induced cellular and humoral immunity against OVA more efficiently compared to naïve 12 mRNA. Together, mRNA engineering approach based on OligoRNA hybridization is versatile to 13 improve bioavailability of naked mRNA and various types of mRNA carriers, and also enhance the 14 activity of mRNA vaccine, opening up broad opportunities for expanding the potential of mRNA 15 therapeutics.

17 3. Nanomedicine-approaches for mRNA delivery

The application of nano-scaled carriers is necessary for allowing mRNA molecules to endure 19 in the harsh in vivo environments, as well as promote the intracellular delivery of mRNA. Various 20 materials have been employed for constructing such mRNA-loaded nanomedicines, allowing 21 physicochemical and functional control. By engineering the interaction with mRNA and the carrier 22 components, it is then possible to obtain nanomedicines capable of maximizing the stability of mRNA 23 in biological settings, obtaining optimal translation in targeted cells for therapeutic purposes, and reduce 24 the side effects from mRNA molecules or off-target translation. The choice of the carrier components 
1 will depend on the eventual route of administration and therapeutic purpose of the nanomedicines. In the 2 following sections, we review major nanomedicine approaches for mRNA delivery categorized by the 3 materials used to make the carriers. The delivery systems highlighted in this section are summarized in

6 Table 1 Nanomedicine-approaches for mRNA delivery

\begin{tabular}{|c|c|c|c|c|c|c|}
\hline Category & Key component(s) & Core technologies & $\begin{array}{l}\text { Size } \\
(\mathrm{nm})\end{array}$ & Delivery route(s) & Gene(s) & Ref \\
\hline \multirow{8}{*}{$\begin{array}{c}\text { Lipid-based } \\
\text { nanoparticles }\end{array}$} & DLin-MC3-DMA ${ }^{\text {a) }}$ & Clinically approved ionizable lipid & $75-85$ & i.v., i.c.v. (mouse) & Luc, frataxin & 133 \\
\hline & Lipid 5 & Optimized ionizable lipids & 86 & $\begin{array}{l}\text { in vitro, i.v. (mouse, } \\
\text { rat, NHP) }\end{array}$ & Luc, EPO, IgG & 135 \\
\hline & TT3 $^{\text {a) }}$ & Orthogonal array optimization & 110 & in vitro, i.v. (mouse) & Luc, hFIX & 136 \\
\hline & A18-Iso5-2DC18) & $\begin{array}{l}\text { cyclic head group in ionizable } \\
\text { lipid for STING activation }\end{array}$ & 96 & in vitro, s.c. & $\begin{array}{l}\text { Luc, Cre, } \\
\text { OVA, tumor } \\
\text { antigens }\end{array}$ & 137 \\
\hline & $\mathrm{C} 12-200^{\mathrm{a})}$ & $\begin{array}{l}\text { A large scale in vivo screening of } \\
\text { mixture ratio }\end{array}$ & 152 & i.v. (mouse) & Luc, EPO & 139 \\
\hline & 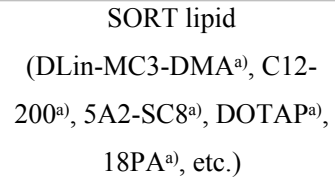 & $\begin{array}{l}\text { Addition of cationic, anionic and } \\
\text { ionizable lipid to change tissue } \\
\text { tropism }\end{array}$ & $\begin{array}{l}70- \\
200\end{array}$ & i.v. (mouse) & $\begin{array}{l}\text { Cre, EPO, IL- } \\
10, \text { Cas9 }\end{array}$ & 141 \\
\hline & C-24 alkyl phytosterols ${ }^{\text {a) }}$ & Optimized cholesterol & 102 & in vitro & $\begin{array}{l}\text { Luc, GFP, } \\
\text { Cas9 }\end{array}$ & 143 \\
\hline & $5 \mathrm{~A} 2-\mathrm{SC}^{\mathrm{a})}$ & Dendrimer LNP & 100 & in vitro, i.v. (mouse) & Luc, FAH & 147 \\
\hline \multirow{6}{*}{ Polyplexes } & PEtOx-PEI & $\begin{array}{c}\text { Optimization of Mw and charge } \\
\text { density }\end{array}$ & $\begin{array}{l}80- \\
450\end{array}$ & in vitro & Luc & 152 \\
\hline & hyperbranched PBAE & $\begin{array}{l}\text { Hyperbranched polycation for } \\
\text { nebulization. }\end{array}$ & 150 & inhalation (mouse) & Luc, GFP, Cre & 153 \\
\hline & Dimannose-PGA/PBAE & Macrophage targeting & 100 & $\begin{array}{l}\text { in vitro, i.p., i.v. } \\
\text { (mouse) }\end{array}$ & IRF5, IKK $\beta$ & 154 \\
\hline & PAsp(EDA), PAsp(TET) & Polyplex stabilization & 82,93 & in vitro & Luc & 155 \\
\hline & PAsp(TET), PAsp(TEP) & Efficient translation & 62,51 & in vitro & Luc & 156 \\
\hline & PAsp(DPT), PAsp(TET) & $\begin{array}{l}\text { Pre-complexation with eIF4E to } \\
\text { facilitate translation }\end{array}$ & 100 & in vitro, i.v. (mouse) & Luc & 157 \\
\hline \multirow{4}{*}{ Lipopolyplexes } & HpK-PEG + HDHE/chol & Protonable histidylated lipids & 100 & i.v. (mouse) & MART1 & 38 \\
\hline & $\begin{array}{c}\text { PEI }+ \\
\text { Chol/DOPA/DOPE/DSPE- } \\
\text { PEG/Man-lip }\end{array}$ & Neutral and mannosylated LPP & $\begin{array}{l}160- \\
190\end{array}$ & i.m., i.v. (mouse) & Luc, HA & 39 \\
\hline & HpK-PEG + KLN25/MM27 & $\begin{array}{l}\text { Mannosylated and histidylated } \\
\text { lipids }\end{array}$ & $\begin{array}{l}100- \\
140\end{array}$ & i.v. (mouse) & MART1 & 158 \\
\hline & HpK-PEG + & Histidylated lipids and a tri- & $100-$ & i.v. (mouse) & E7 & 164 \\
\hline
\end{tabular}




\begin{tabular}{|c|c|c|c|c|c|c|}
\hline & KLN25/MM27/TriMan-lip & mannosylated diether lipid & 150 & & & \\
\hline & $\begin{array}{c}\text { PBAE }+ \\
\text { EDOPC/DOPE/DSPE-PEG }\end{array}$ & Biodegradable polymer & n.d. & s.c. (mouse) & OVA & 167 \\
\hline & $\begin{array}{c}\text { PBAE + PEGylated DD90- } \\
\text { C12-122 }\end{array}$ & $\begin{array}{l}\text { Alkyl chain installation to PBAE } \\
\text { for anchoring PEG-lipid }\end{array}$ & 190 & i.v. (mouse) & Luc & 168 \\
\hline & TT3 $^{\text {a) }}$, PLGA & $\begin{array}{c}\text { Optimal PLGA formulation for } \\
\text { potentiate TT3LNP }\end{array}$ & $\begin{array}{l}100- \\
250\end{array}$ & in vitro & Luc, GFP & 169 \\
\hline \multirow{6}{*}{$\begin{array}{l}\text { Polymeric } \\
\text { micelles }\end{array}$} & PEG-PAsp(DET) & $\begin{array}{l}\text { Alleviation of mRNA } \\
\text { immunogenicity }\end{array}$ & 50 & $\begin{array}{l}\text { in vitro, i.c., i.n., } \\
\text { HTVi (mouse, rat) }\end{array}$ & $\begin{array}{c}\text { Luc, GFP, } \\
\text { BDNF, Bcl-2, } \\
\text { EPO }\end{array}$ & $\begin{array}{l}40, \\
175, \\
176\end{array}$ \\
\hline & PEG-PAsp(TET)-Chol & $\begin{array}{l}\text { Micelle stabilization using } \\
\text { cholesterol }\end{array}$ & 56 & in vitro, i.v. (mouse) & Luc, sFlt-1 & 41 \\
\hline & $\begin{array}{c}\text { PEG-PAsp(DET)-Chol/Chol- } \\
\text { mRNA }\end{array}$ & $\begin{array}{l}\text { Introduction of cholesterol to } \\
\text { mRNA for stabilization }\end{array}$ & 60 & in vitro, i.t. (mouse) & Luc & 111 \\
\hline & $\begin{array}{l}\text { cRGD-PEG/PNIPAM- } \\
\text { PLys(SH) }\end{array}$ & $\begin{array}{l}\text { Tumor targeting; hydrophobic } \\
\text { layer and disulfide crosslinking } \\
\text { for stabilization }\end{array}$ & 59 & in vitro, i.v. (mouse) & Luc, GFP & 173 \\
\hline & PEG-PLys(AMP) & $\begin{array}{l}\text { Disulfide crosslinking and } \\
\text { polycation optimization for } \\
\text { stabilization }\end{array}$ & 53 & in vitro & Luc & 178 \\
\hline & PEG-PGBA & $\begin{array}{l}\text { Flexible polycation for } \\
\text { stabilization }\end{array}$ & 56 & $\begin{array}{l}\text { in vitro, i.t., i.v. } \\
\text { (mouse) }\end{array}$ & Luc & 181 \\
\hline \multirow[b]{2}{*}{ Exosomes } & HEK293T-derived exosome & $\begin{array}{l}\text { miRNA-responsive translation } \\
\text { system }\end{array}$ & $\begin{array}{l}70- \\
220\end{array}$ & i.v. (mouse) & Luc, PGC1 $\alpha$ & 189 \\
\hline & $\begin{array}{l}\text { Exosome possessing glioma- } \\
\text { targeting peptides }\end{array}$ & $\begin{array}{l}\text { microfluidic cellular nanoporation } \\
\text { biochip with electrical pulses to } \\
\text { increase exosome production and } \\
\text { DNA transfection }\end{array}$ & $\begin{array}{l}30- \\
170\end{array}$ & i.v. (mouse) & PTEN & 192 \\
\hline
\end{tabular}

$1 \quad$ a) See Figure 6 for chemical structure

2 Lipid5, ; Heptadecan-9-yl 8-((2-hydroxyethyl)(8-(nonyloxy)-8-oxooctyl)amino)octanoate PEtOx, poly(2-ethyl-2-oxazoline); PEI, poly(ethylene imine); 3 PBAE, poly(beta amino esters); PGA, poly(glutamic acid); PAsp(EDA), poly[N-(2-aminoethyl)aspartamide]; PAsp(TET), poly( $N$ - $\left\{N^{\prime}\right.$-[ $\left[N^{\prime \prime}-(2\right.$-aminoethyl)4 2-aminoethyl]-2-aminoethyl $\}$ aspartamide); PAsp(TEP), poly-[N-( $N^{\prime}-\left\{N^{\prime \prime}\right.$-[ $N^{\prime \prime \prime}$-(2-aminoethyl)-2-aminoethyl]-2-aminoethyl $\}$-2-aminoethyl)aspartamide]; 5 PAsp(DPT), poly $\left\{N^{\prime}\right.$-[N-(3-aminopropyl)-3-aminopropyl]aspartamide $\} ; \quad$ HpK, Histidylated polylysine; HDHE, L-Histidine-(N,N-di-n6 hexadecylamine)ethylamide; Chol, Cholesterol; DOPA, 1,2-dioleoyl-sn-glycero-3-phosphate; DOPE, 1,2-dioleoyl-sn-glycero-3-phosphatidyl7 ethanolamine; DSPE, 1,2-distearoyl-sn-glycero-3-hosphoethanolamine; Man-lip, 16:0 1,2-dipalmitoyl-sn-glycero-3-phospho((ethyl-1',20,308 triazole)triethyleneglycolmannose; TriMan-lip, trimannosylated archeal diether lipid; EDOPC, 1,2-dioleoyl-sn-glycero-3-ethylphosphocholine; PLGA, 9 poly(lactic-co-glycolic acid); n.d., not determined; i.v., intravenous injection; i.c.v., intra-cerebroventricular injection; s.c.; subcutaneous injection; i.c., intracisternal injection; i.n., intranasal delivery; HTVi, hydrodynamic tail-vein injection; i.t., intratracheal delivery; NHP, non-human primate; Luc, luciferase; EPO, erythropoietin; OVA, ovalbumin; IL-10, interleukin 10; FAH, fumarylacetoacetate hydrolase; hFIX, human factor IX, IRF5, interferon regulatory factor 5 ; IKK $\beta$ inhibitor of nuclear factor kappa- $\beta$ kinase subunit $\beta$; MART-1, Melanoma antigen recognized by T cells 1 ; E7, human papillomavirus 16 oncoprotein E7; HA, Hemagglutinin; eIF4E, eukaryotic translation initiation factor 4E; BDNF, brain-derived neurotrophic factor; Bcl-2, B-cell lymphoma-2; sFlt-1, soluble fms-like tyrosine kinase-1; PGC1 $\alpha$, proxisome proliferator- activated receptor $\gamma$ coactivator $1 \alpha$; PTEN: phosphatase and tensin homolog. 
LNPs are one of the most advanced mRNA delivery systems (reviewed in ${ }^{46,103}$ ). LNPs are 2 prepared by microfluidic mixing of lipids in ethanol and mRNA in acidic buffer ( $\mathrm{pH} 3 \cdot 0-4.0) .{ }^{128}$ Lipids 3 include an ionizable lipid $(\mathrm{pKa}<7)$ that will be protonated at acidic $\mathrm{pH}$ to condense mRNA and release 4 it inside the cells, cholesterol for stabilization, an helper lipid for endosomal escape (usually DOPE, 5 Figure 6) and a PEGylated lipid to prevent aggregation of LNPs. ${ }^{129}$ Using an ionizable cationic lipid for 6 mRNA complexation instead of a permanently charged one limits toxicity in vivo and increases half-life 7 of the mRNA. ${ }^{130}$ The rapid mixing leads to the formation of an electron dense core surrounded by a lipid 8 monolayer. ${ }^{131}$ Mixing is followed by dialysis against a neutral buffer to remove ethanol.

LNPs were first developed for siRNA delivery, mostly to the liver. The system has produced an FDA-approved siRNA LNP called Onpattro, which includes the DLin-MC3-DMA (MC3, Figure 6) 11 ionizable lipid. ${ }^{132}$ Accordingly, earlier studies on mRNA LNPs used ionizable lipids with a structure 12 similar to DLin-MC3-DMA. ${ }^{46,133}$ LNPs are internalized by clathrin-mediated endocytosis, resulting in 13 their accumulation in endosomes and possible clearance by exocytosis. ${ }^{134,135}$ Protonation of the ionizable 14 lipid at endosomal $\mathrm{pH}(5.5-6.5)$ and presence of fusogenic lipids such as DOPE disrupts the endosomal membrane allowing intracellular delivery of mRNA and its translation. ${ }^{46,135}$

Biodegradability is an important parameter for the clinical translation of mRNA LNPs. Sabnis 17

et al. screened a library of different amino lipid-based LNPs and compared their safety and expression levels in rodents and non-human primates to MC3-LNPs. ${ }^{135}$ They identified ethanolamine as the best headgroup and their library included ethanolamine with different lipid tails. Intravenous administration of all the variants led to expression in the liver of mice. By measuring lipid levels in the liver along time, they reported that ester linkages accelerated liver clearance. Whereas primary esters increased $\mathrm{pKa}$ and decreased mRNA expression, secondary esters improved mRNA expression. The best lipid, lipid 5 (Heptadecan-9-yl 8-((2-hydroxyethyl)(8-(nonyloxy)-8-oxooctyl)amino)octanoate), contains one lipid chain with a primary ester and one lipid chain with a secondary ester and provided 3-fold higher 
1 expression over MC3-LNP. Higher expression was correlated with enhanced endosomal escape with 62 fold more cytosolic mRNA after transfection of HeLa cells with lipid 5-LNPs over MC3-LNPs. Lipid 53 LNPs were more rapidly cleared from liver, spleen and plasma than MC3-LNPs and, contrary to MC34 LNPs did not accumulate in the heart, arguing for better biosafety. Evaluation of the LNPs then moved 5 to Cynomolgus monkeys. Intravenous injection of $0.01 \mathrm{mg} / \mathrm{kg}$ of $\mathrm{mRNA}$ encoding either human 6 erythropoietin or anti-human IgG influenza antibody resulted in 5-fold higher protein levels of lipid 57 LNPs over MC3-LNPs, with minimal activation of immune markers.

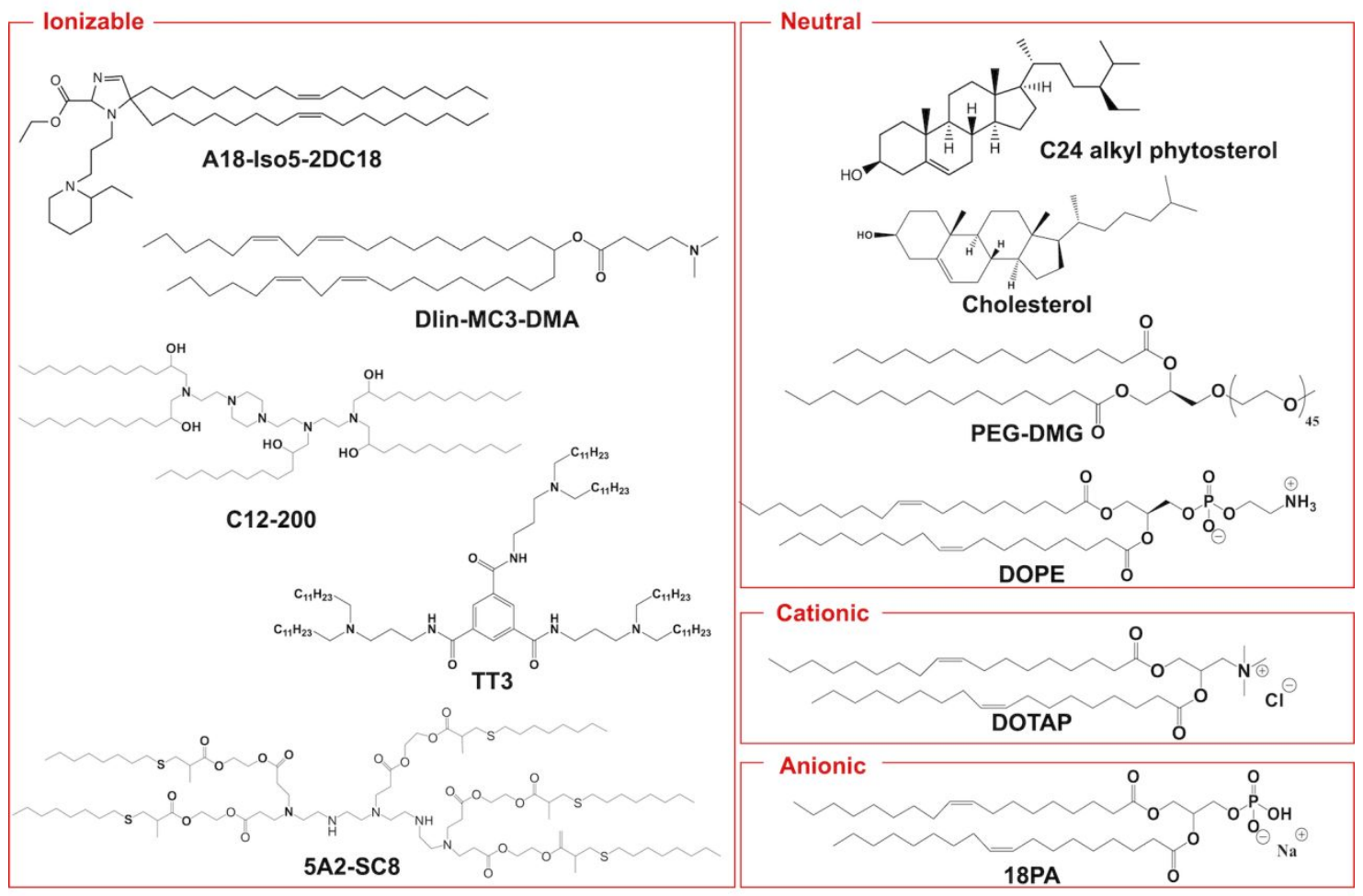

Figure 6. Common lipid and small surfactant structures for preparing LNPs.

13 aminoethyl)benzene-1,3,5-tricarboxamide, Figure 6), a group consisting of a phenyl ring, three amide 14 linkers and three amino lipid chains. ${ }^{136}$ LNPs were prepared with TT3 (T3, DOPE, Cholesterol, DMG- 
1 PEG2000 at molar ratios of 20/30/40/0.75). Intravenous injection of TT3-LNPs resulted in 6-fold higher 2 bioluminescence in mice spleen over C12-200 LNPs (Figure 6). They also prepared LNPs using mRNA 3 coding human factor IX (hFIX), a blood clotting factor deficient in hemophilia. Intravenous injection of 4 hFIX mRNA TT3-LNPs at a dose of $1.1 \mathrm{mg} / \mathrm{kg}$ was able to restore FIX levels to normal physiological 5

values in FIX knockout mice, suggesting a broad potential for protein replacement therapies.

A further improvement over MC3-LNPs was to use a cyclic lipid headgroup instead of a linear one. ${ }^{137}$ The Anderson group screened a library of LNPs formed with headgroups containing linear or heterocyclic amines (dimethylamino, dimethylaminopropyl, dibutylaminopropyl, dipropylaminopropyl) which were benchmarked against MC3-LNPs. Irrespective of the number of carbon bonds, subcutaneous injection of OVA mRNA LNPs with heterocyclic polar heads showed superior activation of murine splenocytes compared to linear polar heads. Piperazin and azepanyl polar heads induced the highest levels of specific lymphocytes. LNPs with the A18 polar head increased IFN- $\gamma$ secretion by 10 -fold over MC3-LNPs and 75-fold over LNPs with a linear tertiary amine polar head (Figure 6). This was explained by enhanced affinity of cyclic lipids towards the binding pocket of the STING protein, resulting in superior expression of the dendritic cell activation markers CD40, CD86 and HLA-DR (Human Leukocyte Antigen DR isotype). A18-LNPs achieved superior protection against tumor growth and extended survival over MC3-LNPs in two murine cancer models.

Helper lipids such as DOPE and cholesterol are critical components of LNPs (Figure 6). ${ }^{46,103}$ DOPE is preferred to DSPC as helper lipid as presence of DSPC leads to the formation of protrusions on the surface of LNPs and mRNA LNPs enriched in DSPC have low transfection efficiency in cellulo and lower expression in vivo. ${ }^{131,137-139}$ mRNA LNPs containing DSPC were also reported to induce inflammation at the injection site. ${ }^{140}$

All mRNA LNPs to date include cholesterol as a stabilizer and to promote membrane fusion. ${ }^{135}$,

137, 139-144 Substitution of cholesterol by natural analogues has been proposed to increase the potency of 
1 mRNA LNPs. ${ }^{143}$ Authors prepared LNPs with MC3:sterol:DSPC:DMG-PEG at 50:38.5:10:1.5 molar 2 ratios using three groups of cholesterol analogs. Group I included Vitamin D analogs (e.g. Vitamin D3), 3 group II analogs included phytosterols (e.g. $\beta$-Sitosterol, Figure 6), group III included pentacyclic 4 terpenoids (e.g. botulin). LNPs containing group I analogs had similar size and mRNA encapsulation 5 efficiency as cholesterol LNPs but low transfection efficiency. Inclusion of group III analogs decreased 6 encapsulation efficiency by $\geq 50 \%$ and increased the size of LNPs resulting in poor transfection 7 efficiency. The group II analog $\beta$-Sitosterol did not alter LNPs size nor encapsulation efficiency but 8 improved translation efficiency by 48 -fold in cancer cells. This enhancement in transfection efficiency 9 was even observed in primary cells, with a 14-fold enhancement in ex vivo transfected human peripheral 10

blood macrophages over MC3-LNPs. Improved transfection was due to differences in both microstructure of LNPs and intracellular trafficking. Whereas cholesterol-LNPs presented a smooth surface, $\beta$-Sitosterol-LNPs' surface was highly faceted suggesting phase separation of lipid domains ${ }^{145}$, packing defects suggested to improve fusion with membranes and thus intracellular delivery. ${ }^{146}$ Confocal microscopy imaging of transfected cells highlighted a higher rate of cellular uptake and retention of $\beta$ Sitosterol-LNPs, with a no significant enhancement in endosomal escape but higher cytoplasmic mobility of $\beta$-Sitosterol-LNPs.

Cheng et al. developed LNPs for mRNA delivery and gene editing in lungs, spleen or liver 18 after intravenous injection. ${ }^{141}$ The tissue tropism of these particles is based on modulation of the internal 19 charge of the LNPs by addition of an additional sorting lipid. LNPs consisted of ionizable lipid (11.920 50\%), DOPE as co-lipid (5-23.8\%), cholesterol (19.3-47.6 \%), DMG-PEG (1,2-dimyristoyl-rac21 glycerol-methoxy(poly(ethylene glycol, 0.8-4.8\%) (Figure 6) and an increasing percentage of sorting 22 lipid (0-50\%). They compared three different ionizable lipids: the 5A2-SC8 dendrimer (Figure 6) which 23 allowed FAH (fumarylacetoacetate hydrolase) mRNA delivery in the hepatocytes of FAH knockout mice 24 and extended their survival ${ }^{147}$, the MC3 lipid and the same lipid composition as the FDA-approved 
1 siRNA LNP Onpattro ${ }^{132}$, the C12-200 lipid (Figure 6) which allowed mRNA delivery in the liver. ${ }^{139}$ For 2 LNPs prepared with these 3 different ionizable lipids, expression of mRNA in organs was controlled by 3 the content of DOTAP (1,2-dioleoyl-3-trimethylammonium-propane, Figure 6) permanently charged 4 cationic lipid. LNPs without DOTAP were expressed in the liver, LNPs with intermediate DOTAP 5 content (10-15\%) were expressed in the spleen and LNPs with $50 \%$ DOTAP were expressed in the lungs. 6 Measurements of surface charge showed that DOTAP is in the core of LNPs together with the mRNA as 7 zeta potentials were close to 0 . Interestingly, the type of lipid dictated organ specificity. Using an 8 ionizable lipid as sorting lipid reinforced the liver tropism of LNPs. Adding an extra $20 \%$ of 5A2-SC8 9 increased mRNA expression in the liver by 3 -fold. Using a zwitterionic sorting lipid favored spleen 10 injection of $0.3 \mathrm{mg} / \mathrm{kg}$ of mRNA. targeting with exclusive distribution to the spleen of LNPs containing 80\% DSPC (1,2-distearoyl-snglycero-3-phosphocholine) or 50\% DOPCe (2-((2,3-bis(oleoyloxy)propyl)dimethylammonio)ethyl ethyl phosphate). Negatively charged sorting lipids also favored spleen targeting with exclusive expression in the spleen of LNPs with 10-40\% 18PA (1,2-dioleoyl-sn-glycero-3-phosphate) (Figure 6). Selective organ targeting (SORT) LNPs achieved high expression of erythropoietin and interleukin 10 after intravenous injection and nearly $100 \%$ gene editing in murine hepatocytes after a single intravenous

\subsection{Polyplexes}

Polymer-mRNA complexes (polyplexes), particularly using PEI (polyethylenimine) is one of 20 the earliest strategies used for nucleic acid delivery. ${ }^{148}$ Whereas the high cationic density of PEI allows 21 RNA complexation and endosomal escape by "proton-sponge" effect, ${ }^{149}$ this also induces cytotoxicity ${ }^{150}$ 22 and alters cellular homeostasis. ${ }^{151}$ Formation of conjugates of low molecular weight PEI with lipids 23 decreases the cytotoxicity while preserving transfection efficiency. ${ }^{149}$ Using a library of poly(2-ethyl-224 oxazoline) with varying molar mass and charge densities identified the optimal $\mathrm{M}_{\mathrm{W}}$ of PEI for pDNA or 
1 mRNA delivery, the EI content being controlled by hydrolysis kinetics. ${ }^{152}$ Whereas large and densely 2 charged polymer ( $83 \mathrm{kDa}$ and $100 \%$ hydrolysis) was optimal for pDNA transfection of HEK $293 \mathrm{~T}$ cells, 3 the optimal polymer for mRNA was smaller and with lower charge density ( $45 \mathrm{kDa}$ and $80 \%$ hydrolysis). $4 \quad$ This polymer has not been used in vivo yet. Poly( $(\beta$-amino) esters (PBAEs) are biodegradable polymers that are less toxic than PEI and 6 showed efficient mRNA delivery in vivo. ${ }^{153,}{ }^{154}$ An hyperbranched PBAEs (hPBAEs) formulation has 7 been designed for nebulized mRNA delivery to the lungs. ${ }^{153}$ To evaluate the influence of PBAEs 8 structure on mRNA inhalation, Authors compared linear PBAEs (IPBAEs) and hPBAEs. Whereas 9 1PBAEs and hPBAEs showed similar transfection of A549 lung cells in culture, only hPBAEs were suited 10 for nebulization. Indeed, size of IPBAEs increased from 150- to 1200-nm after nebulization with high 11 polydispersity. Oppositely, hPBAEs size remained stable under $200 \mathrm{~nm}$ with low polydispersity. 12 Nebulization of luciferase mRNA polyplexes prepared with hPBAEs resulted in 16-fold higher luciferase 13 protein levels in mice lungs compared to $25 \mathrm{kDa}$ branched PEI polyplexes. Notably, hPBAEs allowed mRNA delivery to all lung lobes and the transfection of $24.6 \%$ of lung epithelial cells with no transfection of lung immune cells nor alveolar damage. This technology holds potential for future clinical application of mRNA polyplexes.

The control of the structure of the polycations may also provide opportunity for intracellular navigation. For example, polyplexes made from $N$-substituted polyaspartamides having odd number of repeats, i.e. polyaspartamides modified with ethylene diamine (P(Asp(EDA)) or triethylamine ( $\mathrm{P}(\mathrm{Asp}(\mathrm{TET}))$, showed higher and prolonged expression in vitro compared to polyaspartamides having even number of repeats, i.e. polyaspartamides modified with diethylenetriamine $\mathrm{P}(\mathrm{Asp}(\mathrm{DET}))$ or tetraethylenepentamine $\left(\mathrm{P}(\mathrm{Asp}(\mathrm{TEP})) .{ }^{155}\right.$ This effect was associated with the protonation behaviors of the aminoethylene groups in response to changes in $\mathrm{pH}$ during endosomal uptake, which direct the endosomal escape and the stability of the polyplexes. Thus, despite the polyaspartamides with even 
1 number of repeats promoted endosomal escape, they showed lower stability of mRNA in the cytosol of 2 cells, which may lead to mRNA degradation and less protein translation. On the other hand, 3 polyaspartamides having odd number of repeats facilitated a rapid escape from endosomes, though their 4 higher stability in the cytosol resulted in prolonged protein translation. Thus, the stability of these 5 polyplexes in the cytosol appears to correlate with the protonation of the primary amino groups at the 6 side chains. These primary amines are almost fully protonated for polyaspartamides having odd number 7 of repeats, while for polyaspartamides having even number of repeats, the protonation is lower. The polycation structure may also affect the initiation of mRNA translation. For example, by 9 evaluating the translation of polyplexes from a series of polyaspartamides in cell free conditions, it was

\subsection{Lipopolyplexes}

Lipopolyplexes (LPP) are ternary Lipid-Polycation-nucleic acid complexes. ${ }^{39,}$ 158, 159 These 24 ternary complexes were introduced by Leaf's group by complexation of DNA by protamine or polylysine 
1 into polyplexes before interaction with DOTAP cationic liposomes. ${ }^{160,161}$ Lipopolyplexes allowed a 2 better protection against DNAses and a superior gene expression in vivo over DOTAP liposomes / DNA 3 lipoplexes. This technology was later applied to RNA delivery by Pichon's group. ${ }^{162}$

We used LPP where mRNA is first complexed with PEGylated and histidylated polylysine

5 6 7

(PEGHpK) before interaction with cationic liposomes made of cholesterol/HDHE (L-Histidine-(N,N-dinhexadecylamine)ethylamide). ${ }^{38}$ The interesting feature of this formulation is the spleen targeting obtained following intravenous administration. Vaccination of mice with LPP prepared with mRNA (termed LPR) coding a melanoma antigen resulted in superior inhibition of melanoma tumor growth compared to mRNA polyplexes or mRNA lipoplexes. To better target dendritic cells harboring mannose receptors on their surface, liposomes harboring mannose moieties have been synthesized. In this second set of study, liposomes were made with bio-inspired lipids: N-methyl imidazolium lipophosphoramidate (cationic lipid, KLN25) and histamine lipophosphoramidate (protonable lipid, MM27), and a mannosylated lipid. These cationic lipopolyplexes made of PEGHpK polymer and KLN25/MM27 mannosylated liposomes were designated LPR. Following IV injection, they allowed a better in vivo transfection of DCs over unmannosylated LPR resulting in superior tumor growth inhibition and extended survival of mice bearing B16F10 melanoma. ${ }^{158}$ To further increase the transfection of DCs in vivo, a second generation of mannosylated LPR were also formed with the PEG-HpK polymer and KLN25/MM27 liposomes but included a glycolipid containing a tri-antenna of a-D-mannopyranoside instead of a monovalent mannose for improved endocytosis by DCs. ${ }^{163}$ LPR prepared with the tri-antenna targeting motif allowed better transfection of DCs in vitro and a stronger tumor growth inhibition in mice compared to untargeted LPRs or LPRs with a mannosylated lipid harboring only one mannose. ${ }^{164,} 165$ Indeed, knowing the structure of oligossacharides on the ligands recognized by mannose receptors on dendritic cells, having more than one moiety leads to an increase of the receptor avidity and an improved targeting. ${ }^{166}$ One of the interesting feature of this formulation is the fact that mRNA lipopolyplexes e did 
1 not rely on type I IFN for effective T-cell immunity by contrast to lipoplexes (Figure 7A). This property 2 led to a similar protection against melanoma growth after vaccination with unmodified or $\mathrm{m} 1 \Psi$-modified 3 mRNA encoding a tumor antigen (Figure 7B)

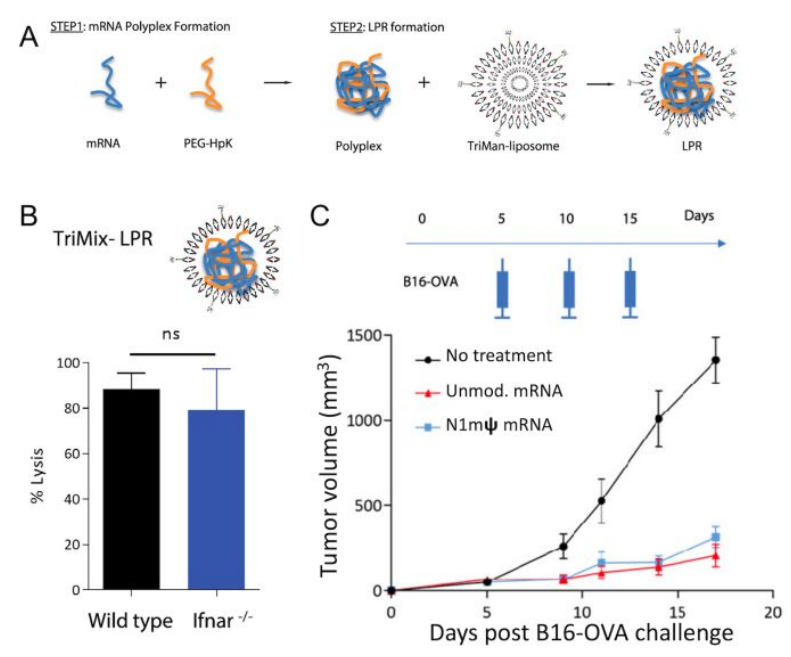

5 Figure 7. Cationic and trimannosylated lipopolyplexes induce protection against melanoma. A.

6 Preparation procedure of hybrid lipid-shell polymer core mRNA nanoparticles (LPR). B. Percent of 7 target cell lysis as measurement of cytolytic $\mathrm{T}$ cell response following a single intravenous immunization 8 with LPR containing Trimix RNA in wild-type mice and Ifnar-/- mice. C. Tumor growth curves of mice 9 vaccinated with unmodified or modified OVA mRNA trimannosylated LPR bearing B16-OVA 10 melanoma. Adapted with permission from reference ${ }^{164}$. Copyright 2018 American Chemical Society.

LPP have also been prepared using other polymers such as PBAE and PEI. ${ }^{39,} 1674 \mathrm{kDa}$ PBAE/mRNA polyplexes were encapsulated in (1,2-dioleoyl-sn-glycero-3-ethylphosphocholine/1,2-dioleoyl-snglycero-3-phosphatidyl-ethanolamine/1,2-distearoyl-sn-glycero-3-hosphoethanolamine-N-

[amino(polyethyleneglycol)-2000, EDOPC/DOPE/DSPE-PEG) liposomes. ${ }^{167}$ Subcutaneous injection of these LPP resulted in stronger stimulation of DCs and better antigen presentation over lipoplexes or polyplexes confirming the superiority of the ternary platform. Importantly, LPP formulation has a potential to improve the functionalities of existing polyplexes and LNPs. For example, PBAE-based polymer was installed with alkyl tail to anchor PEG-lipids, which allowed efficient mRNA introduction 20 to the lung after systemic delivery. ${ }^{168}$ Incorporation of poly(lactic-co-glycolic acid) (PLGA) to TT3- 
1 based LNP (Figure 6) was effective in increasing mRNA introduction efficiency to several human cell $2 \quad$ lines. ${ }^{169}$

4 3.5. Polymeric Micelles

5 6 7

Polymeric micelles (PMs) based on polyion complexation have also shown high potential for delivering mRNA. ${ }^{170,} 171$ The PMs are self-assembled in aqueous conditions by ionic and hydrogen bonding between the negatively charged mRNA and block catiomers, having a neutral segment and polycation block. Thus, PMs form a nano-compartmentalized structure with a hydrophilic protective shell surrounding the mRNA payload in the polyion complex core. ${ }^{172}$ The mRNA inside the PMs is packaged in globular shape, ${ }^{40,173}$ probably due to the flexibility of single stranded mRNA. The catiomers can then be engineered to elicit effective protection of the loaded mRNA against enzymatic degradation, as well as promote the cellular uptake by endocytosis and the eventual endosomal escape and access to the cytosol. PMs also allowed to suppress immune responses of mRNA, probably by inhibiting the interaction of mRNA with TLRs and/or hindering TLR mediated signals by endosomal disruption. ${ }^{40,174}$ These features indicate PMs as promising carriers for dealing with major challenges of mRNA therapy, i.e. instability, immunogenicity and translation efficiency.

The potential of PMs for effective mRNA delivery has been demonstrated in vivo after local or systemic administration. mRNA-loaded micelles based on the block catiomer poly(ethylene glycol)$b$-poly $\left\{\mathrm{N}^{\prime}-[\mathrm{N}-(2\right.$-aminoethyl)-2-aminoethyl]aspartamide $\} \quad$ (PEG-P(Asp(DET))) showed successful transfection in the nasal epithelium, ${ }^{175}$ the central nervous system, ${ }^{40}$ and the liver. ${ }^{176}$ The PEG$\mathrm{P}(\mathrm{Asp}(\mathrm{DET}))$ block copolymer was designed to protect mRNA from rapid degradation and improve the intracellular delivery of mRNA by polyion complexation and shielding with the PEG blocks. Moreover, the polyaspartamide block, i.e. $\mathrm{P}(\mathrm{Asp}(\mathrm{DET}))$, presents $2 \mathrm{pKas}$, i.e. 6.2 and 8.9, which allow for effective polyion complexation at $\mathrm{pH} 7.4$ and enhance endosomal escape after protonation at endosomal $\mathrm{pH}(\mathrm{pH}$ 
While mRNA-loaded PMs are stable under physiological salt conditions, polyelectrolytes in

3 biological environments can disrupt them by interfering with the polyion complex between polymers and 4 mRNA. ${ }^{177}$ Thus, efforts directed to stabilize mRNA-loaded PMs have focused on maintaining the micelle 5 structure by cross-linking the core with stimuli-sensitive covalent bonds, ${ }^{178}$ or by introducing 6 hydrophobic moieties in polycation segments or nucleic acids. ${ }^{41,111}$ For example, PMs prepared by block 7 copolymers having cholesteryl group at the end (Figure 8A), as well as a relatively large PEG segment 8 of $23 \mathrm{kDa}$ and polycation blocks for endosomal escape, showed improved blood circulation upon 9 intravenous injections, achieving 3-orders of magnitude higher concentration in blood compared to naked mRNA. The high stability and extended bioavailability of these micelles promoted their tumor targeting, 11 which resulted in high translation of a mRNA encoding luciferase (Figure 8B). The ability of these 12 micelles to elicit antitumor effects was tested by using mRNAs producing the anti-angiogenic sFlt-1 in 13 a model of pancreatic cancer. The enhanced delivery by the cholesterol modified micelles significantly 14 improved the efficacy compared to the micelles without cholesterol (Figure 8C). ${ }^{41}$ PMs having their core

crosslinked via reduction-sensitive disulfide bonds by using cyclic-RGD peptide-modified PEG-poly(LLysine-thiol) copolymers (cRGD-PEG-P(Lys(SH))) showed improved stability compared to PMs 17 prepared from PEG-P(Lys) block copolymers. Moreover, by adding a hydrophobic layer of 18 thermoresponsive blocks into these micelles just by mixing with poly(N-isopropylacrylamide)19 poly(lysine-thiol) (PNIPAM-P(Lys(SH))) copolymers at a temperature below the lower critical solution 20 temperature (LCST) of PNIPAM and then incubating the micelles at physiological temperature, it was 21 possible to further improve the bioavailability of polyion complex micelles 3-orders of magnitude higher 22 compared to PMs prepared from PEG-P(Lys) block copolymers. ${ }^{179}$ The enhanced stability of the PMs 23 from cRGD-PEG-P(Lys(SH))/PNIPAM-P(Lys(SH)), as well as the tumor targeting by the cRGD ligand 24 on the surface of the PMs improved the mRNA accumulation in a mouse model of gliobastoma. ${ }^{173}$ 
Besides crosslinking and increasing the hydrophobicity of the core, the stability of PMs could

2 be enhanced by improving the affinity of the polymers to the mRNA. In this regard, controlling the 3 rigidity of the main chain of the catiomers could provide a straightforward approach for promoting the 4 stability of mRNA-loaded PMs. In fact, molecular dynamics simulations have shown that polycations

5 6 with higher flexibility may have stronger binding to DNA and double stranded RNAs (dsRNAs) by increasing the entropic gain through water release. ${ }^{180}$ We have recently demonstrated this possibility by using 2 catiomers having similar structure, except for their polycation backbone, i.e. the standard PEG$\mathrm{P}(\mathrm{Lys})$ bearing a relatively rigid polycation backbone composed of peptide bonds and PEG-poly(glycidyl butylamine) (PEG-PGBA) block copolymer, which has a relatively flexible polycation block comprised of a polyether backbone (Figure 8D). ${ }^{181}$ While both copolymers spontaneously formed PMs after mixing with mRNA in aqueous conditions, PMs made from PEG-PGBA required less polymers to stabilize the micelle structure. By isothermal titration calorimetry measurements (Figure 8D), PEG-PGBA was found to have 50-fold higher binding to mRNA than PEG-P(Lys) due to the decreased in the binding enthalpy and the increase in the binding entropy, which leads to lower Gibbs free energy and enhanced the binding affinity to mRNA (Figure 8D). The stronger binding of PEG-PGBA resulted in PMs with significantly enhanced the protection against enzymatic attack and disassembly by polyanions. The PMs from PEGPGBA showed higher intracellular delivery of mRNA, resulting in higher protein translation in vitro and in vivo. When systemically injected, the PMs from PEG-PGBA were able to circulate in the bloodstream longer time than the PMs from PEG-P(Lys).

These observations indicate the possibility to construct stable and functional mRNA-loaded PMs for systemic applications through precise control of the chemical structure of the catiomers. Such nanomedicine platforms could allow guiding mRNA molecules into hard to reach tissues and cells for eliciting unprecedented therapies. The development of such advanced PM formulations will be associated with systems capable of enduring harsh in vivo settings, promoting extravasation in through the blood 
1 vessels of the target organ and effectively engaging with the targeted cells for efficient protein translation.

A

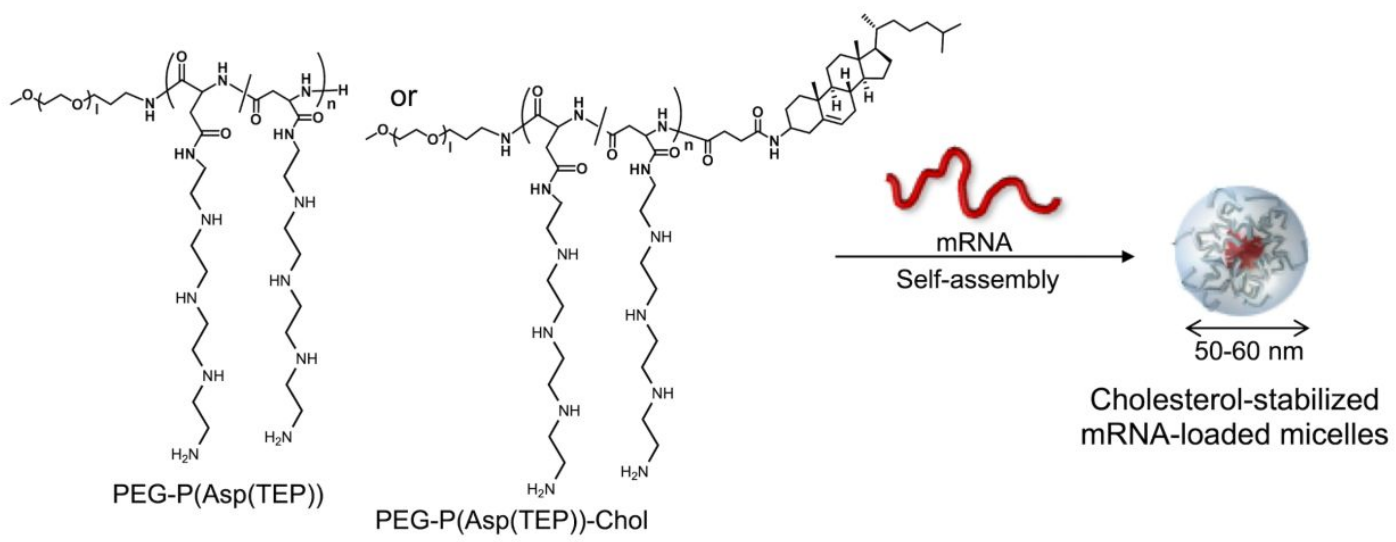

B

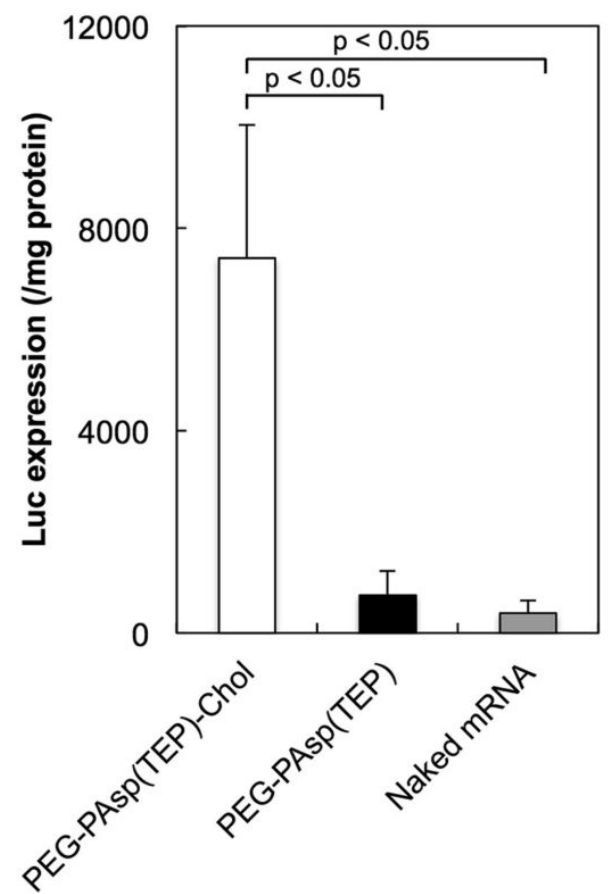

C

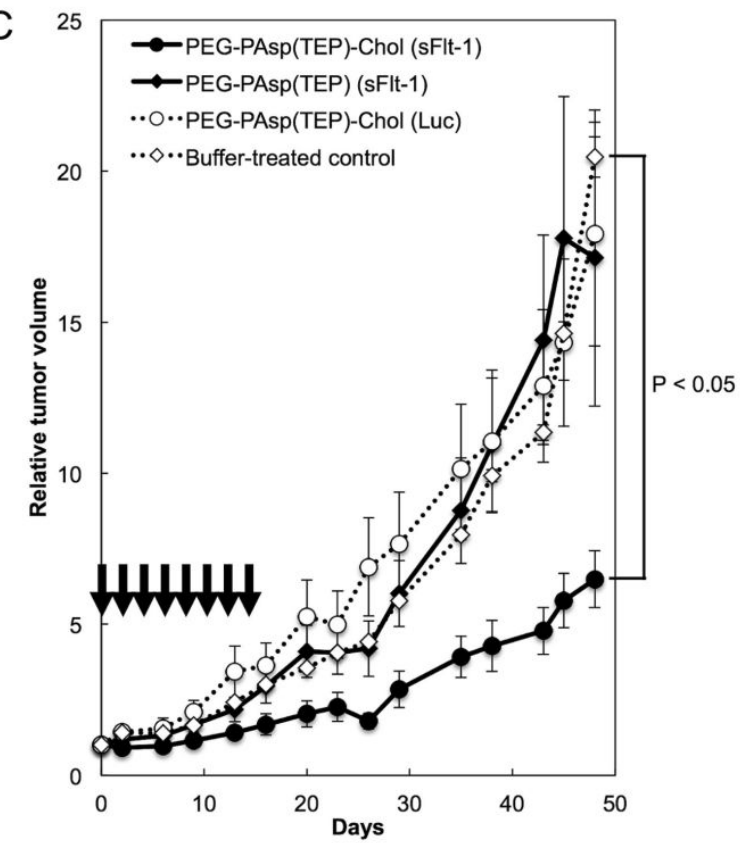

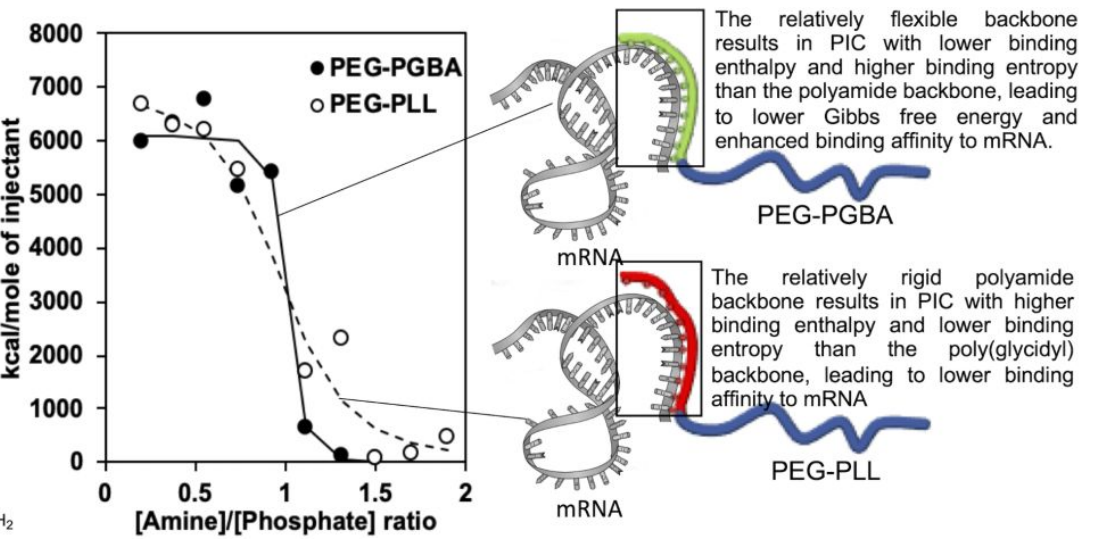

3 Figure 8. Control of the catiomer structure enhance mRNA-loaded micelles performance. A. Self- 
1 assembly of mRNA-loaded micelles by PEG-P(Asp(TEP)) or cholesterol-conjugated PEG-P(Asp(TEP)) 2 (PEG-P(Asp(TEP))-Chol). The block copolymers contain TEP units for endosomal escape and 3 cholesterol for hydrophobic stabilization. B. Expression of luciferase in pancreatic BxPC3 tumors after 4 systemic mRNA delivery by PEG-P(Asp(TEP))-Chol or PEG-P(Asp(TEP)) based micelles. Data 5 expressed as the mean \pm S.E.M $(n=4)$. Statistical significance determined by one-way analysis of 6 variance (ANOVA) followed by Tukey's multiple comparison test. C. Efficacy of systemically injected 7 micelles loading sFlt-1-encoding mRNA against BxPC3. Data presented as the mean \pm S.E.M. $(n=8)$. 8 Statistical significance determined by ANOVA followed by Tukey's multiple comparison test. Arrows 9 indicate injection points. Reprinted in part with permission from reference ${ }^{41}$. Copyright 2016 Elsevier.

10 D. The flexibility of the polycation segment affect the binding affinity to mRNA. Structures of PEG11 P(Lys) bearing a relatively rigid polycation backbone composed of peptide bonds and PEG-poly(glycidyl 12 butylamine) (PEG-PGBA) copolymer with a backbone having flexible ether bonds (left panel). 13 Isothermal titration calorimetry curves of the formation of mRNA-loaded micelles from PEG-P(Lys) or 14 PEG-PGBA (right panel). Adapted with permission from reference ${ }^{181}$. Copyright 2020 John Wiley and 15 Sons.

\section{3.6. Exosomes}

18 In the search for biocompatible mRNA delivery systems, exosomes secreted by almost cell types have 19 been proposed as biological nanocarriers (Reviewed in ${ }^{182,}{ }^{183}$ ). Exosomes are 50-150 nm vesicles 20 originating from the fusion of multivesicular bodies with the plasma membrane. ${ }^{184}$ These vesicles are a 21 means of exchanging proteins, lipids and nucleic acids between producing and receiving cell types ${ }^{182}$ 22 with as much as 1,300 different mRNAs in mast cell-derived exosomes. ${ }^{185}$ Thanks to their cellular origin, 23 the surface of exosomes presents membrane proteins, transmembrane proteins and immunoglobulins 24 which are "don't eat me" signals decreasing their clearance from the circulation. ${ }^{186,}{ }^{187}$ In addition, these 
1 endogenous membrane proteins promote their fusion with cells allowing intracellular delivery of 2 cargo. ${ }^{182,}, 188$ Nucleic acids can be loaded in exosomes either indirectly or directly. For indirect loading, 3 cells are transfected with nucleic acids before isolation of exosomes: transfection using pDNA to obtain 4 mRNA-loaded exosomes. For direct loading, purified exosomes in suspension are electroporated with 5 nucleic acids, this method is called bulk electroporation (BEP). Cell-derived exosomes are isolated and 6 purified from conditioned media of cells transfected with pDNA coding the desired mRNA or from 7 biological (e.g. blood) by ultracentrifugation or sucrose gradient ultracentrifugation and then stored at $8 \quad 80^{\circ} \mathrm{C}$ until use. ${ }^{182}$

9

To decrease the expression of delivered mRNA in undesired tissues, Sun et al. applied tissuespecific miRNA-controlled mRNA expression to exosome borne mRNA as an alternative to tissue targeting. ${ }^{189}$ In their system, the mRNA IRES contains two specific miRNA binding sites and binding of the miRNA induces a conformational change resolving tertiary structures inhibiting translation. Using luciferase mRNA harboring miR-21 binding sites they reported a 6-fold increase in luciferase expression in the presence of miR-21. They later moved to adipocyte-targeted expression. They produced exosomes by transfection of HEK293T packaging cells with a plasmid coding PGC1 $\alpha$ (Peroxisome proliferatoractivated receptor Gamma Coactivator $1 \alpha$ ) harboring two miR-148 binding sites. PGC1 $\alpha$ is an essential transcription factor for fat browning ${ }^{190}$ and miR-148 an adipose tissue specific miRNA. ${ }^{191}$ Exosomes isolated from cell culture media contained 50-70 mRNA copies per 100 exosomes. Exosomes were intravenously injected to fat died-induced obesity mice and they proved that PGC1 $\alpha$ expression was increased in adipose tissue but not in liver and lungs, common off-target accumulation organs of exosomes after intravenous injection. Moreover, overexpression of PGC1 $\alpha$ in adipocytes promoted fat browning suggesting promising applications for obesity therapy.

Using microfluidics and multiple transfections, Yang et al. were able increase the production of mRNA-loaded exosomes and decorate them with a targeting peptide for anti-glioma therapy. ${ }^{192}$ They 
1 developed a microfluidic cellular nanoporation biochip (CNP) where pDNA enters cells through $500 \mathrm{~nm}$

2 channels at the bottom and secreted exosomes are collected from the top, followed by isolation using 3 sequential ultracentrifugation. As secretion of exosomes is a stress response, they compared exosome 4 production after stress by starvation, hypoxia, heat or electrical pulses. Electrical pulses generated 105 fold more exosomes than all the other stress signals with a maximal secretion of 150 exosomes per $10^{4}$ 6 mouse embryonic fibroblasts (MEFs) at 200V. Using a plasmid coding the tumor suppressor PTEN 7 (Phosphatase and TENsin homolog) and RT-qPCR quantitation, they demonstrated that exosomes 8 produced by CNP and electrical pulses stimulation contained 1,000-fold more intact mRNA over BEP 9 cells or Lipofectamine $2000^{\circledR}$-transfected cells. To target glioma cells, they used a CDX-CD47 plasmid 10 coding the glioma targeting peptide $\mathrm{CDX}^{193}$ fused to the $\mathrm{N}$ terminus of the exosome-enriched 11 transmembrane protein CD47 to produce targeted exosomes (Exo-T). Adding the CDX-CD47 plasmid 12 resulted in the production of PTEN mRNA-loaded Exo-T harboring the CDX peptide on their external 13 surface. Presence of the targeting peptide increased cellular uptake and PTEN expression in murine U87 14 glioma cells over untargeted exosomes. Finally, intravenously injected Exo-T were able to cross the 15 blood-brain barrier and accumulate in mice brain leading to superior tumor growth inhibition and 16 extended survival of mice bearing orthotopic gliomas compared to untargeted exosomes. As CNP 17 improve the yield of mRNA loading in exosomes using a microfluidic platform and versatile targeting 18 can be implemented using a CD47 fusion plasmid, this technology shows high translational potential for 19 exosomal mRNA targeted delivery.

\section{4. Applications}

\section{4.1. Vaccination}

23 Early applications of mRNA have been focused to the development of vaccines. This is because mRNA 24 presents several advantages for eliciting potent immunization, as well as the potential to fast and cheap 
1 processing and easy handling. ${ }^{3}$ Moreover, as variety of antigens can be encoded in the mRNA sequence,

2 it is possible to utilize the same carrier platform for eliciting effective immunization against a wide-range 3 of diseases. The carriers used for mRNA vaccination are designed to deliver the antigen-encoding mRNA 4 molecules to antigen presenting cells (APCs). Inside the APCs the mRNA molecules produce proteins 5 that are processed into peptide epitopes for presentation through the major histocompatibility complex 6 (MHC) class I. The efficiency of the immunization will depend on several aspects, including the route 7 of vaccination, the cellular targeting, and the translation efficiency and the toxicity of the carrier.

\subsubsection{Carrier development for $m R N A$ vaccines}

Among various mRNA carriers for mRNA vaccines, LNPs are most vigorously studied. In the researches introduced in Section 3.1, LNP development was mainly directed to maximizing its protein expression potential. Meanwhile, some researches optimized LNP formulations based on its vaccination capability. Oberli et al. ranked LNPs on their ability to induce ovalbumin (OVA)-specific T cells 7 days after subcutaneous injection. ${ }^{140}$ They compared several ionizable lipids (C12-200, cKK-E12 and 503O13) and positively charged lipids combined with a lipid-anchored PEG, cholesterol and a helper lipid (DSPC or DOPE). The best formulation, B11, was composed of cKK-E12/DOPE/Chol/C14PEG2000 (10/15/26/40.5/2.5 mol \%) and induced 4.2 \% OVA-specific T cells. Therapeutic vaccination of mice harboring established B16-F10 melanoma with B11 LNPs prepared with TRP2 (Tyrosinase Related Protein 2) and gp100 (glycoprotein of $100 \mathrm{kDa}$ ) tumor antigen mRNAs extended their survival compared to LNPs prepared with irrelevant mRNAs.

Lutz et al. compared the vaccinal potency of LNPs to licensed influenza vaccines in non-human primates. ${ }^{194}$ They prepared LNPs using the ionizable lipid L319, DSPC, cholesterol and PEG-DMG at a molar ratio of 555:10:32.5:2.5. They showed that intramuscular vaccination of cynomolgus monkeys with LNPs formed with mRNA encoding the hemagglutinin antigen from the pandemic influenza strain 
1 H1N1pdm09 induced functional antibody titers above protective levels for 5 months after vaccination.

2 Antibody titers were comparable to those obtained after vaccination of monkeys with the licensed Fluad 3 vaccine. In addition, the LNP vaccine induced antigen-specific CD4 and CD8 T cells which were absent 4 in the Fluad $^{\circledR}$ group.

5

To advance the application of mRNA-LNP vaccines, the Coalition for Epidemic Preparedness innovations initiated a partnership agreement worth up to US\$ 34 million with the German mRNA vaccine company Curevac to develop a downscaled and transportable facility called RNA Printer for the production of several grams of mRNA LNPs in a few weeks. Altogether, these data show that the LNP technology is a powerful and biocompatible mRNA delivery platform and warrants clinical trials in the near future. As of now few mRNA LNPs are under phase 1 clinical trial for several applications: SARSCoV-2 Infection (NCT04283461 in USA and BNT162 in Europe), a phase 1 melanoma trial (mRNA4157) and a phase 1 trial in several cancers (NCI-4650), phase 1 against cystic fibrosis (NCT03375047). Besides LNPs, mRNA complexation with protamine, a small arginine-rich protein, provides a promising platform. ${ }^{195}$ Protamine/mRNA complex functions as an immunostimulatory adjuvant, by stimulating TLR7 signaling. While tight complexation with protamine resulted in drastic reduction of protein translational capability of mRNA, translational efficiency was recovered by decreasing protamine/mRNA ratio to prepare mixture of naked mRNA and protamine/mRNA complexes. ${ }^{196}$ The optimal formulation that balanced the properties of immunostimulation and protein translation was used in clinical trials of vaccination against infectious diseases (NCT02241135), ${ }^{197}$ and cancer (NCT01915524). ${ }^{198}$ While carriers were used in most researches of mRNA vaccine, even naked mRNA provided vaccination effects as described in the next section.

\subsubsection{Route of vaccination}

mRNA-based vaccines are usually administered through local or systemic injection depending 
1 on the antigen expression localization requirements. Direct subcutaneous, intramuscular, or intradermal 2 injection of mRNA have been the main routes for vaccines directed to infectious diseases, while 3 intravenous injections are used when the systemic expression of antigens is required.

4

5 Intradermal

\section{Intranodal}

After intradermal delivery, mRNA-transfected resident DC need to migrate to lymph nodes to present antigens to $\mathrm{T}$ cells and induce an adaptive immune response. ${ }^{199}$ Intradermal injection of naked mRNA resulted in the transfection of dermal DC with subsequent priming of antigen-specific $\mathrm{CD} 8^{+} \mathrm{T}$ cells. ${ }^{200}$ Using fluorescently-labeled mRNA, authors could show mRNA expression occurred in the dermis not the epidermis and, that dermal DCs and dermal macrophages internalized the mRNA. Although mRNA was delivered to dermal DCs and macrophages to the same extent (5\% mRNA positive cells for both), using transgenic mice expressing the DC-specific integrin $\mathrm{cD} 11 \mathrm{c}$ fused to the diphtheria toxin receptor they could demonstrate that dermal DCs are the main contributor to mRNA expression in the dermis. Internalization occurred via macropinocytosis as pre-conditioning the injection site with the micropinocytosis inhibitor rottlerin dramatically decreased the expression of luciferase mRNA in the dermis. Finally, $\mathrm{T}$ cell priming was reduced in rottlerin-treated animals confirming that intradermal mRNA vaccination proceeds by macropinocytosis in dermal DCs. Feasibility of this administration route 18 for mRNA vaccine has already been demonstrated even in large animals, with mRNA LNP inducing the 19 production of antibodies against human immunodeficiency virus type 1 (HIV-1) in rhesus macaques. ${ }^{201}$

22 Because ultimately, the naked mRNA requires to reach a lymph node, some groups directly 23 inject the mRNA in the lymph nodes: by intranodal injection. ${ }^{46}$ As the lymph nodes are rich in immune 24 cells, intranodal injection results in mRNA accumulation in both macrophages and dendritic cells, 
1 antigen-presenting cells capable of inducing an adaptive immune response. ${ }^{202}$ However, in injections 2 need to be performed by highly-trained personnel: by surgically exposing the inguinal lymph node 3 followed by injection and wound closure in mice, ${ }^{203}$ by a radiologist guided by echography in inguinal 4 lymph nodes in humans. ${ }^{204}$

5 6 7 8 9 10

Kreiter et al. compared the vaccine activity of naked mRNA administered by intranodal, subcutaneous or intradermal routes in mice. ${ }^{205}$ Using luciferase mRNA they showed highest bioluminescence after intranodal injection, 3 -fold higher than intradermal injection at $16 \mathrm{~h}$ whereas no signal was detected after subcutaneous injection. By injecting mRNA coding the influenza antigen hemagglutinin they reported that only intranodal injection led to the expansion of antigen-specific $\mathrm{T}$ cells both in lymph node, blood and spleen. Therapeutic evaluation as a preventive cancer vaccine demonstrated superior survival of intranodally vaccinated mice over s.c. or i.d. vaccinated mice with s.c. route offering no protection at all.

The same authors then evidenced that naked mRNA selectively accumulated in lymph node 14 DCs after intranodal injection via macropinocytosis highlighting the importance of this endocytic 15 pathway for naked mRNA vaccination both by intradermal and intranodal routes. ${ }^{202}$

16 Joe et al. compared intranodal mRNA vaccination to intramuscular pDNA vaccination against 17 influenza. ${ }^{203}$ Intramuscular pDNA vaccination was used as a benchmark. mRNA vaccination induced 18 more antigen-specific cytotoxic T lymphocytes both in the lymph nodes and the spleen over pDNA. 19 Intranodal mRNA also partially protected mice from viral challenge.

20 Intranodal mRNA vaccination recently reached Phase 1 clinical trial in HIV patients. ${ }^{204} \mathrm{HIV}$ 21 patients received three intranodal doses of mRNA coding HIV immunogen sequences. This vaccine was 22 well tolerated in patients and induced a moderate HIV-specific T cell response supporting the ongoing 23 Phase 2 clinical trial. 


\section{Intravenous}

Successful outcomes obtained by intranodal administration provided proof of concept to the 3 strategy of targeting lymphoid organs for effective vaccination. Intravenous administration allows for 4 targeting multiple lymphoid organs throughout the body, with an easier and less invasive procedure,

compared to intranodal administration. While uptake of mRNA carriers by reticuloendothelial system typically induced negative influence on their application to disease treatment, this process provides beneficial outcomes in mRNA vaccine. After intravenous administration of cationic mRNA LNPs based on DOTAP, efficient protein expression was obtained in $\mathrm{CD}_{1} 1^{+}$antigen presenting cell in the spleen. ${ }^{206}$ In addition, this formulation activated APCs in several organs, including the spleen, liver, bone marrow and lymph nodes. As a result, intravenous administration of the LNPs loading model antigen mRNA induced enhanced cellular immunity compared to their intradermal and subcutaneous administration. Another group also demonstrated the advantage of intravenous administration over intramuscular and subcutaneous administration, using negatively charged mRNA LNPs based on lipofectamine RNAi Max. ${ }^{207}$ Several reports attempted to improve the efficacy of intravenous mRNA vaccination by introducing (tri-)mannose ligands to LNPs for targeting dendritic cell, 208,209 or by incorporating lipidbased immunostimulatory adjuvant to LNPs. ${ }^{210}$ In another report, $\alpha$-galactosylceramide was coencapsulated to LNPs with mRNA encoding tumor antigens to activate natural killer T cells, leading to improved efficiency of cancer vaccines. ${ }^{211}$

Intravenous mRNA vaccination was tested also in patients with advanced malignant melanoma, in a phase I clinical trial. In the study, LNPs with various surface charges were prepared by tuning LNP/mRNA mixture ratio, for optimization in animal experiments. As a result, LNPs with slightly negative charge induced efficient protein expression from mRNA in the spleen, bone marrow and lymph nodes, with histological observation showing efficient protein expression in dendritic cells. This formulation showed efficient anti-tumor activity in several mouse models, and successfully induced 
1 antigen-specific $\mathrm{T}$ cell responses in a clinical trial. ${ }^{116}$ A subsequent study indicated successful immune 2 activation in the spleen of patients, using [ $\left[{ }^{18}\right.$ F $]$ Fluoro-2-deoxy-2-D-glucose positron emission 3 tomography (FDG-PET). ${ }^{212}$ The same group recently used this LNP formulation to potentiate chimeric 4 antigen receptor (CAR)-T cell therapy against solid tumor in an animal study. ${ }^{213}$ In many cases of CAR-T 5 cell therapy against solid tumors, CAR-T cells are inactivated rapidly after transplantation due to low 6 accessibility to target cells, leading to reduced proliferative signal in CAR T cells. To solve this problem, 7 mRNA expressing cancer antigen that CAR-T cells target was administered using LNPs to obtain its 8 expression in APCs throughout lymphoid tissues in the body. Through interaction with APCs expressing 9 the cancer antigen, CAR-T cells proliferated with preserved activity, thereby inducing efficient anti10 cancer effect in mouse models.

11

\section{4.1.3. saRNA vaccines} vectors. $^{219}$

saRNA vaccines were first used in the form of Virus RNA Particles (VRPs). ${ }^{214,215}$ In VRPs the structural proteins have been replace by the antigen, they are provided in trans in packaging cells to produce replication-defective VRPs. ${ }^{215}, 216$ As reviewed previously, ${ }^{216}$ alphavirus-based VRPs showed promising results, among which protection against Meta pneumonia virus, respiratory syncytial virus and dengue in primates. ${ }^{217,} 218$ However, VRPs face the same biosafety and production limits as viral

Synthetic saRNA has been developed as an alternative to VRPs and, since synthetic saRNA do not use packaging cells delivery systems are required. Delivery of saRNA faces the size challenge of saRNA: as saRNA code for the replicase and the antigen(s) they are longer than mRNA: $10,000 \mathrm{nt}$ vs $1,000 \mathrm{nt}$ for mRNA. Despite this increased length saRNA are produced by in vitro transcription from a DNA template with yields similar to mRNA. ${ }^{39}$

Because synthetic saRNA are more recent than mRNA, fewer formulations have been 44 
1 developed for their delivery. ${ }^{56,104,220}$ saRNA has been used for vaccination both by intradermal injection 2 of naked or complexed saRNA followed by electroporation ${ }^{74}$, as intramuscular injection of saRNA 3 lipopolyplexes ${ }^{39}$, intramuscular injection of saRNA complexes with dendrimers. ${ }^{69}$ In these studies, 4 saRNA demonstrated higher expression and extended duration of expression over mRNA. ${ }^{66,67,71} \mathrm{~A}$ few 5 examples will be detailed.

Vogel et al. used PEI polyplexes to deliver saRNA coding an influenza antigen. ${ }^{66}$ Using 7 luciferase reporter gene they evidenced extended saRNA expression after intramuscular injection of 8 polyplexes over mRNA polyplexes with an expression delay of saRNA attributable to the necessary 9 production of replicase, minus strand RNA and translation of minus strand RNA. saRNA gave equivalent 11

11 three strains of influenza protected against sequential viral challenges. They later reported the induction 12 of CD4 and CD8 specific T cells against conserved HIV-1 regions after vaccination with saRNA 13 polyplexes. ${ }^{221}$ These results validate the versatility and therapeutic potential of saRNA polyplexes.

14 A dendrimer platform has been used for multipurpose intramuscular saRNA vaccination. ${ }^{69,222}$ 15 VEEV-derived saRNA was complexed using Modified Dendrimer Nanoparticles (MDNPs) into c.a. 100 $16 \mathrm{~nm}$ stable in human serum. Intramuscular injection of MDNPs resulted in the induction of antigen17 specific T cells in vivo. Interestingly, when authors injected MDNPs prepared with luciferase saRNA, 18 they reported an increase in luciferase activity between $36 \mathrm{~h}$ and $60 \mathrm{~h}$ post injection suggesting in situ 19 replication of the saRNA. MDNPs formed with antigen-coding saRNA protected against lethal influenza 20 challenge, ebola virus, Zika virus and Toxoplasma gondii. ${ }^{69,222}$

21 We introduced neutral targeted lipopolyplexes (LPP) for the delivery of VEEV-derived saRNA 22 to dendritic cells. ${ }^{39}$ Here, saRNA was first complexed in positively-charged polyplexes using PEI 23 (polyethylenimine) before interaction with anionic PEGylated liposomes to form neutral LPP (Figure 24 9A). A mannosylated lipid (16:0 PA-PEG3-mannose 1,2-dipalmitoyl-sn-glycero-3-phospho((ethyl- 
$11^{\prime}, 2^{\prime}, 3^{\prime}$-triazole)triethyleneglycolmannose) was included in liposomes to engage the mannose receptor on 2 dendritic cells. ${ }^{158,159}$ LPP were capable of transfecting a murine dendritic cell line in vitro. Intramuscular 3 injection of LPP prepared with luciferase saRNA resulted in durable expression in the quadriceps (Figure 4 9B). Vaccination with LPP formed with saRNA coding influenza antigens led to the induction of antigen5 specific CD4 and CD8 T cells (Figure 9C). Another benefit of using saRNA, particularly saRNA derived 6 from Venezuelan equine encephalitis virus has another advantage as the non-structural proteins also 7 inhibit type I IFN signaling. ${ }^{74,223}$

A

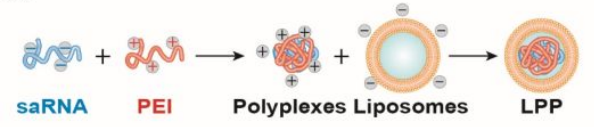

B

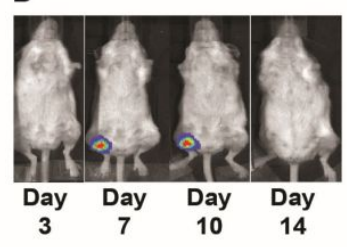

$\prod_{-0.8}^{1}$

$\begin{array}{rr}-0.8 \\ -0.6 \\ -0.4\end{array} \quad \times 10^{6}$

$-0.2$

radiance

$\mathrm{p} / \mathrm{sec} / \mathrm{cm}^{2}$

$\operatorname{Min}=5 \mathrm{e}^{4}$
$\operatorname{Max}=1 \mathrm{e}^{6}$

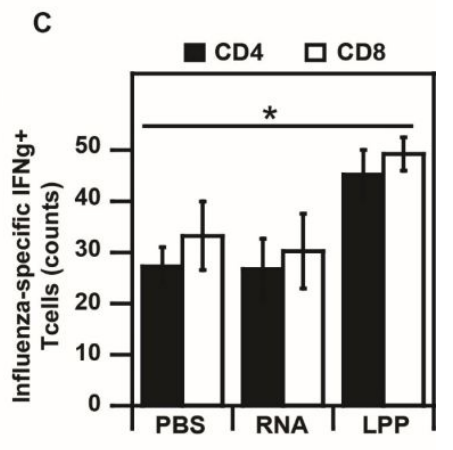

Figure 9. Formation of LPP-saRNA and activity in vivo. A. To form neutral Lipopolyplexes, saRNA

is first complexed with branched PEI to form positively charged polyplexes. Then, positively charged

polyplexes are mixed with anionic liposomes resulting in the formation of neutral LPP. B. Intramuscular

injection of LPP- luciferase saRNA complexes allowed sustained expression in vivo. C. Vaccination of 14 mice by intramuscular injection of LPP- hemagglutinin saRNA induced antigen-specific IFN- $\gamma$ secreting cells with superior immunogenicity over naked RNA or unvaccinated mice. Adapted with permission 16 from reference ${ }^{39}$. Copyright 2019 Elsevier. 


\section{$1 \quad 4.2$ Protein replacement therapy}

2

Alongside with vaccine, mRNA delivery was widely used for supplying therapeutic peptides or proteins, which is called as protein replacement therapy. As early as 1992, in vivo protein replacement therapy was reported, in which vasopressin mRNA was injected to hypothalamus of model rats that lacks vasopressin expression, to treat diabetes insipidus. ${ }^{224}$ However, over 20 years after the report, therapeutic application of mRNA was focused on vaccine and immunotherapy, with very few reports addressing the potential of mRNA for protein replacement. A major challenge for mRNA-based protein replacement is the control of mRNA immunogenicity, as inflammatory responses after mRNA delivery would hamper the therapeutic processes and pose safety concerns. This is in sharp contrast to the cases of vaccine and immunotherapy, in which induction of innate immune responses is essential to obtain preventive or therapeutic outcomes. To control mRNA immunogenicity, various techniques have been developed. Among them, replacement of mRNA nucleosides with chemical modified species, such as m5C, t2C, $\Psi U$ and $\mathrm{m} 1 \Psi \mathrm{U}$, is the most common approach, which inhibits the recognition of mRNA by innate immune receptors (see Section 2.1.4 for detail). ${ }^{54,110}$ High performance liquid chromatography (HPLC) purification to remove dsRNA contaminants was also reported to be effective in reducing mRNA immunogenicity. ${ }^{225}$ Along with these approaches focusing on mRNA, fine-tuned designing of mRNA carriers allows for the inhibition of mRNA recognition by immune receptors. After encapsulation of mRNA into PEGylated polymeric micelles (PMs), its recognition by TLR7 in endosome was suppressed, presumably through steric repulsive effect of PEG, leading to efficient in vivo delivery of mRNA with minimal inflammatory responses (see Section 3.5 for detail). ${ }^{40,}{ }^{174}$ Notably, even without mRNA chemical modification and HPLC purification, mRNA PMs exhibited successful outcome in tissue regenerative treatment to several diseases in model animals, such as osteoarthritis, intravertebral disc disease and spinal cord injury. ${ }^{226-228}$ Such immune regulation approach without relying on mRNA chemical modification is practically important, because mRNA chemical modification often leads to 
1 impaired translational activity, compromising therapeutic potential of mRNA. ${ }^{61-63,229}$

2

3 application to protein replacement therapy. In the past decade, numerous reports demonstrated the 4 potential of mRNA for this therapeutic approach, with following 5 fields vigorously pursued: (1) Single 5 gene disorder treatment using mRNA encoding deficient genes, e.g. treatment of lung surfactant protein 6 deficiency, ${ }^{110}$ hemophilia, ${ }^{230}$ cystic fibrosis, ${ }^{231}, 232$ ornithine transcarbamylase deficiency, ${ }^{233}$ acute 7 intermittent porphyria, ${ }^{234}$ Fabry disease, ${ }^{235}$ and acute intermittent porphyria; ${ }^{236}$ (2) Production of 8 antibody, including single chain antibody $(\mathrm{scFv}),{ }^{237}$ whole antibody, ${ }^{238-240}$ and bi-specific antibody, ${ }^{241}$ 9 targeting amyloid deposition, toxin, infectious diseases, and cancers; (3) Tissue repair and regeneration 10 $114.3)$; (5) Cancer therapy (see Section 4.4).

While details of these applications were extensively reviewed elsewhere, ${ }^{1,}{ }^{245-247}$ here, we discussed therapeutic application of mRNA, by focusing on following 3 advantages of mRNA over DNA in protein replacement therapy. (1) mRNA provides earlier onset of protein expression compared to DNA, because mRNA does not require the processes of nuclear transport and transcription for protein production (Figure 10A). ${ }^{40,248}$ This time-dependent protein expression profile of mRNA is attractive for targeting acute diseases. (2) Duration of protein expression from mRNA is at most one week, allowing 18 the use of mRNA to express therapeutic factors that would induce detrimental effects after prolonged 19 expression. (3) mRNA tends to induce protein expression in higher percentage of target cells compared 20 to DNA (Figure 10B), presumably because nuclear entry of DNA becomes a barrier for protein 21 expression in a large percentage of cells. ${ }^{176,248}$ In the use of gene expressing secreted factors, their 22 expression in a small percentage of the target cells is sufficient for obtaining therapeutic outcome, 23 because untransfected cells also receives therapeutic factors secreted from transfected cells. On the 24 contrary, in the delivery of genes encoding intracellular factors, untransfected cells would obtain less 
1 beneficial effect compared to transfected cells. Thus, mRNA is a more suitable option in this case, 2 because of is capability to induce protein expression in a large percentage of cells (Figure 10B).
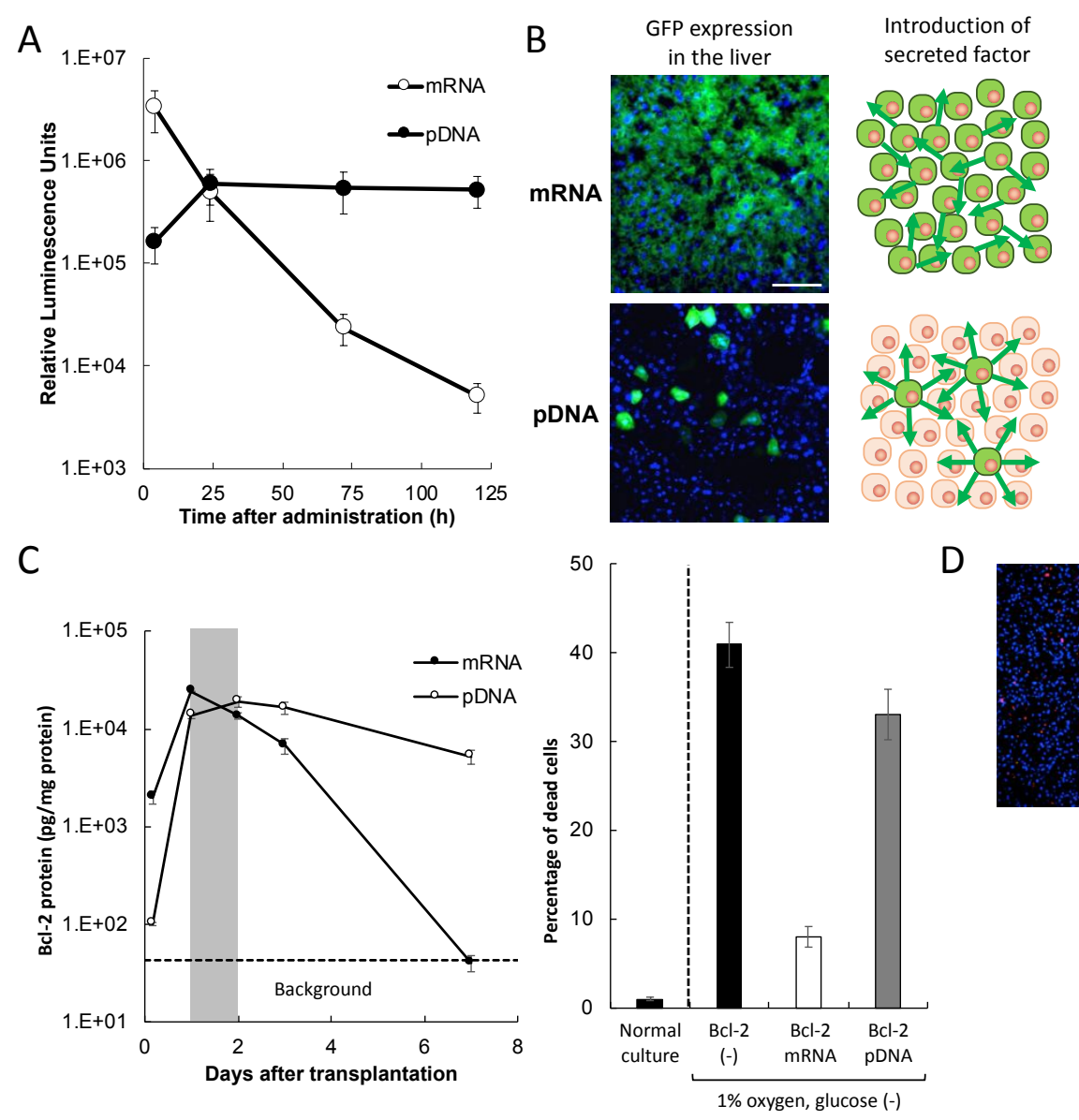

Introduction of
intracellular factor

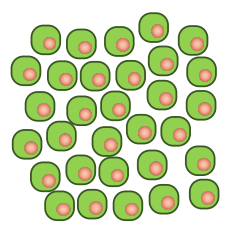

Cell without transgene expression

Cell expressing transgene
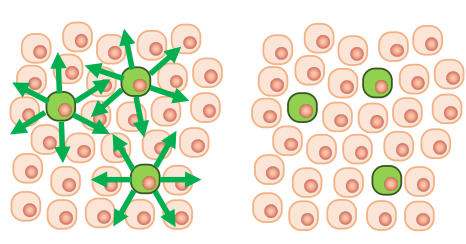

\section{$\rightarrow$ Secretion of} therapeutic protein

C

\section{E}
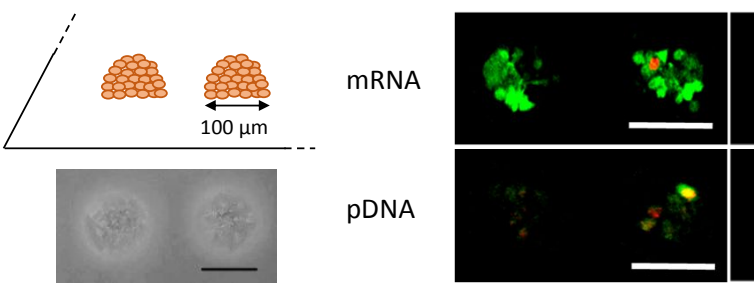

D

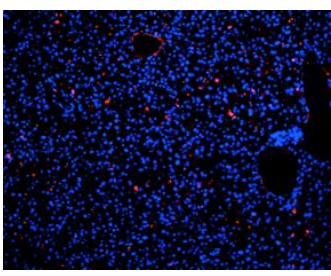

mRNA

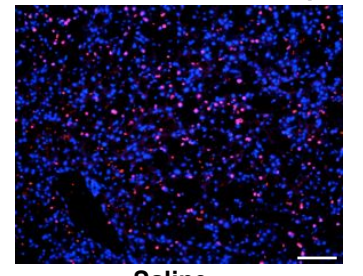

pDNA

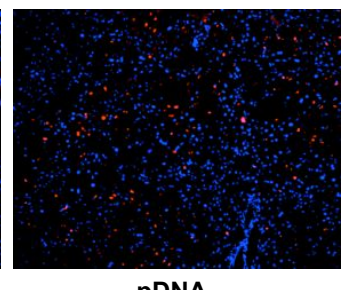

Saline

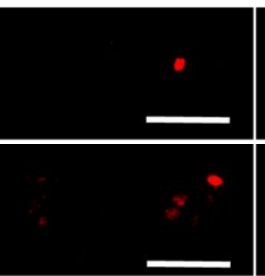

4 Figure 10. Comparison of mRNA and pDNA delivery.

A. Time dependent protein expression profile.

5 PEG-PAsp(DET)-based polyplex micelles (PMs, see Section 3.5.) loading luciferase mRNA or pDNA

6 were injected to cerebrospinal fluid (CSF) of rats, followed by measurement of luciferase levels in CSF.

7 The figure is adapted from In Vivo Messenger RNA Introduction into the Central Nervous System Using

8 Polyplex Nanomicelle by S. Uchida, et al. ${ }^{40}$ to show pDNA and mRNA. The figure is licensed under

9 https://creativecommons.org/licenses/by/2.0/. B. Tissue distribution of protein expression from mRNA 
1 (upper panels) and pDNA (lower panels). Left panels: GFP expression in mouse liver observed $24 \mathrm{~h}$ after 2 hydrodynamic injection of PMs loading GFP mRNA or pDNA. Green: GFP, Blue: cell nuclei (DAPI). 3 Scale bar: $100 \mu \mathrm{m}$. The figure is adapted from Messenger RNA-based therapeutics for the treatment of 4 apoptosis-associated diseases by A. Matsui et al. ${ }^{176}$ to show the difference between mRNA and pDNA. 5 The figure is licensed under https://creativecommons.org/licenses/by/4.0/. Middle panels: Therapy using 6 gene encoding secreted proteins. Protein expression in a small percentage of the target cells is sufficient 7 for obtaining therapeutic outcome, because untransfected cells also receives therapeutic factors secreted 8 from transfected cells. Left panels: Therapy using gene encoding intracellular proteins. Protein 9 expression in a large percentage of the cells is required for therapy, as untransfected cells typically failed 10 to receive therapeutic effects. C. Primary hepatocytes were transfected with Bcl-2 mRNA or pDNA for 11 measuring of Bcl-2 protein expression levels (left). Bcl-2 mRNA and pDNA showed comparable levels 12 of Bcl-2 protein expression from day 1 to day 2 after the transfection (highlighted with gray). In this 13 period, cell death was induced by deprivation of oxygen and glucose. Bcl-2 mRNA showed enhanced 14 pro-survival effect compared to Bcl-2 pDNA, although total Bcl-2 expression levels were comparable 15 between these two groups. This result highlights the importance of obtaining Bcl-2 expression in a large 16 percentage of cells. Reprinted with permission from reference ${ }^{249}$. Copyright 2018 Elsevier. D. Treatment 17 of mouse model of fulminant hepatitis using Bcl-2 mRNA and pDNA. Liver sections $4 \mathrm{~h}$ post-treatment. 18 Red: apoptotic cells (TUNEL). Blue: cell nuclei (DAPI). Scale bar: $100 \mu \mathrm{m}$. The figure is adapted from 19 Messenger RNA-based therapeutics for the treatment of apoptosis-associated diseases by A. Matsui et 20 al. ${ }^{176}$ to show the difference between mRNA and pDNA. The figure is licensed under 21 https://creativecommons.org/licenses/by/4.0/. E. Introduction of mRNA and pDNA to 3D cultured cells. 22 Left: An array of mesenchymal stem cell spheroids, prepared using micropatterned plate. ${ }^{250}$ Right: 23 Confocal microscopic images of the spheroids $24 \mathrm{~h}$ after introduction of GFP mRNA and pDNA. 24 Dividing cells were labeled with 5-ethynyl-2-deoxyuridine (EdU, red), a nucleic acid analogue, which is 
1 incorporated into the genome during S phase. Green: GFP, Blue: cell nuclei (DAPI). Scale bars: $100 \mu \mathrm{m}$. 2 The figure is reproduced from mRNA as a Tool for Gene Transfection in 3D Cell Culture for Future 3 Regenerative Therapy by S. Uchida et al. ${ }^{251}$ under https://creativecommons.org/licenses/by/4.0/.

These three advantages of mRNA provide strong rationale for the use of mRNA in some 6 therapeutic settings. For example, the treatment of acute myocardial infarction using vascular endothelial 7 growth factor $(V E G F)-A$ mRNA utilized the advantages (1) and (2). ${ }^{242}$ While both of $V E G F-A$ mRNA 8 and plasmid DNA (pDNA) were effective in reducing infarct area through their angiogenic effects, only 9 mRNA improved the survival of model animals. Surprisingly, $V E G F-A$ pDNA decreased the survival 10 11 12 introduction might cause prolonged expression of pro-survival factors after genomic integration of the

even when compared to control groups, due to edema caused by prolonged VEGF-A expression. Thus transient protein expression profile of mRNA was advantageous in this application.

mRNA delivery is also a preferable method to introduce pro-survival genes, as DNA-based

17 hepatocytes treated with cell death stimuli, mRNA provided enhanced pro-survival effects to hepatocytes 18 compared to pDNA (Figure 10C). ${ }^{249}$ The enhanced potential of $B c l-2$ mRNA is attributed to its 19 capability to provide Bcl-2 protein expression and pro-survival effects to a larger percentage of cells compared to $B c l-2$ pDNA. As a result, in the treatment of acute hepatitis, mRNA showed enhanced antiapoptotic effect in the liver compared to pDNA (Figure 10D). Along with such in vivo administration, $22 B c l-2$ mRNA is applicable for ex vivo administration to improve the engraftment efficiency after cell 23 transplantation therapy ${ }^{249}$. In hepatocyte transplantation to mouse liver, ex vivo Bcl-2 mRNA introduction 24 provided up to 5-fold increase in the hepatocyte engraftment efficiency with improved outcome in liver 
1 functional support to mouse model of chronic hepatitis. Together, $B c l-2$ mRNA provides a safe and 2 effective option to prevent cell death in a variety of therapeutic settings.

$4 \quad 4.3$ Cell reprogramming

5

6 induced pluripotent cells (iPSCs), differentiation of stem cells, direct reprogramming, and genome 7 editing, with several advantages over the other commonly used methods, such as the use of viral gene 8 transduction. ${ }^{252,} 253$ iPSCs were firstly generated using retrovirus gene vectors, ${ }^{254}$ which cause random 9 integration of the encapsulated genes into host genome. Genomic integration may result in the activation 10 1 12

mRNA therapeutics also provide an excellent tool for converting cell fates, i.e. generation of of oncogenes near the integration sites, as reported in a clinical trial. ${ }^{255}$ Moreover, prolonged expression of Yamanaka factors after genomic integration may hamper differentiation of iPSCs and also cause tumor formation. ${ }^{256-258}$ Although adenovirus vectors and non-viral pDNA transfection also allowed iPSC generation in a manner less prone to cause genomic integration, ${ }^{259,} 260$ thorough examination of genome sequence of iPSCs would still be required before clinical usage, to check the genomic integration, which occurs at certain rates after introduction of adenovirus vector and pDNA. ${ }^{261,} 262$ This issue of genomic integration also poses problems in gene transfection for stem cell differentiation, direct reprogramming, and genome editing. On the contrary, mRNA delivery would provide a safer option to cell 18 reprogramming. In addition, transient protein expression profile of mRNA allows precise temporal 19 control of protein expression, which is often needed for (trans-)differentiation of cells.

For iPSC generation, repeated mRNA transfection is needed due to short duration of protein expression from mRNA and relatively short intracellular half-life of transcriptional factor proteins. In repeated transfection, toxicity of each transfection procedure should be minimized to preserve cell viability and obtain efficient and prolonged protein expression. Thus, in the first successful report of mRNA-based iPSC generation, chemically modified mRNA with $100 \%$ substitution of $\mathrm{C}$ and $\mathrm{U}$ with 
$15 \mathrm{mC}$ and $\Psi \mathrm{U}$ was used with supplementation of B18R protein, a decoy receptor for type I interferon, to 2 reduce immunogenicity of mRNA. ${ }^{263}$ Further, $5^{\prime}$ triphosphate of uncapped mRNA contaminants, a 3 potential substrate for an innate immune receptor, RIG-I, was enzymatically removed, and low oxygen 4 culture was performed to improve iPSC generation efficiency. In subsequent researches, this protocol 5 was modified to include additional reprogramming mRNA or micro RNA (miRNA). ${ }^{264,}{ }^{265}$ Despite these 6 advances, daily dosing of mRNA is still needed. To circumvent this troublesome procedure, self7 amplifying RNA (saRNA) encoding all four Yamanaka factors were employed (see Section 2.2 for detail 8 about saRNA), which induced protein expression for more than a week. ${ }^{266}$ With supplementation of 9 B18R protein to reduce immune responses, single administration of saRNA successfully generated iPSCs. 1

mRNA-based iPSC generation described above, $M y o D$ mRNA transfection to iPSCs allowed their differentiation to myotube. ${ }^{263}$ Several reports succeeded in osteogenic differentiation of mesenchymal stem cells (MSCs) in vitro using mRNA encoding bone morphogenetic protein-2 (BMP-2), and also in vivo bone regeneration after $B M P-2$ mRNA delivery to the region of bone defect in animal models. ${ }^{243}$, ${ }^{267}$ Alongside with such in vivo delivery of differentiation factor mRNA, transplantation of cells after ex vivo differentiation using mRNA transfection is a promising approach of regenerative therapy. As threedimensional (3D) culturing is a wide-spread method to potential cell transplantation therapy, ${ }^{268-270}$ we undertook ex vivo differentiation of 3D-cultured cells using mRNA. Interestingly, in osteogenic differentiation of MSC spheroids using runt-related transcription factor 2 (Runx2), transfection of Runx2 mRNA exhibited improved outcomes compared to that of Runx2 pDNA. ${ }^{251}$ In mechanistic analysis using a reporter gene, reporter protein expression efficiency from mRNA in MSC spheroids was higher than that from pDNA (Figure 10E), while both of mRNA and pDNA induced comparable level of the protein expression in MSCs in monolayer culture. This result is explained by the observation that MSCs in spheroids showed lower rate of cell division compared to those in monolayer culture, and mRNA induced 
1 more efficient protein expression in non-dividing cells compared to pDNA. This study demonstrated 2 additional advantage of mRNA over pDNA in transfection to 3D culture cells.

Various reports demonstrated the utility of mRNA for direct reprogramming, e.g. from

4 fibroblasts to hepatocyte-like cells, ${ }^{271}$ endothelial progenitor cells, ${ }^{272}$ neurons, ${ }^{273}$ and neural precursor 5 cells, ${ }^{274}$ from pancreatic exocrine cells to insulin-producing cells, ${ }^{275}$ and from MSCs to neural stem 6 cells. ${ }^{276}$ Notably, in vivo direct reprogramming to neurons was achieved by injection of 4 types of mRNA 7 to brain parenchyma, leading to alleviation of Parkinson's disease symptoms in mouse models. ${ }^{273}$ Other 8 exciting targets of cell programming include hematopoietic and immune cells. In CAR-T cell therapy, 9 Foxol mRNA was used to increase the fraction of central memory $\mathrm{T}$ cells before transplantation, which 10

11 proliferation of hematopoietic stem cells (HSCs) without differentiation, which would solve the problem 12 of HSC shortage for clinical use. ${ }^{277}$ Because prolonged overexpression of Musashi-2 is cancer 13 promoting, ${ }^{278}$ its transient expression using mRNA is desirable, as is the case in Bcl-2 (see Section 4.2). ${ }^{176}$, $14{ }^{249}$ Regulation of macrophage polarization attracts much attention in various therapeutic fields, with M1 15 macrophages desirable for cancer treatment, and M2 macrophages for tissue regeneration. Several reports 16 succeeded in M1-to-M2 and M2-to-M1 transition in vivo, providing a new tool for macrophage 17 polarization. ${ }^{279}, 280$ Other interesting strategies of macrophage potentiation include mRNA-based 18 introduction of anti-microbial peptide in lysosome for treating bacterial infection. ${ }^{281}$ In this strategy, 19 mRNA encodes anti-microbial peptide connected with a cathepsin B, which translocates the peptide to 20 lysosome after its translation in cytoplasm, and transplantation of the mRNA-treated macrophages was 21 effective in treatment of multidrug-resistant bacteria-induced sepsis in mice.

22 Genome editing is another promising strategy of cellular reprogramming. Transient protein 23 expression profile of mRNA is beneficial for genome editing, because prolonged expression increases 24 the rate of off-target genome cleavage. ${ }^{282}$ In clinical trials, gene encoding $C$-C chemokine receptor 5 
1 (CCR5), a receptor for HIV entry, was disrupted ex vivo using zinc finger nucleases (ZFN) mRNA, for 2 making the transplanted cells resistant to HIV infection (ClinicalTrials.gov Identifier: NCT02500849, 3 NCT02225665). Recently, research focus was shifted to RNA-based delivery of clustered regularly 4 interspaced short palindromic repeat (CRISPR)/CRISPR-associated protein (Cas) 9. In co-delivery of $5 \operatorname{Cas} 9$ mRNA and single guide RNA (sgRNA), sgRNA was degraded in cytoplasm before translation of 6 sufficient amount of Cas9 protein, leading to reduced genome editing efficiency. ${ }^{283}$ Intracellular 7 degradation of sgRNA was effectively prevented by chemical modification of sgRNA, which provided 8 a boost in genome editing efficiency. ${ }^{115,284}$ By in vivo co-delivery of Cas 9 mRNA and sgRNA, several 9 reports succeeded in the disruption of disease-related genes in the liver, such as proprotein convertase 10 transfection (see Section 4.2). ${ }^{176,248,249}$

\subsection{Cancer}

mRNA-based vaccines were the first application to be considered for using mRNA against tumors. ${ }^{116,}$ 290-293 After the vaccination, the immune system can recognize cancer cells to elicit cellmediated antitumor responses. Thus, mRNA-based cancer vaccines can be directed to promote immunity against tumor-associated antigens, ${ }^{294}$ or against neoepitopes due to cancer mutations. ${ }^{295}$ As the neoepitope signature, i.e. mutanome, is exclusive for each patient and the mRNA molecules can encode several neoantigen epitopes in their sequence, Sahin et al. proposed to use mRNA-based vaccines as personalized therapeutics. ${ }^{295}, 296$ This concept was demonstrated in first-in-human application by 
1 immunizing metastatic melanoma patients against 10 epitopes. ${ }^{297}$ This initial success has triggered 2 several clinical trials against melanoma and other tumors, as reviewed elsewhere. ${ }^{3}$ mRNA can also be used to produce therapeutic proteins with antitumor activity, such as anti4 angiogenic proteins or antibodies ${ }^{41,241}$ thereby, using the organs and cells in the body as temporary 5 factories. This approach could be used to promote the bioavailability of agents that otherwise are rapidly 6 cleared from the body, thereby, reducing the number of injections and decreasing the burden for patients. 7 Moreover, producing the proteins in situ could avoid cumbersome procedures for synthesizing and 8 purifying protein drugs in clinical grade. For example, Stadler et al. developed mRNA-loaded 9 lipopolyplexes encoding bispecific tandem single-chain variable fragments $(\mathrm{scFv})$, i.e. bi-(scFv $)_{2}$ 10 proteins, directed to simultaneously target both CD3 expressed on T cells and tumor-associated antigens, 11 i.e. claudin 6 , claudin 18.2 , and the epithelial cell adhesion molecule (EpCAM)). ${ }^{241}$ These bi-(scFv) 12 work by connecting $\mathrm{T}$ cells to cancer cells for improving the cell killing efficiency. The mRNA-loaded 13 nanomedicines accumulated in liver to achieve effective mRNA translation and sustained release of bi$14(\mathrm{scFv})_{2}$ for around 7-days. The nanomedicines encoding bi-(scFv) $)_{2}$ directed to $\mathrm{CD} 3$ and claudin 6 eradicated large ovarian tumors, and their activity was comparable to that of the clinical recombinant bispecific antibody. However, the nanomedicines required 3-fold less frequency than the antibodies to exert the same antitumor effect.

mRNA-loaded nanomedicines can be applied to introduce specific proteins into cancer cells. 19 Such approach can be exploited to reduce cancer malignancy or sensitize cancer cells to other treatments. 20 For example, by using polymer-lipid hybrid nanoparticles comprised of PAMAM (generation 0) 21 dendrimer for complexation with mRNA, poly(lactic-co-glycolic acid) (PLGA) for increasing 22 hydrophobicity and ceramide-PEG for coating, it was possible to deliver mRNA encoding the tumor23 suppressor gene phosphatase and tensin homologue (PTEN) to tumors. The resulting expression of 24 functional PTEN in PTEN-null prostate cancer cells suppressed the phosphatidylinositol 3-kinase 
1 (PI3K)-AKT pathway and increased apoptosis. ${ }^{298}$ In another report, mRNA encoding $p 53$, a tumor 2 suppressor gene, was introduced to $p 53$-deficient tumors using polymer-lipid hybrid nanoparticles, 3 comprised of cationic lipid-like molecules for mRNA complexation, disulfate-containing polymers for 4 mRNA release in reductive intracellular environment and PEGylated lipids. ${ }^{299}$ The treatment with $p 53$ 5 mRNA suppressed the growth of $p 53$-deficient tumors, potentiated the function of a mammalian target 6 of rapamycin (mTOR) inhibitor and ultimately exhibited successful outcomes in mouse models of 7 orthotopic hepatocellular carcinoma and disseminated non-small cell lung cancer. More recently, PEI8 based polyplexes were used to introduce mRNA encoding vascular endothelial growth factor-C (VEGF9 C) into brain tumor cells to promote lymphangiogenesis and induce the infiltration of CD8 T cells into 10 the tumors. ${ }^{300}$ The combination of these mRNA-loaded polyplexes with immune checkpoint inhibitors 11 allowed the effective treatment of mice models of brain tumors.

\section{5. Future perspectives}

14 mRNA therapeutics are now gradually moving toward clinical applications. Vaccination 15 against cancer is one of the most advanced fields, with the first report of the clinical trials dating back to $162002 .{ }^{301}$ Targeting neoantigens, which are expressed only in cancer cells, is a good approach to improve 17 the efficacy of vaccines by circumventing immune tolerance mechanisms. A recent clinical trial provided 18 a proof of concept to this approach, by preparing mRNA expressing neoantigens, which were determined 19 by deep sequencing of cancer samples from each patient. ${ }^{297}$ With advances in mRNA vaccine 20 technologies, including RNA design, administration routes and delivery system, further improvement of 21 therapeutic outcomes are expected. Such personalized therapy has the potential to revolutionize the 22 methodology of cancer treatment.

Vaccine against infectious disease is another important field. In the pandemic of COVID-19 24 caused by severe acute respiratory syndrome coronavirus 2 (SARS-CoV2), several companies have 
1 launched or planned to start clinical trials of mRNA vaccine against the viral spike protein 2 (ClinicalTrials.gov Identifier: NCT04283461, NCT04368728), based on their promising results in 3 preclinical or clinical studies of mRNA vaccine against other viruses, including Zika, influenza and 4 rabies viruses. ${ }^{197,}{ }^{302-305}$ Importantly, mRNA vaccine against a new infectious disease can be easily 5 prepared just by changing the mRNA sequence in vaccine formulations developed for other viruses, 6 which allowed fast start of clinical trials within a few months after sequencing of SARS-CoV2 genome. 7 The utility of mRNA vaccine against pandemic will be evaluated within a year in large clinical trials. 8 Notably, competing technologies of nucleic acid vaccines, such as electroporation of pDNA and 9 adenovirus vector administration, are also being pursued for vaccination against SARS-CoV2. ${ }^{306,307}$ Pros 10 11 effects, production costs, quality control and large-scale production.

12 Clinical trials of mRNA therapeutics were conducted also for protein replacement therapy and 13 genome editing, with VEGF-A mRNA injection for heart regeneration (ClinicalTrials.gov Identifier: 14 NCT03370887), cystic fibrosis transmembrane conductance regulator (CFTR) supplementation for 15 cystic fibrosis (ClinicalTrials.gov Identifier: NCT03375047), and ex vivo ZFN-mediated disruption of 16 CCR5 gene for HIV treatment, as extensively reviewed elsewhere. ${ }^{308,309}$ However, clinical trials in these 17 fields are still much fewer than that those for mRNA vaccines, which may be partially due to the issues 18 of mRNA delivery. Protein replacement therapies and genome editing often targets larger organs 19 compared to the case of mRNA vaccine, which makes mRNA delivery difficult. While various delivery 20 systems exhibited successful outcomes in small animals, their functions should be evaluated using larger 21 animals for clinical translation. Because tremendous advances have been made in the core technologies 22 of mRNA delivery as reviewed here, combination of these technologies may provide effective systems 23 for clinical usage.

24 Target diseases and genes should be properly selected based on advantages of mRNA 58 
1 therapeutics over competing methodologies, including viral gene therapy and protein therapeutics. As 2 described above, mRNA provided a more proper option compared to viral gene vectors, when prolonged 3 gene expression induces detrimental effects (see Sections 4.2, 4.3). Acute diseases are a promising target 4 of mRNA therapeutics, as the onset of protein expression from mRNA is as early as a few hours after the 5 transfection..$^{40,248} \mathrm{~A}$ major problem of viral gene therapy is the production of neutralizing antibody, which 6 hampers repeated systemic administration of viral vectors. ${ }^{310}$ mRNA delivery is less prone to produce 7 neutralizing antibody, allowing multiple systemic injection without reduction of delivery efficiency. ${ }^{233}$, $8 \quad{ }^{234}$ On the other hand, transient profile of protein expression from mRNA should be taken into account 9 in selecting target diseases. Repeated injections would be required for a long term to treat chronic 10 diseases. When compared to protein therapeutics, mRNA therapeutics are more cost-effective due to 11 their ability to produce numerous copies of proteins from single mRNA. ${ }^{311}$ While global market of 12 antibody therapeutics is growing, ${ }^{312}$ mRNA may provide an inexpensive and effective option for 13 antibody-based treatment. ${ }^{237-241}$ Moreover, mRNA delivery is an easier approach to introduce 14 intracellular and membrane proteins compared to protein delivery, expanding the candidates of 15 therapeutic proteins for disease treatment.

17 6. Conclusion

Vigorous efforts were devoted to solve the problems of mRNA therapeutics, such as 19 immunogenicity, short duration of protein expression, rapid enzymatic degradation, and limited cellular 20 uptake. The strategies are classified into two orthogonal approaches, mRNA designing and 21 nanomedicines, which cooperatively function to facilitate mRNA delivery and minimize safety issues. 22 These technological advances allowed various therapeutic applications of mRNA including vaccinations, 23 protein replacement therapy, cancer therapy and cell reprogramming in preclinical and clinical studies. 55 
1 nanomedicines will solve various medical problems, which are intractable using conventional approaches, 2 as well as promote unprecedent therapeutic strategies.

\section{Acknowledgments}

5 This work was supported by Grants-in-Aid for Challenging Research (Exploratory) (18K19901; H.C.), 6 Grants-in-Aid for Scientific Research B (20H04524 and JP16H03179; H.C.) from the Japan Society for 7 the Promotion of Science (JSPS). This work has also been supported by fellowships from the Ligue 8 Nationale Contre le Cancer (FP).

\section{References}

12 1. Sahin, U.; Kariko, K.; Tureci, O., mRNA-based therapeutics - developing a new class of 13 drugs. Nat. Rev. Drug Discov. 2014, 13 (10), 759-80.

$142 . \quad$ Morse, D. E.; Yanofsky, C., Polarity and the degradation of mRNA. Nature 1969, 224 (5217), $15 \quad 329-31$.

16 3. Pardi, N.; Hogan, M. J.; Porter, F. W.; Weissman, D., mRNA vaccines - a new era in 17 vaccinology. Nat. Rev. Drug Discov. 2018, 17 (4), 261-279.

18 4. Naldini, L., Gene therapy returns to centre stage. Nature 2015, 526 (7573), 351-60.

19 5. Bessis, N.; GarciaCozar, F. J.; Boissier, M. C., Immune responses to gene therapy vectors: 20 influence on vector function and effector mechanisms. Gene Ther. 2004, 11 Suppl 1, S10-7.

216 Hajj, K. A.; Whitehead, K. A., Tools for translation: non-viral materials for therapeutic mRNA 22 delivery. Nature Reviews Materials 2017, 2 (10), 17056.

23 7. Zhong, Z.; Mc Cafferty, S.; Combes, F.; Huysmans, H.; De Temmerman, J.; Gitsels, 24 A.; Vanrompay, D.; Portela Catani, J.; Sanders, N. N., mRNA therapeutics deliver a hopeful message. 
$1 \quad$ Nano Today 2018, 23, 16-39.

2 8. Warminski, M.; Sikorski, P. J.; Kowalska, J.; Jemielity, J., Applications of phosphate 3 modification and labeling to study (m) RNA caps. In Phosphate Labeling and Sensing in Chemical 4 Biology, Springer: 2017; pp 211-239.

59 9. Wojtczak, B. A.; Sikorski, P. J.; Fac-Dabrowska, K.; Nowicka, A.; Warminski, M.; 6 Kubacka, D.; Nowak, E.; Nowotny, M.; Kowalska, J.; Jemielity, J., 5'-Phosphorothiolate 7 dinucleotide cap analogues: reagents for messenger RNA modification and potent small-molecular 8 inhibitors of decapping enzymes. Journal of the American Chemical Society 2018, 140 (18), 5987-5999. 9 10. Vallazza, B.; Petri, S.; Poleganov, M. A.; Eberle, F.; Kuhn, A. N.; Sahin, U., 10 Recombinant messenger RNA technology and its application in cancer immunotherapy, transcript 11 replacement therapies, pluripotent stem cell induction, and beyond. Wiley Interdisciplinary Reviews: 12 RNA 2015, $6(5), 471-499$.

13 11. Granot, Y.; Peer, D. In Delivering the right message: Challenges and opportunities in lipid 14 nanoparticles-mediated modified mRNA therapeutics-An innate immune system standpoint, Seminars 15 in immunology, Elsevier: 2017; pp 68-77.

16 12. Asrani, K. H.; Farelli, J. D.; Stahley, M. R.; Miller, R. L.; Cheng, C. J.; Subramanian, 17 R. R.; Brown, J. M., Optimization of mRNA untranslated regions for improved expression of therapeutic 18 mRNA. RNA biology 2018, 15 (6), 756-762.

19 13. Wadhwa, A.; Aljabbari, A.; Lokras, A.; Foged, C.; Thakur, A., Opportunities and 20 Challenges in the Delivery of mRNA-based Vaccines. Pharmaceutics 2020, 12 (2), 102.

21 14. Rabinovich, P. M., Synthetic messenger RNA and cell metabolism modulation: methods and 22 protocols. Springer: 2013.

23 15. Langberg, S. R.; Moss, B., Post-transcriptional modifications of mRNA. Purification and 24 characterization of cap I and cap II RNA (nucleoside-2'-)-methyltransferases from HeLa cells. Journal 
1 of Biological Chemistry 1981, 256 (19), 10054-10060.

2 16. Daffis, S.; $\quad$ Szretter, K. J.; $\quad$ Schriewer, J.; Li, J.; Youn, S.; $\quad$ Errett, J.; $\quad$ Lin, T.-Y.; 3 Schneller, S.; Zust, R.; Dong, H., 2'-O methylation of the viral mRNA cap evades host restriction by 4 IFIT family members. Nature 2010, 468 (7322), 452-456.

5 17. Muttach, F.; Muthmann, N.; Rentmeister, A., Synthetic mRNA capping. Beilstein journal of 6 organic chemistry 2017, 13 (1), 2819-2832.

7 18. McCormick, C.; Khaperskyy, D. A., Translation inhibition and stress granules in the antiviral 8 immune response. Nature Reviews Immunology 2017, 17 (10), 647.

9 19. Grudzien-Nogalska, E.; Kiledjian, M., New insights into decapping enzymes and selective 10 mRNA decay. Wiley Interdisciplinary Reviews: RNA 2017, 8 (1), e1379.

$1120 . \quad$ Fuchs, A.-L.; Neu, A.; Sprangers, R., A general method for rapid and cost-efficient large12 scale production of 5' capped RNA. RNA 2016, 22 (9), 1454-1466.

13 21. Pasquinelli, A.; Dahlberg, J. E.; Lund, E., Reverse 5'caps in RNAs made in vitro by phage 14 RNA polymerases. Rna 1995, 1 (9), 957-967.

15 22. JEMIELITY, J.; FOWLER, T.; ZUBEREK, J.; STEPINSKI, J.; LEWDOROWICZ, 16 M.; NIEDZWIECKA, A.; STOLARSKI, R.; DARZYNKIEWICZ, E.; RHOADS, R. E., Novel 17 "anti-reverse" cap analogs with superior translational properties. Rna 2003, 9 (9), 1108-1122.

18 23. STEPINSKI, J.; WADDELL, C.; STOLARSKI, R.; DARZYNKIEWICZ, E.; RHOADS, 19 R. E., Synthesis and properties of mRNAs containing the novel "anti-reverse" cap analogs 7-methyl (3'20 O-methyl) GpppG and 7-methyl (3'-deoxy) GpppG. Rna 2001, 7 (10), 1486-1495.

21 24. Kalek, M.; Jemielity, J.; Darzynkiewicz, Z. M.; Bojarska, E.; Stepinski, J.; Stolarski, 22 R.; Davis, R. E.; Darzynkiewicz, E., Enzymatically stable 5' mRNA cap analogs: synthesis and binding 23 studies with human DcpS decapping enzyme. Bioorganic \& medicinal chemistry 2006, 14 (9), 3223243230. 
1 25. Rydzik, A. M.; Kulis, M.; Lukaszewicz, M.; Kowalska, J.; Zuberek, J.; 2 Darzynkiewicz, Z. M.; Darzynkiewicz, E.; Jemielity, J., Synthesis and properties of mRNA cap analogs 3 containing imidodiphosphate moiety_fairly mimicking natural cap structure, yet resistant to enzymatic 4 hydrolysis. Bioorganic \& medicinal chemistry 2012, 20 (5), 1699-1710.

5 26. Rydzik, A. M.; Warminski, M.; Sikorski, P. J.; Baranowski, M. R.; Walczak, S.; 6 Kowalska, J.; Zuberek, J.; Lukaszewicz, M.; Nowak, E.; W. Claridge, T. D., mRNA cap analogues 7 substituted in the tetraphosphate chain with $\mathrm{CX} 2$ : identification of O-to-CC12 as the first bridging 8 modification that confers resistance to decapping without impairing translation. Nucleic acids research $9 \mathbf{2 0 1 7}, 45(15), 8661-8675$.

10 27. Grudzien-Nogalska, E.; Jemielity, J.; Kowalska, J.; Darzynkiewicz, E.; Rhoads, R. E., 11 Phosphorothioate cap analogs stabilize mRNA and increase translational efficiency in mammalian cells. $12 \quad R N A$ 2007, $13(10), 1745-1755$.

13 28. Kuhn, A.; Diken, M.; Kreiter, S.; Selmi, A.; Kowalska, J.; Jemielity, J.; 14 Darzynkiewicz, E.; Huber, C.; Türeci, Ö.; Sahin, U., Phosphorothioate cap analogs increase stability 15 and translational efficiency of RNA vaccines in immature dendritic cells and induce superior immune 16 responses in vivo. Gene therapy $\mathbf{2 0 1 0}, 17(8), 961-971$.

17 29. Kowalska, J.; Lewdorowicz, M.; Zuberek, J.; Grudzien-Nogalska, E.; Bojarska, E.; 18 Stepinski, J.; Rhoads, R. E.; Darzynkiewicz, E.; Davis, R. E.; Jemielity, J., Synthesis and 19 characterization of mRNA cap analogs containing phosphorothioate substitutions that bind tightly to 20 eIF4E and are resistant to the decapping pyrophosphatase DcpS. Rna 2008, 14 (6), 1119-1131.

21 30. Wang, J.; Alvin Chew, B. L.; Lai, Y.; Dong, H.; Xu, L.; Balamkundu, S.; Cai, W. 22 M.; Cui, L.; Liu, C. F.; Fu, X.-Y., Quantifying the RNA cap epitranscriptome reveals novel caps in 23 cellular and viral RNA. Nucleic acids research 2019, 47 (20), e130-e130.

24 31. Sikorski, P. J.; Warminski, M.; Kubacka, D.; Ratajczak, T.; Nowis, D.; Kowalska, J.; 
1 Jemielity, J., The identity and methylation status of the first transcribed nucleotide in eukaryotic mRNA $25^{\prime}$ cap modulates protein expression in living cells. Nucleic acids research 2020, 48 (4), 1607-1626.

3 32. Walczak, S.; Nowicka, A.; Kubacka, D.; Fac, K.; Wanat, P.; Mroczek, S.; 4 Kowalska, J.; Jemielity, J., A novel route for preparing 5' cap mimics and capped RNAs: phosphate5 modified cap analogues obtained via click chemistry. Chemical science 2017, 8 (1), 260-267.

6 33. Nagarajan, V. K.; Jones, C. I.; Newbury, S. F.; Green, P. J., XRN 5' $\rightarrow$ 3' exoribonucleases: 7 structure, mechanisms and functions. Biochimica et Biophysica Acta (BBA)-Gene Regulatory 8 Mechanisms 2013, 1829 (6-7), 590-603.

9 34. Proudfoot, N. J., Ending the message: poly (A) signals then and now. Genes \& development 10 2011, $25(17), 1770-1782$.

11 35. Holtkamp, S.; Kreiter, S.; Selmi, A.; Simon, P.; Koslowski, M.; Huber, C.; Türeci, 12 O. z.; Sahin, U., Modification of antigen-encoding RNA increases stability, translational efficacy, and 13 T-cell stimulatory capacity of dendritic cells. Blood 2006, 108 (13), 4009-4017.

14 36. Grier, A. E.; Burleigh, S.; Sahni, J.; Clough, C. A.; Cardot, V.; Choe, D. C.; 15 Krutein, M. C.; Rawlings, D. J.; Jensen, M. C.; Scharenberg, A. M., pEVL: A linear plasmid for 16 generating mRNA IVT templates with extended encoded poly (A) sequences. Molecular Therapy17 Nucleic Acids 2016, 5, e306.

18 37. Mockey, M.; Gonçalves, C.; Dupuy, F. P.; Lemoine, F. M.; Pichon, C.; Midoux, P., 19 mRNA transfection of dendritic cells: synergistic effect of ARCA mRNA capping with Poly (A) chains 20 in cis and in trans for a high protein expression level. Biochemical and biophysical research 21 communications 2006, 340 (4), 1062-1068.

22 38. Mockey, M.; Bourseau, E.; Chandrashekhar, V.; Chaudhuri, A.; Lafosse, S.; Le Cam, 23 E.; Quesniaux, V.; Ryffel, B.; Pichon, C.; Midoux, P., mRNA-based cancer vaccine: prevention of 24 B16 melanoma progression and metastasis by systemic injection of MART1 mRNA histidylated 
1 lipopolyplexes. Cancer gene therapy 2007, 14 (9), 802-814.

2 39. Perche, F.; Clemençon, R.; Schulze, K.; Ebensen, T.; Guzmán, C. A.; Pichon, C., 3 Neutral Lipopolyplexes for In Vivo Delivery of Conventional and Replicative RNA Vaccine. Molecular 4 Therapy-Nucleic Acids 2019, 17, 767-775.

5 40. Uchida, S.; Itaka, K.; Uchida, H.; Hayakawa, K.; Ogata, T.; Ishii, T.; Fukushima, 6 S.; Osada, K.; Kataoka, K., In vivo messenger RNA introduction into the central nervous system using 7 polyplex nanomicelle. PLoS One 2013, 8 (2), e56220.

8 41. Uchida, S.; Kinoh, H.; Ishii, T.; Matsui, A.; Tockary, T. A.; Takeda, K. M.; Uchida, 9 H.; Osada, K.; Itaka, K.; Kataoka, K., Systemic delivery of messenger RNA for the treatment of 10 pancreatic cancer using polyplex nanomicelles with a cholesterol moiety. Biomaterials 2016, 82, 22111228.

12 42. Hinnebusch, A. G.; Ivanov, I. P.; Sonenberg, N., Translational control by 5'-untranslated 13 regions of eukaryotic mRNAs. Science 2016, 352 (6292), 1413-1416.

14 43. Peixeiro, I.; Silva, A. L.; Romão, L., Control of human $\beta$-globin mRNA stability and its 15 impact on beta-thalassemia phenotype. Haematologica 2011, 96 (6), 905-913.

16 44. Bradley, R. D.; Hillis, D. M., Recombinant DNA sequences generated by PCR amplification. 17 Molecular biology and evolution 1997, 14 (5), 592-593.

$18 \quad 45 . \quad$ von Niessen, A. G. O.; Poleganov, M. A.; Rechner, C.; Plaschke, A.; Kranz, L. M.; 19 Fesser, S.; Diken, M.; Löwer, M.; Vallazza, B.; Beissert, T., Improving mRNA-based therapeutic 20 gene delivery by expression-augmenting $3^{\prime}$ UTRs identified by cellular library screening. Molecular 21 Therapy 2019, 27 (4), 824-836.

22 46. Verbeke, R.; Lentacker, I.; De Smedt, S. C.; Dewitte, H., Three decades of messenger RNA 23 vaccine development. Nano Today 2019, 100766.

24 47. Chen, C.-Y.; Gherzi, R.; Ong, S.-E.; Chan, E. L.; Raijmakers, R.; Pruijn, G. J.; 65 
1 Stoecklin, G.; Moroni, C.; Mann, M.; Karin, M., AU binding proteins recruit the exosome to degrade 2 ARE-containing mRNAs. Cell 2001, 107 (4), 451-464.

3 48. Kudla, G.; Lipinski, L.; Caffin, F.; Helwak, A.; Zylicz, M., High guanine and cytosine 4 content increases mRNA levels in mammalian cells. PLoS biology 2006, 4 (6).

$5 \quad 49 . \quad$ Courel, M.; Clément, Y.; Bossevain, C.; Foretek, D.; Cruchez, O. V.; Yi, Z.; 6 Bénard, M.; Benassy, M.-N.; Kress, M.; Vindry, C., GC content shapes mRNA storage and decay in 7 human cells. eLife 2019, 8 .

8 50. Petsch, B.; Schnee, M.; Vogel, A. B.; Lange, E.; Hoffmann, B.; Voss, D.; Schlake, 9 T.; Thess, A.; Kallen, K.-J.; Stitz, L., Protective efficacy of in vitro synthesized, specific mRNA 10 vaccines against influenza A virus infection. Nature biotechnology 2012, 30 (12), 1210.

11 51. Hoerr, I.; Obst, R.; Rammensee, H. G.; Jung, G., In vivo application of RNA leads to 12 induction of specific cytotoxic T lymphocytes and antibodies. European journal of immunology 2000, $1330(1), 1-7$.

14 52. Thess, A.; Grund, S.; Mui, B. L.; Hope, M. J.; Baumhof, P.; Fotin-Mleczek, M.; 15 Schlake, T., Sequence-engineered mRNA without chemical nucleoside modifications enables an 16 effective protein therapy in large animals. Molecular Therapy 2015, 23 (9), 1456-1464.

17 53. Wang, P.; Perche, F.; Logeart-Avramoglou, D.; Pichon, C., RNA-based therapy for 18 osteogenesis. International Journal of Pharmaceutics 2019, 569, 118594.

19 54. Kariko, K.; Buckstein, M.; Ni, H.; Weissman, D., Suppression of RNA recognition by Toll20 like receptors: the impact of nucleoside modification and the evolutionary origin of RNA. Immunity $\mathbf{2 0 0 5}$, $2123(2), 165-75$.

22 55. Dan, M.; Zheng, D.; Field, L. L.; Bonnevie-Nielsen, V., Induction and activation of 23 antiviral enzyme 2', 5'-oligoadenylate synthetase by in vitro transcribed insulin mRNA and other cellular 24 RNAs. Molecular biology reports 2012, 39 (7), 7813-7822. 
1 56. Sahin, U.; Karikó, K.; Türeci, Ö., mRNA-based therapeutics-developing a new class of 2 drugs. Nature reviews Drug discovery 2014, 13 (10), 759.

3 57. Anderson, B. R.; Muramatsu, H.; Jha, B. K.; Silverman, R. H.; Weissman, D.; Kariko, 4 K., Nucleoside modifications in RNA limit activation of 2'-5'-oligoadenylate synthetase and increase 5 resistance to cleavage by RNase L. Nucleic acids research 2011, 39 (21), 9329-9338.

6 58. Kariko, K.; Muramatsu, H.; Welsh, F. A.; Ludwig, J.; Kato, H.; Akira, S.; Weissman, 7 D., Incorporation of pseudouridine into mRNA yields superior nonimmunogenic vector with increased 8 translational capacity and biological stability. Mol. Ther. 2008, $16(11), 1833-40$.

9 59. Karikó, K.; Muramatsu, H.; Keller, J. M.; Weissman, D., Increased erythropoiesis in mice 10 injected with submicrogram quantities of pseudouridine-containing mRNA encoding erythropoietin. 11 Molecular therapy 2012, 20 (5), 948-953.

12 60. Andries, O.; Mc Cafferty, S.; De Smedt, S. C.; Weiss, R.; Sanders, N. N.; Kitada, T., 13 N(1)-methylpseudouridine-incorporated mRNA outperforms pseudouridine-incorporated mRNA by 14 providing enhanced protein expression and reduced immunogenicity in mammalian cell lines and mice. 15 J. Control. Release 2015, 217, 337-44.

16 61. Uchida, S.; Kataoka, K.; Itaka, K., Screening of mRNA Chemical Modification to Maximize 17 Protein Expression with Reduced Immunogenicity. Pharmaceutics 2015, 7 (3), 137-151.

18 62. Li, B.; Luo, X.; Dong, Y., Effects of Chemically Modified Messenger RNA on Protein 19 Expression. Bioconjug. Chem. 2016, 27 (3), 849-53.

20 63. Kauffman, K. J.; Mir, F. F.; Jhunjhunwala, S.; Kaczmarek, J. C.; Hurtado, J. E.; Yang, 21 J. H.; Webber, M. J.; Kowalski, P. S.; Heartlein, M. W.; DeRosa, F.; Anderson, D. G., Efficacy 22 and immunogenicity of unmodified and pseudouridine-modified mRNA delivered systemically with 23 lipid nanoparticles in vivo. Biomaterials 2016, 109, 78-87.

2464 Lundstrom, K., Self-replicating RNA viral vectors in vaccine development and gene therapy. 
$1 \quad$ Future Virology 2016, 11 (5), 345-356.

2 65. Ying, H.; Zaks, T. Z.; Wang, R.-F.; Irvine, K. R.; Kammula, U. S.; Marincola, F. M.; 3 Leitner, W. W.; Restifo, N. P., Cancer therapy using a self-replicating RNA vaccine. Nature medicine $4 \quad 1999,5(7), 823$.

$5 \quad 66 . \quad$ Vogel, A. B.; Lambert, L.; Kinnear, E.; Busse, D.; Erbar, S.; Reuter, K. C.; Wicke, $6 \quad$ L.; Perkovic, M.; Beissert, T.; Haas, H., Self-amplifying RNA vaccines give equivalent protection 7 against influenza to mRNA vaccines but at much lower doses. Molecular Therapy 2018, 26 (2), 446-455. $8 \quad 67 . \quad$ Pardi, N.; Hogan, M. J.; Porter, F. W.; Weissman, D., mRNA vaccines-a new era in 9 vaccinology. Nature Reviews Drug Discovery 2018, 17 (4), 261. 68. Blakney, A. K.; McKay, P. F.; Christensen, D.; Yus, B. I.; Aldon, Y.; Follmann, F.; 11 Shattock, R. J., Effects of cationic adjuvant formulation particle type, fluidity and immunomodulators 12 on delivery and immunogenicity of saRNA. Journal of Controlled Release 2019, 304, 65-74.

13 69. Chahal, J. S.; Khan, O. F.; Cooper, C. L.; McPartlan, J. S.; Tsosie, J. K.; Tilley, L. 14 D.; Sidik, S. M.; Lourido, S.; Langer, R.; Bavari, S., Dendrimer-RNA nanoparticles generate 15 protective immunity against lethal Ebola, H1N1 influenza, and Toxoplasma gondii challenges with a 16 single dose. Proceedings of the National Academy of Sciences 2016, 113 (29), E4133-E4142.

17 70. Atasheva, S.; McAuley, A. J.; Plante, J. A.; Frolova, E. I.; Beasley, D. W.; Frolov, I., 18 Enhancement of protein expression by alphavirus replicons by designing self-replicating subgenomic 19 RNAs. Proceedings of the National Academy of Sciences 2014, 111 (29), 10708-10713.

20 71. Brito, L. A.; Kommareddy, S.; Maione, D.; Uematsu, Y.; Giovani, C.; Scorza, F. B.; 21 Otten, G. R.; Yu, D.; Mandl, C. W.; Mason, P. W., Self-amplifying mRNA vaccines. In Advances in 22 genetics, Elsevier: 2015; Vol. 89, pp 179-233.

$23 \quad 72 . \quad$ Perri, S.; $\quad$ Greer, C. E.; $\quad$ Thudium, K.; $\quad$ Doe, B.; $\quad$ Legg, H.; $\quad$ Liu, H.; Romero, R. E.; 24 Tang, Z.; Bin, Q.; Dubensky, T. W., An alphavirus replicon particle chimera derived from venezuelan 
1 equine encephalitis and sindbis viruses is a potent gene-based vaccine delivery vector. Journal of 2 virology 2003, 77 (19), 10394-10403.

3 73. Rupp, J. C.; Sokoloski, K. J.; Gebhart, N. N.; Hardy, R. W., Alphavirus RNA synthesis and 4 non-structural protein functions. The Journal of general virology 2015, 96 (Pt 9), 2483.

5 74. Huysmans, H.; Zhong, Z.; De Temmerman, J.; Mui, B. L.; Tam, Y. K.; Mc Cafferty, $6 \quad$ S.; Gitsels, A.; Vanrompay, D.; Sanders, N. N., Expression Kinetics and Innate Immune Response 7 after Electroporation and LNP-Mediated Delivery of a Self-Amplifying mRNA in the Skin. Molecular 8 Therapy-Nucleic Acids 2019, 17, 867-878.

9 75. Atkins, G. J.; Fleeton, M. N.; Sheahan, B. J., Therapeutic and prophylactic applications of 10 alphavirus vectors. Expert reviews in molecular medicine 2008, 10.

11 76. Chen, Y. G.; Chen, R.; Ahmad, S.; Verma, R.; Kasturi, S. P.; Amaya, L.; 12 Broughton, J. P.; Kim, J.; Cadena, C.; Pulendran, B., N6-Methyladenosine Modification Controls 13 Circular RNA Immunity. Molecular cell 2019.

$1477 . \quad$ Litke, J. L.; Jaffrey, S. R., Highly efficient expression of circular RNA aptamers in cells using 15 autocatalytic transcripts. Nature biotechnology 2019, 37 (6), 667.

16 78. Wesselhoeft, R. A.; Kowalski, P. S.; Anderson, D. G., Engineering circular RNA for potent 17 and stable translation in eukaryotic cells. Nature communications 2018, 9 (1), 2629.

18 79. Wesselhoeft, R. A.; Kowalski, P. S.; Parker-Hale, F. C.; Huang, Y.; Bisaria, N.; 19 Anderson, D. G., RNA Circularization Diminishes Immunogenicity and Can Extend Translation 20 Duration In Vivo. Molecular cell 2019, 74 (3), 508-520. e4.

21 80. Kos, A.; Dijkema, R.; Arnberg, A.; Van der Meide, P.; Schellekens, H., The hepatitis 22 delta $(\delta)$ virus possesses a circular RNA. Nature 1986, 323 (6088), 558.

23 81. Kjems, J.; Garrett, R. A., Novel splicing mechanism for the ribosomal RNA intron in the 24 archaebacterium Desulfurococcus mobilis. Cell 1988, 54 (5), 693-703. 
1 82. Wang, P. L.; Bao, Y.; Yee, M.-C.; Barrett, S. P.; Hogan, G. J.; Olsen, M. N.;

2 Dinneny, J. R.; Brown, P. O.; Salzman, J., Circular RNA is expressed across the eukaryotic tree of life. $3 \quad$ PloS one 2014, 9 (3), e90859.

4 83. Salzman, J.; Gawad, C.; Wang, P. L.; Lacayo, N.; Brown, P. O., Circular RNAs are the 5 predominant transcript isoform from hundreds of human genes in diverse cell types. PloS one 2012, 7 $6 \quad(2), \mathrm{e} 30733$.

$7 \quad$ 84. Zhang, Y.; Zhang, X.-O.; Chen, T.; Xiang, J.-F.; Yin, Q.-F.; Xing, Y.-H.; Zhu, S.;

8 Yang, L.; Chen, L.-L., Circular intronic long noncoding RNAs. Molecular cell 2013, 51 (6), $792-806$.

$9 \quad$ 85. Vicens, Q.; Westhof, E., Biogenesis of circular RNAs. Cell 2014, 159 (1), 13-14.

$1086 . \quad$ Chen, L.-L., The biogenesis and emerging roles of circular RNAs. Nature reviews Molecular 11 cell biology 2016, 17 (4), 205.

12 87. Wilusz, J. E., A 360 view of circular RNAs: from biogenesis to functions. Wiley 13 Interdisciplinary Reviews: RNA 2018, 9 (4), e1478.

$1488 . \quad$ Cech, T. R., Self-splicing of group I introns. Annual review of biochemistry 1990, 59 (1), $543-$ 15568.

16 89. De Conti, L.; Baralle, M.; Buratti, E., Exon and intron definition in pre-mRNA splicing. 17 Wiley Interdisciplinary Reviews: RNA 2013, 4 (1), 49-60.

$1890 . \quad$ Petkovic, S.; Müller, S., RNA circularization strategies in vivo and in vitro. Nucleic acids 19 research 2015, $43(4), 2454-2465$.

20 91. $\quad$ Kramer, M. C.; Liang, D.; Tatomer, D. C.; Gold, B.; March, Z. M.; Cherry, S.; 21 Wilusz, J. E., Combinatorial control of Drosophila circular RNA expression by intronic repeats, hnRNPs, 22 and SR proteins. Genes \& development 2015, 29 (20), 2168-2182.

23 92. Müller, S.; Appel, B., In vitro circularization of RNA. RNA biology 2017, 14 (8), 1018-1027. 24 93. Zhang, Y.; Xue, W.; Li, X.; Zhang, J.; Chen, S.; Zhang, J.-L.; Yang, L.; Chen, L.- 
1 L., The biogenesis of nascent circular RNAs. Cell reports 2016, 15 (3), 611-624.

2 94. Zhang, X.-O.; Wang, H.-B.; Zhang, Y.; Lu, X.; Chen, L.-L.; Yang, L., Complementary 3 sequence-mediated exon circularization. Cell 2014, 159 (1), 134-147.

4 95. Hansen, T. B.; Jensen, T. I.; Clausen, B. H.; Bramsen, J. B.; Finsen, B.; Damgaard, 5 C. K.; Kjems, J., Natural RNA circles function as efficient microRNA sponges. Nature 2013, 495 (7441), 6384.

7 96. Grabowski, P. J.; Zaug, A. J.; Cech, T. R., The intervening sequence of the ribosomal RNA 8 precursor is converted to a circular RNA in isolated nuclei of Tetrahymena. Cell 1981, 23 (2), 467-476. 9 97. Enuka, Y.; Lauriola, M.; Feldman, M. E.; Sas-Chen, A.; Ulitsky, I.; Yarden, Y., 10 Circular RNAs are long-lived and display only minimal early alterations in response to a growth factor. $11 \quad$ Nucleic acids research 2015, 44 (3), 1370-1383.

12 98. Guo, J. U.; Agarwal, V.; Guo, H.; Bartel, D. P., Expanded identification and 13 characterization of mammalian circular RNAs. Genome biology 2014, 15 (7), 409.

14 99. $\quad$ Memczak, S.; Jens, M.; Elefsinioti, A.; Torti, F.; Krueger, J.; Rybak, A.; Maier, L.; 15 Mackowiak, S. D.; Gregersen, L. H.; Munschauer, M., Circular RNAs are a large class of animal RNAs 16 with regulatory potency. Nature 2013, 495 (7441), 333.

17 100. Piwecka, M.; Glažar, P.; Hernandez-Miranda, L. R.; Memczak, S.; Wolf, S. A.; 18 Rybak-Wolf, A.; Filipchyk, A.; Klironomos, F.; Jara, C. A. C.; Fenske, P., Loss of a mammalian 19 circular RNA locus causes miRNA deregulation and affects brain function. Science 2017, 357 (6357), 20 eaam8526.

21 101. Legnini, I.; Di Timoteo, G.; Rossi, F.; Morlando, M.; Briganti, F.; Sthandier, O.; 22 Fatica, A.; Santini, T.; Andronache, A.; Wade, M., Circ-ZNF609 is a circular RNA that can be 23 translated and functions in myogenesis. Molecular cell 2017, 66 (1), 22-37. e9.

24 102. Pamudurti, N. R.; Bartok, O.; Jens, M.; Ashwal-Fluss, R.; Stottmeister, C.; Ruhe, L.; 
1 Hanan, M.; Wyler, E.; Perez-Hernandez, D.; Ramberger, E., Translation of circRNAs. Molecular cell $2 \quad \mathbf{2 0 1 7}, 66(1), 9-21 . \mathrm{e} 7$.

3 103. Kowalski, P. S.; Rudra, A.; Miao, L.; Anderson, D. G., Delivering the messenger: advances 4 in technologies for therapeutic mRNA delivery. Molecular Therapy 2019.

5 104. Kaczmarek, J. C.; Kowalski, P. S.; Anderson, D. G., Advances in the delivery of RNA 6 therapeutics: from concept to clinical reality. Genome medicine 2017, 9 (1), 60.

7 105. Xiao, M.-S.; Wilusz, J. E., An improved method for circular RNA purification using RNase R 8 that efficiently removes linear RNAs containing G-quadruplexes or structured 3' ends. Nucleic acids 9 research 2019, 47 (16), 8755-8769.

10 106. Ford, E.; Ares, M., Synthesis of circular RNA in bacteria and yeast using RNA cyclase 11 ribozymes derived from a group I intron of phage T4. Proceedings of the National Academy of Sciences $12 \quad \mathbf{1 9 9 4 ,} 91(8), 3117-3121$.

13 107. Kariko, K.; Muramatsu, H.; Ludwig, J.; Weissman, D., Generating the optimal mRNA for 14 therapy: HPLC purification eliminates immune activation and improves translation of nucleoside15 modified, protein-encoding mRNA. Nucleic acids research 2011, 39 (21), e142-e142.

16 108. Abe, N.; Hiroshima, M.; Maruyama, H.; Nakashima, Y.; Nakano, Y.; Matsuda, A.; 17 Sako, Y.; Ito, Y.; Abe, H., Rolling circle amplification in a prokaryotic translation system using small 18 circular RNA. Angew Chem Int Ed Engl 2013, 52 (27), 7004-8.

19 109. Abe, N.; Matsumoto, K.; Nishihara, M.; Nakano, Y.; Shibata, A.; Maruyama, H.; 20 Shuto, S.; Matsuda, A.; Yoshida, M.; Ito, Y.; Abe, H., Rolling Circle Translation of Circular RNA 21 in Living Human Cells. Sci. Rep. 2015, 5, 16435.

22 110. Kormann, M. S.; Hasenpusch, G.; Aneja, M. K.; Nica, G.; Flemmer, A. W.; Herber23 Jonat, S.; Huppmann, M.; Mays, L. E.; Illenyi, M.; Schams, A.; Griese, M.; Bittmann, I.; 24 Handgretinger, R.; Hartl, D.; Rosenecker, J.; Rudolph, C., Expression of therapeutic proteins after 
1 delivery of chemically modified mRNA in mice. Nature Biotechnol. 2011, 29 (2), 154-7.

2 111. Yoshinaga, N.; Uchida, S.; Naito, M.; Osada, K.; Cabral, H.; Kataoka, K., Induced 3 packaging of mRNA into polyplex micelles by regulated hybridization with a small number of 4 cholesteryl RNA oligonucleotides directed enhanced in vivo transfection. Biomaterials 2019, 197, 2555267.

6 112. Kurimoto, S.; Yoshinaga, N.; Igarashi, K.; Matsumoto, Y.; Cabral, H.; Uchida, S., 7 PEG-OligoRNA Hybridization of mRNA for Developing Sterically Stable Lipid Nanoparticles toward 8 In Vivo Administration. Molecules 2019, 24 (7), 1303.

9 113. Yoshinaga, N.; Cho, E.; Koji, K.; Mochida, Y.; Naito, M.; Osada, K.; Kataoka, K.; 10 Cabral, H.; Uchida, S., Bundling mRNA Strands to Prepare Nano-Assemblies with Enhanced Stability 11 Towards RNase for In Vivo Delivery. Angew. Chem. Int. Ed. 2019, 58 (33), 11360-11363.

12 114. Uchida, S.; Yoshinaga, N.; Yanagihara, K.; Yuba, E.; Kataoka, K.; Itaka, K.,

13 Designing immunostimulatory double stranded messenger RNA with maintained translational activity 14 through hybridization with poly A sequences for effective vaccination. Biomaterials 2018, 150, 162-170. $15 \quad$ 115. Yin, H.; Song, C. Q.; Suresh, S.; Wu, Q.; Walsh, S.; Rhym, L. H.; Mintzer, E.; 16 Bolukbasi, M. F.; $\quad$ Zhu, L. J.; Kauffman, K.; $\quad$ Mou, H.; Oberholzer, A.; $\quad$ Ding, J.; Kwan, S. Y.; 17 Bogorad, R. L.; Zatsepin, T.; Koteliansky, V.; Wolfe, S. A.; Xue, W.; Langer, R.; Anderson, 18 D. G., Structure-guided chemical modification of guide RNA enables potent non-viral in vivo genome 19 editing. Nature Biotechnol. 2017, 35 (12), 1179-1187.

20 116. Kranz, L. M.; Diken, M.; Haas, H.; Kreiter, S.; Loquai, C.; Reuter, K. C.; Meng, 21 M.; Fritz, D.; Vascotto, F.; Hefesha, H.; Grunwitz, C.; Vormehr, M.; Husemann, Y.; Selmi, 22 A.; Kuhn, A. N.; Buck, J.; Derhovanessian, E.; Rae, R.; Attig, S.; Diekmann, J.; 23 Jabulowsky, R. A.; Heesch, S.; Hassel, J.; Langguth, P.; Grabbe, S.; Huber, C.; Tureci, O.; 24 Sahin, U., Systemic RNA delivery to dendritic cells exploits antiviral defence for cancer immunotherapy. 
$1 \quad$ Nature 2016, 534 (7607), 396-401.

2 117. Cullis, P. R.; Hope, M. J., Lipid Nanoparticle Systems for Enabling Gene Therapies. Mol. Ther. $3 \quad \mathbf{2 0 1 7}, 25(7), 1467-1475$.

4 118. Fenton, O. S.; Kauffman, K. J.; Kaczmarek, J. C.; McClellan, R. L.; Jhunjhunwala, S.; 5 Tibbitt, M. W.; Zeng, M. D.; Appel, E. A.; Dorkin, J. R.; Mir, F. F.; Yang, J. H.; Oberli, M. 6 A.; Heartlein, M. W.; DeRosa, F.; Langer, R.; Anderson, D. G., Synthesis and Biological 7 Evaluation of Ionizable Lipid Materials for the In Vivo Delivery of Messenger RNA to B Lymphocytes. 8 Adv. Mater. 2017, $29(33)$.

9 119. Kurimoto, S.; Yoshinaga, N.; Igarashi, K.; Matsumoto, Y.; Cabral, H.; Uchida, S., 10 PEG-OligoRNA Hybridization of mRNA for Developing Sterically Stable Lipid Nanoparticles toward 11 In Vivo Administration. Molecules (Basel, Switzerland) 2019, 24 (7).

12 120. Lee, J. B.; Hong, J.; Bonner, D. K.; Poon, Z.; Hammond, P. T., Self-assembled RNA 13 interference microsponges for efficient siRNA delivery. Nature Mater. 2012, 11 (4), 316-22.

14 121. Hao, C.; Li, X.; Tian, C.; Jiang, W.; Wang, G.; Mao, C., Construction of RNA 15 nanocages by re-engineering the packaging RNA of Phi29 bacteriophage. Nature Commun. 2014, 5, 163890.

17 122. Yoshinaga, N.; Cho, E.; Koji, K.; Mochida, Y.; Naito, M.; Osada, K.; Kataoka, K.; 18 Cabral, H.; Uchida, S., Bundling mRNA Strands to Prepare Nano-Assemblies with Enhanced Stability 19 Towards RNase for In Vivo Delivery. Angew Chem Int Ed Engl 2019, 58 (33), 11360-11363.

20 123. Kim, H.; Park, Y.; Lee, J. B., Self-assembled Messenger RNA Nanoparticles (mRNA-NPs) 21 for Efficient Gene Expression. Sci. Rep. 2015, 5, 12737.

22 124. Mizuguchi, H.; Xu, Z.; Ishii-Watabe, A.; Uchida, E.; Hayakawa, T., IRES-dependent 23 second gene expression is significantly lower than cap-dependent first gene expression in a bicistronic 24 vector. Mol. Ther. 2000, 1 (4), 376-82. 
1 125. Poliskey, J. A.; Crowley, S. T.; Ramanathan, R.; White, C. W.; Mathew, B.; Rice, K. 2 G., Metabolically stabilized double-stranded mRNA polyplexes. Gene Ther. 2018.

3 126. Kim, D. H.; Longo, M.; Han, Y.; Lundberg, P.; Cantin, E.; Rossi, J. J., Interferon 4 induction by siRNAs and ssRNAs synthesized by phage polymerase. Nature Biotechnol. 2004, 22 (3), $5 \quad 321-5$.

6 127. Barbalat, R.; Ewald, S. E.; Mouchess, M. L.; Barton, G. M., Nucleic acid recognition by 7 the innate immune system. Annual review of immunology 2011, 29, 185-214.

8 128. Leung, A. K.; Hafez, I. M.; Baoukina, S.; Belliveau, N. M.; Zhigaltsev, I. V.; 9 Afshinmanesh, E.; Tieleman, D. P.; Hansen, C. L.; Hope, M. J.; Cullis, P. R., Lipid nanoparticles 10 containing siRNA synthesized by microfluidic mixing exhibit an electron-dense nanostructured core. The 11 Journal of Physical Chemistry C 2012, 116 (34), 18440-18450.

12 129. Cheng, X.; Lee, R. J., The role of helper lipids in lipid nanoparticles (LNPs) designed for 13 oligonucleotide delivery. Advanced drug delivery reviews 2016, 99, 129-137.

14 130. Rietwyk, S.; Peer, D., Next-generation lipids in RNA interference therapeutics. ACS nano 2017, $15 \quad 11(8), 7572-7586$.

16 131. Leung, A. K.; Tam, Y. Y. C.; Chen, S.; Hafez, I. M.; Cullis, P. R., Microfluidic mixing: 17 a general method for encapsulating macromolecules in lipid nanoparticle systems. The journal of 18 physical chemistry B 2015, 119 (28), 8698-8706.

19 132. Wood, H., FDA approves patisiran to treat hereditary transthyretin amyloidosis. Nature 20 Publishing Group: 2018.

21 133. Nabhan, J. F.; Wood, K. M.; Rao, V. P.; Morin, J.; Bhamidipaty, S.; LaBranche, T. 22 P.; Gooch, R. L.; Bozal, F.; Bulawa, C. E.; Guild, B. C., Intrathecal delivery of frataxin mRNA 23 encapsulated in lipid nanoparticles to dorsal root ganglia as a potential therapeutic for Friedreich's ataxia. 24 Scientific reports 2016, 6 (1), 1-10. 
1 134. Sahay, G.; Querbes, W.; Alabi, C.; Eltoukhy, A.; Sarkar, S.; Zurenko, C.;

2 Karagiannis, E.; Love, K.; Chen, D.; Zoncu, R., Efficiency of siRNA delivery by lipid nanoparticles 3 is limited by endocytic recycling. Nature biotechnology 2013, 31 (7), 653.

4 135. Sabnis, S.; Kumarasinghe, E. S.; Salerno, T.; Mihai, C.; Ketova, T.; Senn, J. J.; 5 Lynn, A.; Bulychev, A.; McFadyen, I.; Chan, J., A novel amino lipid series for mRNA delivery: 6 improved endosomal escape and sustained pharmacology and safety in non-human primates. Molecular 7 Therapy 2018, $26(6), 1509-1519$.

$8 \quad$ 136. Li, B.; Luo, X.; Deng, B.; Wang, J.; McComb, D. W.; Shi, Y.; Gaensler, K. M.; 9 Tan, X.; Dunn, A. L.; Kerlin, B. A.; Dong, Y., An Orthogonal Array Optimization of Lipid-like 10 Nanoparticles for mRNA Delivery in Vivo. Nano Lett. 2015, 15 (12), 8099-107.

11 137. Miao, L.; Li, L.; Huang, Y.; Delcassian, D.; Chahal, J.; Han, J.; Shi, Y.; Sadtler, 12 K.; Gao, W.; Lin, J., Delivery of mRNA vaccines with heterocyclic lipids increases anti-tumor efficacy 13 by STING-mediated immune cell activation. Nature biotechnology 2019, 37 (10), 1174-1185.

14 138. Kulkarni, J. A.; Witzigmann, D.; Leung, J.; van der Meel, R.; Zaifman, J.; Darjuan, 15 M. M.; Grisch-Chan, H. M.; Thöny, B.; Tam, Y. Y. C.; Cullis, P. R., Fusion-dependent formation 16 of lipid nanoparticles containing macromolecular payloads. Nanoscale 2019, 11 (18), 9023-9031.

17 139. Kauffman, K. J.; Dorkin, J. R.; Yang, J. H.; Heartlein, M. W.; DeRosa, F.; Mir, F. F.; 18 Fenton, O. S.; Anderson, D. G., Optimization of lipid nanoparticle formulations for mRNA delivery in 19 vivo with fractional factorial and definitive screening designs. Nano letters 2015, 15 (11), 7300-7306. 20 140. Oberli, M. A.; Reichmuth, A. M.; Dorkin, J. R.; Mitchell, M. J.; Fenton, O. S.; 21 Jaklenec, A.; Anderson, D. G.; Langer, R.; Blankschtein, D., Lipid nanoparticle assisted mRNA 22 delivery for potent cancer immunotherapy. Nano letters 2017, 17 (3), 1326-1335.

23 141. Cheng, Q.; Wei, T.; Farbiak, L.; Johnson, L. T.; Dilliard, S. A.; Siegwart, D. J., 24 Selective organ targeting (SORT) nanoparticles for tissue-specific mRNA delivery and CRISPR-Cas 
1 gene editing. Nature Nanotechnology 2020, 15 (4), 313-320.

2 142. Eygeris, Y.; Patel, S.; Jozic, A.; Sahay, G., Deconvoluting Lipid Nanoparticle Structure for 3 Messenger RNA Delivery. Nano Letters 2020.

4 143. Patel, S.; Ashwanikumar, N.; Robinson, E.; Xia, Y.; Mihai, C.; Griffith, J. P.; Hou, 5 S.; Esposito, A. A.; Ketova, T.; Welsher, K., Naturally-occurring cholesterol analogues in lipid 6 nanoparticles induce polymorphic shape and enhance intracellular delivery of mRNA. Nature 7 communications 2020, $11(1), 1-13$.

$8 \quad$ 144. Pozzi, D.; Marchini, C.; Cardarelli, F.; Amenitsch, H.; Garulli, C.; Bifone, A.; 9 Caracciolo, G., Transfection efficiency boost of cholesterol-containing lipoplexes. Biochimica et 10 Biophysica Acta (BBA)-Biomembranes 2012, 1818 (9), 2335-2343.

11 145. Ickenstein, L. M.; Arfvidsson, M. C.; Needham, D.; Mayer, L. D.; Edwards, K., Disc 12 formation in cholesterol-free liposomes during phase transition. Biochimica et Biophysica Acta (BBA)13 Biomembranes 2003, 1614 (2), 135-138.

14 146. Imam, Z. I.; Kenyon, L. E.; Ashby, G.; Nagib, F.; Mendicino, M.; Zhao, C.; Gadok, 15 A. K.; Stachowiak, J. C., Phase-separated liposomes enhance the efficiency of macromolecular delivery 16 to the cellular cytoplasm. Cellular and molecular bioengineering 2017, 10 (5), 387-403.

17 147. Cheng, Q.; Wei, T.; Jia, Y.; Farbiak, L.; Zhou, K.; Zhang, S.; Wei, Y.; Zhu, H.;

18 Siegwart, D. J., Dendrimer-based lipid nanoparticles deliver therapeutic FAH mRNA to normalize liver 19 function and extend survival in a mouse model of hepatorenal tyrosinemia type I. Advanced Materials $20 \mathbf{2 0 1 8}, 30(52), 1805308$.

21 148. Demeneix, B.; Behr, J. P., Polyethylenimine (PEI). Advances in genetics 2005, 53, 215-230.

22 149. Ulkoski, D.; Bak, A.; Wilson, J. T.; Krishnamurthy, V. R., Recent advances in polymeric 23 materials for the delivery of RNA therapeutics. Expert opinion on drug delivery 2019, (just-accepted). 24 150. Lv, H.; Zhang, S.; Wang, B.; Cui, S.; Yan, J., Toxicity of cationic lipids and cationic 
1 polymers in gene delivery. Journal of controlled release 2006, 114 (1), 100-109.

2 151. Masago, K.; Itaka, K.; Nishiyama, N.; Chung, U.-i.; Kataoka, K., Gene delivery with 3 biocompatible cationic polymer: pharmacogenomic analysis on cell bioactivity. Biomaterials 2007, 28 4 (34), 5169-5175.

$5 \quad$ 152. Blakney, A. K.; Yilmaz, G.; McKay, P. F.; Becer, C. R.; Shattock, R. J., One size does 6 not fit all: The effect of chain length and charge density of poly (ethylene imine) based copolymers on 7 delivery of pDNA, mRNA, and RepRNA polyplexes. Biomacromolecules 2018, 19 (7), 2870-2879.

$8 \quad$ 153. Patel, A. K.; Kaczmarek, J. C.; Bose, S.; Kauffman, K. J.; Mir, F.; Heartlein, M. W.; 9 DeRosa, F.; Langer, R.; Anderson, D. G., Inhaled nanoformulated mRNA polyplexes for protein 10 production in lung epithelium. Advanced Materials 2019, 31 (8), 1805116.

11 154. Zhang, F.; Parayath, N.; Ene, C.; Stephan, S.; Koehne, A.; Coon, M.; Holland, E.; 12 Stephan, M., Genetic programming of macrophages to perform anti-tumor functions using targeted 13 mRNA nanocarriers. Nature communications 2019, 10 (1), 1-16.

14 155. Uchida, H.; Itaka, K.; Nomoto, T.; Ishii, T.; Suma, T.; Ikegami, M.; Miyata, K.; 15 Oba, M.; Nishiyama, N.; Kataoka, K., Modulated protonation of side chain aminoethylene repeats in 16 N-substituted polyaspartamides promotes mRNA transfection. J. Am. Chem. Soc. 2014, 136 (35), 1239617405.

18 156. Uchida, H.; Itaka, K.; Uchida, S.; Ishii, T.; Suma, T.; Miyata, K.; Oba, M.; 19 Nishiyama, N.; Kataoka, K., Synthetic Polyamines to Regulate mRNA Translation through the 20 Preservative Binding of Eukaryotic Initiation Factor 4E to the Cap Structure. J. Am. Chem. Soc. 2016, $21 \quad 138(5), 1478-81$.

22 157. Li, J.; Wang, W.; He, Y.; Li, Y.; Yan, E. Z.; Zhang, K.; Irvine, D. J.; Hammond, P. 23 T., Structurally Programmed Assembly of Translation Initiation Nanoplex for Superior mRNA Delivery. 24 ACS Nano 2017, 11 (3), 2531-2544. 
1 158. Perche, F.; Benvegnu, T.; Berchel, M.; Lebegue, L.; Pichon, C.; Jaffrès, P.-A.; 2 Midoux, P., Enhancement of dendritic cells transfection in vivo and of vaccination against B16F10 3 melanoma with mannosylated histidylated lipopolyplexes loaded with tumor antigen messenger RNA. 4 Nanomedicine: Nanotechnology, Biology and Medicine 2011, 7 (4), 445-453.

5 159. Perche, F.; Gosset, D.; Mével, M.; Miramon, M.-L.; Yaouanc, J.-J.; Pichon, C.; 6 Benvegnu, T.; Jaffrès, P.-A.; Midoux, P., Selective gene delivery in dendritic cells with mannosylated 7 and histidylated lipopolyplexes. Journal of drug targeting 2011, 19 (5), 315-325.

8 160. Gao, X.; Huang, L., Potentiation of cationic liposome-mediated gene delivery by polycations. 9 Biochemistry 1996, 35 (3), 1027-1036.

10 161. Li, S. d.; Huang, L. y., In vivo gene transfer via intravenous administration of cationic lipid11 protamine-DNA (LPD) complexes. Gene therapy 1997, 4 (9), 891-900.

12 162. Pichon, C.; Midoux, P., Mannosylated and histidylated LPR technology for vaccination with 13 tumor antigen mRNA. In Synthetic Messenger RNA and Cell Metabolism Modulation, Springer: 2013; 14 pp 247-274.

15 163. Barbeau, J.; Lemiègre, L.; Quelen, A.; Malard, V.; Gao, H.; Gonçalves, C.; 16 Berchel, M.; Jaffrès, P.-A.; Pichon, C.; Midoux, P., Synthesis of a trimannosylated-equipped archaeal 17 diether lipid for the development of novel glycoliposomes. Carbohydrate research 2016, 435, $142-148$. 18 164. Van Der Jeught, K.; De Koker, S.; Bialkowski, L.; Heirman, C.; Tjok Joe, P.; Perche, 19 F.; Maenhout, S.; Bevers, S.; Broos, K.; Deswarte, K., Dendritic cell targeting mRNA 20 lipopolyplexes combine strong antitumor T-cell immunity with improved inflammatory safety. ACS nano $21 \quad 2018,12(10), 9815-9829$.

22 165. Le Moignic, A.; Malard, V.; Benvegnu, T.; Lemiègre, L.; Berchel, M.; Jaffrès, P.-A.; 23 Baillou, C.; Delost, M.; Macedo, R.; Rochefort, J., Preclinical evaluation of mRNA trimannosylated 24 lipopolyplexes as therapeutic cancer vaccines targeting dendritic cells. Journal of controlled release $\mathbf{2 0 1 8 ,}$ 
$1 \quad 278,110-121$

2 166. Midoux, P.; Pichon, C., Lipid-based mRNA vaccine delivery systems. Expert review of 3 vaccines 2015, 14 (2), 221-234.

4 167. Persano, S.; Guevara, M. L.; Li, Z.; Mai, J.; Ferrari, M.; Pompa, P. P.; Shen, H., 5 Lipopolyplex potentiates anti-tumor immunity of mRNA-based vaccination. Biomaterials 2017, 125, 81689.

7 168. Kaczmarek, J. C.; Patel, A. K.; Kauffman, K. J.; Fenton, O. S.; Webber, M. J.; 8 Heartlein, M. W.; DeRosa, F.; Anderson, D. G., Polymer-Lipid Nanoparticles for Systemic Delivery 9 of mRNA to the Lungs. Angew Chem Int Ed Engl 2016, 55 (44), 13808-13812. 169. Zhao, W.; Zhang, C.; Li, B.; Zhang, X.; Luo, X.; Zeng, C.; Li, W.; Gao, M.; 11 Dong, Y., Lipid Polymer Hybrid Nanomaterials for mRNA Delivery. Cell. Mol. Bioeng. 2018, 11 (5), $12 \quad 397-406$.

13 170. Lachelt, U.; Wagner, E., Nucleic Acid Therapeutics Using Polyplexes: A Journey of 50 Years 14 (and Beyond). Chem. Rev. 2015, 115 (19), 11043-78.

15 171. Cabral, H.; Miyata, K.; Osada, K.; Kataoka, K., Block copolymer micelles in 16 nanomedicine applications. Chem. Rev. 2018, $118(14), 6844-6892$.

17 172. Kataoka, K.; Harada, A.; Nagasaki, Y., Block copolymer micelles for drug delivery: design, 18 characterization and biological significance. Adv. Drug. Deliv. Rev. 2001, 47 (1), 113-31.

19 173. Chen, Q.; Qi, R.; Chen, X.; Yang, X.; Wu, S.; Xiao, H.; Dong, W., A Targeted and 20 Stable Polymeric Nanoformulation Enhances Systemic Delivery of mRNA to Tumors. Mol. Ther. 2017, $2125(1), 92-101$.

22 174. Uchida, S.; Kataoka, K., Design concepts of polyplex micelles for in vivo therapeutic delivery 23 of plasmid DNA and messenger RNA. J. Biomed. Mater. Res. A 2019, 107 (5), 978-990.

24 175. Baba, M.; Itaka, K.; Kondo, K.; Yamasoba, T.; Kataoka, K., Treatment of neurological 
1 disorders by introducing mRNA in vivo using polyplex nanomicelles. J. Control. Release 2015, 201, $241-8$.

3 176. Matsui, A.; Uchida, S.; Ishii, T.; Itaka, K.; Kataoka, K., Messenger RNA-based 4 therapeutics for the treatment of apoptosis-associated diseases. Sci. Rep. 2015, 5, 15810.

5 177. Zuckerman, J. E.; Choi, C. H.; Han, H.; Davis, M. E., Polycation-siRNA nanoparticles can 6 disassemble at the kidney glomerular basement membrane. Proc. Natl. Acad. Sci. U. S. A. 2012, 109 (8), $7 \quad 3137-42$.

8 178. Dirisala, A.; Uchida, S.; Tockary, T. A.; Yoshinaga, N.; Li, J.; Osawa, S.; Gorantla, $9 \quad$ L.; Fukushima, S.; Osada, K.; Kataoka, K., Precise tuning of disulphide crosslinking in mRNA 10 polyplex micelles for optimising extracellular and intracellular nuclease tolerability. J. Drug Target. $112019,27(5-6), 670-680$.

12 179. Li, J.; Chen, Q.; Zha, Z.; Li, H.; Toh, K.; Dirisala, A.; Matsumoto, Y.; Osada, K.; 13 Kataoka, K.; Ge, Z., Ternary polyplex micelles with PEG shells and intermediate barrier to complexed 14 DNA cores for efficient systemic gene delivery. J. Control. Release 2015, 209, 77-87.

15 180. Grasso, G.; Deriu, M. A.; Patrulea, V.; Borchard, G.; Möller, M.; Danani, A., Free 16 energy landscape of siRNA-polycation complexation: Elucidating the effect of molecular geometry, 17 polymer flexibility, and charge neutralization. PLoS One 2017, 12 (10), e0186816.

18 181. Miyazaki, T.; Uchida, S.; Nagatoishi, S.; Koji, K.; Hong, T.; Fukushima, S.; 19 Tsumoto, K.; Ishihara, K.; Kataoka, K.; Cabral, H., Polymeric Nanocarriers with Controlled Chain 20 Flexibility Boost mRNA Delivery In Vivo through Enhanced Structural Fastening. Advanced Healthcare 21 Materials in press.

22 182. Elsharkasy, O. M.; Nordin, J. Z.; Hagey, D. W.; de Jong, O. G.; Schiffelers, R. M.; 23 Andaloussi, S. E.; Vader, P., Extracellular vesicles as drug delivery systems: Why and how? Advanced Drug Delivery Reviews 2020. 
1 183. Markov, O.; Oshchepkova, A.; Mironova, N., Immunotherapy based on dendritic cell2 targeted/-derived extracellular vesicles - A novel strategy for enhancement of the anti-tumor immune 3 response. Frontiers in pharmacology 2019, 10.

4 184. Colombo, M.; Raposo, G.; Théry, C., Biogenesis, secretion, and intercellular interactions of 5 exosomes and other extracellular vesicles. Annual review of cell and developmental biology 2014, 30, $6 \quad 255-289$.

7 185. Valadi, H.; $\quad$ Ekström, K.; $\quad$ Bossios, A.; $\quad$ Sjöstrand, M.; $\quad$ Lee, J. J.; Lötvall, J. O., Exosome8 mediated transfer of mRNAs and microRNAs is a novel mechanism of genetic exchange between cells. $9 \quad$ Nature cell biology 2007, 9 (6), 654-659.

10 186. Kamerkar, S.; LeBleu, V. S.; Sugimoto, H.; Yang, S.; Ruivo, C. F.; Melo, S. A.; 11 Lee, J. J.; Kalluri, R., Exosomes facilitate therapeutic targeting of oncogenic KRAS in pancreatic cancer. 12 Nature 2017, 546 (7659), 498-503.

13 187. Koh, E.; Lee, E. J.; Nam, G.-H.; Hong, Y.; Cho, E.; Yang, Y.; Kim, I.-S., Exosome14 SIRP $\alpha$, a CD47 blockade increases cancer cell phagocytosis. Biomaterials 2017, 121, 121-129.

15 188. Heusermann, W.; Hean, J.; Trojer, D.; Steib, E.; Von Bueren, S.; Graff-Meyer, A.; 16 Genoud, C.; Martin, K.; Pizzato, N.; Voshol, J., Exosomes surf on filopodia to enter cells at endocytic 17 hot spots, traffic within endosomes, and are targeted to the ER. Journal of Cell Biology 2016, 213 (2), $18 \quad 173-184$.

19 189. Sun, W.; Xing, C.; Zhao, L.; Zhao, P.; Yang, G.; Yuan, L., Ultrasound Assisted 20 Exosomal Delivery of Tissue Responsive mRNA for Enhanced Efficacy and Minimized Off-Target 21 Effects. Molecular Therapy-Nucleic Acids 2020, 20, 558-567.

22 190. Pan, D.; Fujimoto, M.; Lopes, A.; Wang, Y.-X., Twist-1 is a PPAR $\delta$-inducible, negative23 feedback regulator of PGC-1 $\alpha$ in brown fat metabolism. Cell 2009, 137 (1), 73-86.

24 191. Shi, C.; Zhang, M.; Tong, M.; Yang, L.; Pang, L.; Chen, L.; Xu, G.; Chi, X.; 
1 Hong, Q.; Ni, Y., miR-148a is associated with obesity and modulates adipocyte differentiation of 2 mesenchymal stem cells through Wnt signaling. Scientific reports 2015, 5, 9930.

3 192. Yang, Z.; Shi, J.; Xie, J.; Wang, Y.; Sun, J.; Liu, T.; Zhao, Y.; Zhao, X.; Wang, 4 X.; Ma, Y., Large-scale generation of functional mRNA-encapsulating exosomes via cellular 5 nanoporation. Nature Biomedical Engineering 2020, 4 (1), 69-83.

6 193. Wei, X.; Zhan, C.; Shen, Q.; Fu, W.; Xie, C.; Gao, J.; Peng, C.; Zheng, P.; Lu, 7 W., A D-peptide ligand of nicotine acetylcholine receptors for brain-targeted drug delivery. Angewandte 8 Chemie International Edition 2015, 54 (10), 3023-3027.

9 194. Lutz, J.; Lazzaro, S.; Habbeddine, M.; Schmidt, K. E.; Baumhof, P.; Mui, B. L.; 10 Tam, Y. K.; Madden, T. D.; Hope, M. J.; Heidenreich, R., Unmodified mRNA in LNPs constitutes a 11 competitive technology for prophylactic vaccines. NPJ vaccines 2017, 2 (1), 1-9.

12 195. Kallen, K. J.; Heidenreich, R.; Schnee, M.; Petsch, B.; Schlake, T.; Thess, A.; 13 Baumhof, P.; Scheel, B.; Koch, S. D.; Fotin-Mleczek, M., A novel, disruptive vaccination 14 technology: self-adjuvanted RNActive((R)) vaccines. Hum. Vaccin. Immunother. 2013, 9 (10), 2263-76. 15 196. Fotin-Mleczek, M.; Duchardt, K. M.; Lorenz, C.; Pfeiffer, R.; Ojkic-Zrna, S.; Probst, 16 J.; Kallen, K. J., Messenger RNA-based vaccines with dual activity induce balanced TLR-7 dependent 17 adaptive immune responses and provide antitumor activity. J. Immunother. 2011, 34 (1), 1-15.

18 197. Alberer, M.; Gnad-Vogt, U.; Hong, H. S.; Mehr, K. T.; Backert, L.; Finak, G.; 19 Gottardo, R.; Bica, M. A.; Garofano, A.; Koch, S. D.; Fotin-Mleczek, M.; Hoerr, I.; Clemens, 20 R.; von Sonnenburg, F., Safety and immunogenicity of a mRNA rabies vaccine in healthy adults: an 21 open-label, non-randomised, prospective, first-in-human phase 1 clinical trial. The Lancet 2017, 390 22 (10101), 1511-1520.

23 198. Sebastian, M.; Schröder, A.; Scheel, B.; Hong, H. S.; Muth, A.; von Boehmer, L.; 24 Zippelius, A.; Mayer, F.; Reck, M.; Atanackovic, D.; Thomas, M.; Schneller, F.; 
1 Stöhlmacher, J.; Bernhard, H.; Gröschel, A.; Lander, T.; Probst, J.; Strack, T.; Wiegand, V.;

2 Gnad-Vogt, U.; Kallen, K. J.; Hoerr, I.; von der Muelbe, F.; Fotin-Mleczek, M.; Knuth, A.;

3 Koch, S. D., A phase I/IIa study of the mRNA-based cancer immunotherapy CV9201 in patients with 4 stage IIIB/IV non-small cell lung cancer. Cancer Immunol. Immunother. 2019, 68 (5), 799-812.

5 199. Kowalczyk, A.; Doener, F.; Zanzinger, K.; Noth, J.; Baumhof, P.; Fotin-Mleczek, 6 M.; Heidenreich, R., Self-adjuvanted mRNA vaccines induce local innate immune responses that lead to 7 a potent and boostable adaptive immunity. Vaccine 2016, 34 (33), 3882-3893.

8 200. Selmi, A.; Vascotto, F.; Kautz-Neu, K.; Türeci, Ö.; Sahin, U.; von Stebut, E.; 9 Diken, M.; Kreiter, S., Uptake of synthetic naked RNA by skin-resident dendritic cells via 10 macropinocytosis allows antigen expression and induction of T-cell responses in mice. Cancer 11 Immunology, Immunotherapy 2016, 65 (9), 1075-1083.

12 201. Pardi, N.; LaBranche, C. C.; Ferrari, G.; Cain, D. W.; Tombacz, I.; Parks, R. J.; 13 Muramatsu, H.; Mui, B. L.; Tam, Y. K.; Kariko, K.; Polacino, P.; $\quad$ Barbosa, C. J.; Madden, T. 14 D.; Hope, M. J.; Haynes, B. F.; Montefiori, D. C.; Hu, S. L.; Weissman, D., Characterization of 15 HIV-1 Nucleoside-Modified mRNA Vaccines in Rabbits and Rhesus Macaques. Mol Ther Nucleic Acids $162019,15,36-47$.

17 202. Diken, M.; Kreiter, S.; Selmi, A.; Britten, C.; Huber, C.; Türeci, Ö.; Sahin, U., 18 Selective uptake of naked vaccine RNA by dendritic cells is driven by macropinocytosis and abrogated 19 upon DC maturation. Gene therapy 2011, $18(7), 702$.

20 203. Joe, P. T.; Christopoulou, I.; van Hoecke, L.; Schepens, B.; Ysenbaert, T.; Heirman, 21 C.; Thielemans, K.; Saelens, X.; Aerts, J. L., Intranodal administration of mRNA encoding 22 nucleoprotein provides cross-strain immunity against influenza in mice. Journal of translational 23 medicine 2019, 17 (1), 242.

24 204. Leal, L.; Guardo, A. C.; Morón-López, S.; Salgado, M.; Mothe, B.; Heirman, C.; 
1 Pannus, P.; Vanham, G.; van den Ham, H. J.; Gruters, R., Phase I clinical trial of an intranodally 2 administered mRNA-based therapeutic vaccine against HIV-1 infection. AIDS (London, England) 2018, $332(17), 2533$.

$4 \quad$ 205. Kreiter, S.; Selmi, A.; Diken, M.; Koslowski, M.; Britten, C. M.; Huber, C.; Türeci, 5 Ö.; Sahin, U., Intranodal vaccination with naked antigen-encoding RNA elicits potent prophylactic and 6 therapeutic antitumoral immunity. Cancer research 2010, 70 (22), 9031-9040.

$7 \quad$ 206. Sayour, E. J.; $\quad$ De Leon, G.; Pham, C.; Grippin, A.; Kemeny, H.; Chua, J.; Huang, $8 \quad$ J.; Sampson, J. H.; Sanchez-Perez, L.; Flores, C.; Mitchell, D. A., Systemic activation of antigen9 presenting cells via RNA-loaded nanoparticles. Oncoimmunology 2017, 6 (1), e1256527.

10 207. Broos, K.; Van der Jeught, K.; Puttemans, J.; Goyvaerts, C.; Heirman, C.; Dewitte, 11 H.; Verbeke, R.; Lentacker, I.; Thielemans, K.; Breckpot, K., Particle-mediated Intravenous 12 Delivery of Antigen mRNA Results in Strong Antigen-specific T-cell Responses Despite the Induction 13 of Type I Interferon. Mol Ther Nucleic Acids 2016, 5 (6), e326.

14 208. Perche, F.; Benvegnu, T.; Berchel, M.; Lebegue, L.; Pichon, C.; Jaffrès, P. A.; 15 Midoux, P., Enhancement of dendritic cells transfection in vivo and of vaccination against B16F10 16 melanoma with mannosylated histidylated lipopolyplexes loaded with tumor antigen messenger RNA. 17 Nanomedicine 2011, 7 (4), 445-53.

18 209. Van der Jeught, K.; De Koker, S.; Bialkowski, L.; Heirman, C.; Tjok Joe, P.; Perche, 19 F.; Maenhout, S.; Bevers, S.; Broos, K.; Deswarte, K.; Malard, V.; Hammad, H.; Baril, P.; 20 Benvegnu, T.; Jaffres, P. A.; Kooijmans, S. A. A.; Schiffelers, R.; Lienenklaus, S.; Midoux, P.; 21 Pichon, C.; Breckpot, K.; Thielemans, K., Dendritic Cell Targeting mRNA Lipopolyplexes Combine 22 Strong Antitumor T-Cell Immunity with Improved Inflammatory Safety. ACS Nano 2018, 12 (10), 9815239829.

24 210. Verbeke, R.; Lentacker, I.; Wayteck, L.; Breckpot, K.; Van Bockstal, M.; Descamps, 
1 B.; Vanhove, C.; De Smedt, S. C.; Dewitte, H., Co-delivery of nucleoside-modified mRNA and TLR 2 agonists for cancer immunotherapy: Restoring the immunogenicity of immunosilent mRNA. J. Control. 3 Release 2017, 266, 287-300.

4 211. Verbeke, R.; Lentacker, I.; Breckpot, K.; Janssens, J.; Van Calenbergh, S.; De Smedt, 5 S. C.; Dewitte, H., Broadening the Message: A Nanovaccine Co-loaded with Messenger RNA and alpha6 GalCer Induces Antitumor Immunity through Conventional and Natural Killer T Cells. ACS Nano 2019, $7 \quad 13(2), 1655-1669$.

$8 \quad$ 212. Pektor, S.; Hilscher, L.; Walzer, K. C.; Miederer, I.; Bausbacher, N.; Loquai, C.; 9 Schreckenberger, M.; Sahin, U.; Diken, M.; Miederer, M., In vivo imaging of the immune response 10 upon systemic RNA cancer vaccination by FDG-PET. EJNMMI Res 2018, 8 (1), 80.

11 213. Reinhard, K.; Rengstl, B.; Oehm, P.; Michel, K.; Billmeier, A.; Hayduk, N.; Klein, 12 O.; Kuna, K.; Ouchan, Y.; Wöll, S.; Christ, E.; Weber, D.; Suchan, M.; Bukur, T.; Birtel, $13 \quad$ M.; Jahndel, V.; Mroz, K.; Hobohm, K.; Kranz, L.; $\quad$ Diken, M.; Kühlcke, K.; $\quad$ Türeci, Ö.; 14 Sahin, U., An RNA vaccine drives expansion and efficacy of claudin-CAR-T cells against solid tumors. 15 Science 2020, 367 (6476), 446-453.

16 214. Liljeström, P.; Garoff, H., A new generation of animal cell expression vectors based on the 17 Semliki Forest virus replicon. Bio/technology 1991, 9 (12), 1356.

$18 \quad 215 . \quad$ Pushko, P.; Parker, M.; $\quad$ Ludwig, G. V.; Davis, N. L.; Johnston, R. E.; Smith, J. F., 19 Replicon-helper systems from attenuated venezuelan equine encephalitis virus: Expression of 20 heterologous genesin vitroand immunization against heterologous pathogensin vivo. Virology 1997, 239 $21 \quad(2), 389-401$.

22 216. Lundstrom, K., Replicon RNA viral vectors as vaccines. Vaccines 2016, 4 (4), 39.

23 217. Bates, J. T.; Pickens, J. A.; Schuster, J. E.; Johnson, M.; Tollefson, S. J.; Williams, J. 24 V.; Davis, N. L.; Johnston, R. E.; Schultz-Darken, N.; Slaughter, J. C., Immunogenicity and 
1 efficacy of alphavirus-derived replicon vaccines for respiratory syncytial virus and human 2 metapneumovirus in nonhuman primates. Vaccine 2016, 34 (7), 950-956.

3 218. White, L. J.; Sariol, C. A.; Mattocks, M. D.; MPB, W. W.; Yingsiwaphat, V.; Collier, 4 M. L.; Whitley, J.; Mikkelsen, R.; Rodriguez, I. V.; Martinez, M. I., An alphavirus vector-based 5 tetravalent dengue vaccine induces a rapid and protective immune response in macaques that differs 6 qualitatively from immunity induced by live virus infection. Journal of virology 2013, 87 (6), 3409-3424. 7 219. Suárez-Patiño, S. F.; Bernardino, T. C.; Núñez, E. G. F.; Astray, R. M.; Pereira, C. A.; 8 Soares, H. R.; Coroadinha, A. S.; Jorge, S. A. C., Semliki Forest Virus replicon particles production in 9 serum-free medium BHK-21 cell cultures and their use to express different proteins. Cytotechnology 10 2019, 1-14.

$11220 . \quad$ Scorza, F.; Pardi, N., New kids on the block: RNA-based influenza virus vaccines. Vaccines $12 \mathbf{2 0 1 8}, 6(2), 20$.

13 221. Moyo, N.; Vogel, A. B.; Buus, S.; Erbar, S.; Wee, E. G.; Sahin, U.; Hanke, T., 14 Efficient induction of T cells against conserved HIV-1 regions by mosaic vaccines delivered as self15 amplifying mRNA. Molecular Therapy-Methods \& Clinical Development 2019, 12, 32-46.

16 222. Chahal, J. S.; Fang, T.; Woodham, A. W.; Khan, O. F.; Ling, J.; Anderson, D. G.; 17 Ploegh, H. L., An RNA nanoparticle vaccine against Zika virus elicits antibody and CD8+ T cell 18 responses in a mouse model. Scientific reports 2017, 7 (1), 252.

19 223. Simmons, J. D.; White, L. J.; Morrison, T. E.; Montgomery, S. A.; Whitmore, A. C.; 20 Johnston, R. E.; Heise, M. T., Venezuelan equine encephalitis virus disrupts STAT1 signaling by distinct 21 mechanisms independent of host shutoff. Journal of virology 2009, 83 (20), 10571-10581.

22 224. Jirikowski, G. F.; Sanna, P. P.; Maciejewski-Lenoir, D.; Bloom, F. E., Reversal of diabetes 23 insipidus in Brattleboro rats: intrahypothalamic injection of vasopressin mRNA. Science 1992, 255 24 (5047), 996-8. 
1 225. Kariko, K.; Muramatsu, H.; Ludwig, J.; Weissman, D., Generating the optimal mRNA for 2 therapy: HPLC purification eliminates immune activation and improves translation of nucleoside3 modified, protein-encoding mRNA. Nucleic Acids Res. 2011, 39 (21), e142.

4 226. Aini, H.; Itaka, K.; Fujisawa, A.; Uchida, H.; Uchida, S.; Fukushima, S.; Kataoka, $5 \quad$ K.; Saito, T.; Chung, U.-i.; Ohba, S., Messenger RNA delivery of a cartilage-anabolic transcription 6 factor as a disease-modifying strategy for osteoarthritis treatment. Sci. Rep. 2016, 6, 18743.

7 227. Crowley, S. T.; Fukushima, Y.; Uchida, S.; Kataoka, K.; Itaka, K., Enhancement of 8 Motor Function Recovery after Spinal Cord Injury in Mice by Delivery of Brain-Derived Neurotrophic 9 Factor mRNA. Mol Ther Nucleic Acids 2019, 17, 465-476.

10 228. Lin, C. Y.; Crowley, S. T.; Uchida, S.; Komaki, Y.; Kataoka, K.; Itaka, K., Treatment 11 of Intervertebral Disk Disease by the Administration of mRNA Encoding a Cartilage-Anabolic 12 Transcription Factor. Mol Ther Nucleic Acids 2019, 16, 162-171.

13 229. Thess, A.; Grund, S.; Mui, B. L.; Hope, M. J.; Baumhof, P.; Fotin-Mleczek, M.; 14 Schlake, T., Sequence-engineered mRNA Without Chemical Nucleoside Modifications Enables an 15 Effective Protein Therapy in Large Animals. Mol. Ther. 2015.

16 230. Ramaswamy, S.; Tonnu, N.; Tachikawa, K.; Limphong, P.; Vega, J. B.; Karmali, P. 17 P.; Chivukula, P.; Verma, I. M., Systemic delivery of factor IX messenger RNA for protein replacement 18 therapy. Proc. Natl. Acad. Sci. U. S. A. 2017, 114 (10), E1941-E1950.

19 231. Haque, A.; Dewerth, A.; Antony, J. S.; Riethmuller, J.; Schweizer, G. R.; Weinmann, 20 P.; Latifi, N.; Yasar, H.; Pedemonte, N.; Sondo, E.; Weidensee, B.; Ralhan, A.; Laval, J.; 21 Schlegel, P.; Seitz, C.; Loretz, B.; Lehr, C. M.; Handgretinger, R.; Kormann, M. S. D., 22 Chemically modified hCFTR mRNAs recuperate lung function in a mouse model of cystic fibrosis. Sci. 23 Rep. 2018, $8(1), 16776$.

$24 \quad$ 232. Robinson, E.; MacDonald, K. D.; Slaughter, K.; McKinney, M.; Patel, S.; Sun, C.; 
1 Sahay, G., Lipid Nanoparticle-Delivered Chemically Modified mRNA Restores Chloride Secretion in 2 Cystic Fibrosis. Mol. Ther. 2018, 26 (8), 2034-2046.

3 233. Prieve, M. G.; Harvie, P.; Monahan, S. D.; Roy, D.; Li, A. G.; Blevins, T. L.; 4 Paschal, A. E.; Waldheim, M.; Bell, E. C.; Galperin, A.; Ella-Menye, J. R.; Houston, M. E., 5 Targeted mRNA Therapy for Ornithine Transcarbamylase Deficiency. Mol. Ther. 2018, 26 (3), 801-813. 6 234. Jiang, L.; Berraondo, P.; Jerico, D.; Guey, L. T.; Sampedro, A.; Frassetto, A.; 7 Benenato, K. E.; Burke, K.; Santamaria, E.; $\quad$ Alegre, M.; Pejenaute, A.; Kalariya, M.; Butcher, $8 \quad$ W.; Park, J. S.; Zhu, X.; Sabnis, S.; Kumarasinghe, E. S.; Salerno, T.; Kenney, M.; Lukacs, 9 C. M.; Avila, M. A.; Martini, P. G. V.; Fontanellas, A., Systemic messenger RNA as an etiological 10 treatment for acute intermittent porphyria. Nat. Med. 2018, 24 (12), 1899-1909.

11 235. DeRosa, F.; Smith, L.; Shen, Y.; Huang, Y.; Pan, J.; Xie, H.; Yahalom, B.; 12 Heartlein, M. W., Improved Efficacy in a Fabry Disease Model Using a Systemic mRNA Liver Depot 13 System as Compared to Enzyme Replacement Therapy. Mol. Ther. 2019, 27 (4), 878-889.

14 236. Truong, B.; Allegri, G.; Liu, X. B.; Burke, K. E.; Zhu, X.; Cederbaum, S. D.; 15 Haberle, J.; Martini, P. G. V.; Lipshutz, G. S., Lipid nanoparticle-targeted mRNA therapy as a 16 treatment for the inherited metabolic liver disorder arginase deficiency. Proc. Natl. Acad. Sci. U. S. A. 172019.

18 237. Perche, F.; Uchida, S.; Akiba, H.; Lin, C. Y.; Ikegami, M.; Dirisala, A.; Nakashima, 19 T.; Itaka, K.; Tsumoto, K.; Kataoka, K., Improved Brain Expression of Anti-Amyloid beta scFv by 20 Complexation of mRNA Including a Secretion Sequence with PEG-based Block Catiomer. Curr 21 Alzheimer Res 2017, 14 (3), 295-302.

22 238. Pardi, N.; Secreto, A. J.; Shan, X.; Debonera, F.; Glover, J.; Yi, Y.; Muramatsu, H.; 23 Ni, H.; Mui, B. L.; Tam, Y. K.; Shaheen, F.; Collman, R. G.; Kariko, K.; Danet-Desnoyers, 24 G. A.; Madden, T. D.; Hope, M. J.; Weissman, D., Administration of nucleoside-modified mRNA 
1 encoding broadly neutralizing antibody protects humanized mice from HIV-1 challenge. Nature 2 Commun. 2017, 8, 14630.

3 239. Thran, M.; Mukherjee, J.; Ponisch, M.; Fiedler, K.; Thess, A.; Mui, B. L.; Hope, M. $4 \quad$ J.; Tam, Y. K.; Horscroft, N.; Heidenreich, R.; Fotin-Mleczek, M.; Shoemaker, C. B.; Schlake, 5 T., mRNA mediates passive vaccination against infectious agents, toxins, and tumors. EMBO Mol. Med. 62017.

7 240. Rybakova, Y.; Kowalski, P. S.; Huang, Y.; Gonzalez, J. T.; Heartlein, M. W.; 8 DeRosa, F.; Delcassian, D.; Anderson, D. G., mRNA Delivery for Therapeutic Anti-HER2 Antibody 9 Expression In Vivo. Mol. Ther. 2019.

10 241. Stadler, C. R.; Bahr-Mahmud, H.; Celik, L.; Hebich, B.; Roth, A. S.; Roth, R. P.; 11 Kariko, K.; Tureci, O.; Sahin, U., Elimination of large tumors in mice by mRNA-encoded bispecific 12 antibodies. Nat. Med. 2017, 23 (7), 815-817.

13 242. Zangi, L.; Lui, K. O.; von Gise, A.; Ma, Q.; Ebina, W.; Ptaszek, L. M.; Spater, D.; 14 Xu, H.; Tabebordbar, M.; Gorbatov, R.; Sena, B.; Nahrendorf, M.; Briscoe, D. M.; Li, R. A.; 15 Wagers, A. J.; Rossi, D. J.; Pu, W. T.; Chien, K. R., Modified mRNA directs the fate of heart 16 progenitor cells and induces vascular regeneration after myocardial infarction. Nature Biotechnol. 2013, $17 \quad 31(10), 898-907$.

18 243. Balmayor, E. R.; Geiger, J. P.; Aneja, M. K.; Berezhanskyy, T.; Utzinger, M.; 19 Mykhaylyk, O.; Rudolph, C.; Plank, C., Chemically modified RNA induces osteogenesis of stem cells 20 and human tissue explants as well as accelerates bone healing in rats. Biomaterials 2016, 87, 131-46. 21 244. Sun, N.; Ning, B.; Hansson, K. M.; Bruce, A. C.; Seaman, S. A.; Zhang, C.; Rikard, 22 M.; DeRosa, C. A.; Fraser, C. L.; Wagberg, M.; Fritsche-Danielson, R.; Wikstrom, J.; Chien, 23 K. R.; Lundahl, A.; Holtta, M.; Carlsson, L. G.; Peirce, S. M.; Hu, S., Modified VEGF-A mRNA 24 induces sustained multifaceted microvascular response and accelerates diabetic wound healing. Sci. Rep. 
$1 \quad 2018,8(1), 17509$.

2 245. Hajj, K. A.; Whitehead, K. A., Tools for translation: non-viral materials for therapeutic mRNA 3 delivery. Nature Reviews Materials 2017, 2 (10).

4 246. Schlake, T.; Thran, M.; Fiedler, K.; Heidenreich, R.; Petsch, B.; Fotin-Mleczek, M., 5 mRNA: A Novel Avenue to Antibody Therapy? Mol. Ther. 2019, 27 (4), 773-784.

6 247. Zhang, H. X.; Zhang, Y.; Yin, H., Genome Editing with mRNA Encoding ZFN, TALEN, 7 and Cas9. Mol. Ther. 2019, 27 (4), 735-746.

$8 \quad 248 . \quad$ Zou, S.; Scarfo, K.; Nantz, M. H.; Hecker, J. G., Lipid-mediated delivery of RNA is more 9 efficient than delivery of DNA in non-dividing cells. Int. J. Pharm. 2010, 389 (1-2), 232-43.

10 249. Matsui, A.; Uchida, S.; Hayashi, A.; Kataoka, K.; Itaka, K., Prolonged engraftment of 11 transplanted hepatocytes in the liver by transient pro-survival factor supplementation using ex vivo 12 mRNA transfection. J. Control. Release 2018, 285, 1-11.

13 250. Otsuka, H.; Hirano, A.; Nagasaki, Y.; Okano, T.; Horiike, Y.; Kataoka, K., Two14 dimensional multiarray formation of hepatocyte spheroids on a microfabricated PEG-brush surface. 15 Chembiochem 2004, 5 (6), 850-5.

16 251. Uchida, S.; Yanagihara, K.; Matsui, A.; Kataoka, K.; Itaka, K., mRNA as a Tool for Gene 17 Transfection in 3D Cell Culture for Future Regenerative Therapy. Micromachines 2020, 11 (4).

$18 \quad$ 252. Patel, S.; Athirasala, A.; Menezes, P. P.; Ashwanikumar, N.; Zou, T.; Sahay, G.; 19 Bertassoni, L. E., Messenger RNA Delivery for Tissue Engineering and Regenerative Medicine 20 Applications. Tissue Eng Part A 2019, 25 (1-2), 91-112.

21 253. Warren, L.; Lin, C., mRNA-Based Genetic Reprogramming. Mol. Ther. 2019, 27 (4), $729-734$.

22 254. Takahashi, K.; Yamanaka, S., Induction of pluripotent stem cells from mouse embryonic and 23 adult fibroblast cultures by defined factors. Cell 2006, $126(4), 663-76$.

24 255. Hacein-Bey-Abina, S.; Von Kalle, C.; Schmidt, M.; McCormack, M. P.; Wulffraat, N.; 
$1 \quad$ Leboulch, P.; Lim, A.; Osborne, C. S.; Pawliuk, R.; Morillon, E.; Sorensen, R.; Forster, A.;

2 Fraser, P.; Cohen, J. I.; de Saint Basile, G.; Alexander, I.; Wintergerst, U.; Frebourg, T.; 3 Aurias, A.; Stoppa-Lyonnet, D.; Romana, S.; Radford-Weiss, I.; Gross, F.; Valensi, F.; $4 \quad$ Delabesse, E.; $\quad$ Macintyre, E.; Sigaux, F.; $\quad$ Soulier, J.; $\quad$ Leiva, L. E.; Wissler, M.; Prinz, C.; 5 Rabbitts, T. H.; Le Deist, F.; Fischer, A.; Cavazzana-Calvo, M., LMO2-associated clonal T cell 6 proliferation in two patients after gene therapy for SCID-X1. Science 2003, 302 (5644), 415-9.

7 256. Foster, K. W.; Liu, Z.; Nail, C. D.; Li, X.; Fitzgerald, T. J.; Bailey, S. K.; Frost, A. $8 \quad$ R.; Louro, I. D.; Townes, T. M.; Paterson, A. J.; Kudlow, J. E.; Lobo-Ruppert, S. M.; Ruppert, 9 J. M., Induction of KLF4 in basal keratinocytes blocks the proliferation-differentiation switch and 10 initiates squamous epithelial dysplasia. Oncogene 2005, 24 (9), 1491-500.

11 257. Hochedlinger, K.; Yamada, Y.; Beard, C.; Jaenisch, R., Ectopic expression of Oct-4 blocks 12 progenitor-cell differentiation and causes dysplasia in epithelial tissues. Cell 2005, 121 (3), 465-77.

13 258. Nakagawa, M.; Koyanagi, M.; Tanabe, K.; Takahashi, K.; Ichisaka, T.; Aoi, T.; 14 Okita, K.; Mochiduki, Y.; Takizawa, N.; Yamanaka, S., Generation of induced pluripotent stem cells 15 without Myc from mouse and human fibroblasts. Nature Biotechnol. 2008, 26 (1), 101-6.

16 259. Okita, K.; Nakagawa, M.; Hyenjong, H.; Ichisaka, T.; Yamanaka, S., Generation of 17 mouse induced pluripotent stem cells without viral vectors. Science 2008, 322 (5903), 949-53.

18 260. Stadtfeld, M.; Nagaya, M.; Utikal, J.; Weir, G.; Hochedlinger, K., Induced Pluripotent 19 Stem Cells Generated Without Viral Integration. Science 2008, 322 (5903), 945-949.

20 261. Harui, A.; Suzuki, S.; Kochanek, S.; Mitani, K., Frequency and stability of chromosomal 21 integration of adenovirus vectors. J. Virol. 1999, 73 (7), 6141-6.

22 262. Wang, Z.; Troilo, P. J.; Wang, X.; Griffiths, T. G.; Pacchione, S. J.; Barnum, A. B.; 23 Harper, L. B.; Pauley, C. J.; Niu, Z.; Denisova, L.; Follmer, T. T.; Rizzuto, G.; Ciliberto, G.; 24 Fattori, E.; Monica, N. L.; Manam, S.; Ledwith, B. J., Detection of integration of plasmid DNA into 
1 host genomic DNA following intramuscular injection and electroporation. Gene Ther. 2004, 11 (8), 711 21.

3 263. Warren, L.; Manos, P. D.; Ahfeldt, T.; Loh, Y. H.; Li, H.; Lau, F.; Ebina, W.; 4 Mandal, P. K.; Smith, Z. D.; $\quad$ Meissner, A.; Daley, G. Q.; $\quad$ Brack, A. S.; Collins, J. J.; Cowan, 5 C.; Schlaeger, T. M.; Rossi, D. J., Highly efficient reprogramming to pluripotency and directed 6 differentiation of human cells with synthetic modified mRNA. Cell Stem Cell 2010, 7 (5), 618-30.

7 264. Warren, L.; Ni, Y.; Wang, J.; Guo, X., Feeder-free derivation of human induced pluripotent 8 stem cells with messenger RNA. Sci. Rep. 2012, 2, 657.

9 265. Poleganov, M. A.; Eminli, S.; Beissert, T.; Herz, S.; Moon, J. I.; Goldmann, J.; 10 Beyer, A.; Heck, R.; Burkhart, I.; Barea Roldan, D.; Tureci, O.; Yi, K.; Hamilton, B.; Sahin, 11 U., Efficient Reprogramming of Human Fibroblasts and Blood-Derived Endothelial Progenitor Cells 12 Using Nonmodified RNA for Reprogramming and Immune Evasion. Hum. Gene Ther. 2015, 26 (11), $13 \quad 751-66$.

14 266. Yoshioka, N.; Gros, E.; Li, H. R.; Kumar, S.; Deacon, D. C.; Maron, C.; Muotri, A. 15 R.; Chi, N. C.; Fu, X. D.; Yu, B. D.; Dowdy, S. F., Efficient generation of human iPSCs by a 16 synthetic self-replicative RNA. Cell Stem Cell 2013, 13 (2), 246-54.

17 267. Elangovan, S.; Khorsand, B.; Do, A. V.; Hong, L.; Dewerth, A.; Kormann, M.; 18 Ross, R. D.; Sumner, D. R.; Allamargot, C.; Salem, A. K., Chemically modified RNA activated 19 matrices enhance bone regeneration. J. Control. Release 2015, 218, 22-8.

20 268. Bartosh, T. J.; Ylostalo, J. H.; Mohammadipoor, A.; Bazhanov, N.; Coble, K.; 21 Claypool, K.; Lee, R. H.; Choi, H.; Prockop, D. J., Aggregation of human mesenchymal stromal cells 22 (MSCs) into 3D spheroids enhances their antiinflammatory properties. Proc. Natl. Acad. Sci. U. S. A. $23 \mathbf{2 0 1 0}, 107(31), 13724-9$.

24 269. Uchida, S.; Hayakawa, K.; Ogata, T.; Tanaka, S.; Kataoka, K.; Itaka, K., Treatment of 
1 spinal cord injury by an advanced cell transplantation technology using brain-derived neurotrophic 2 factor-transfected mesenchymal stem cell spheroids. Biomaterials 2016, 109, 1-11.

3 270. Vijayavenkataraman, S.; Yan, W. C.; Lu, W. F.; Wang, C. H.; Fuh, J. Y. H., 3D 4 bioprinting of tissues and organs for regenerative medicine. Adv. Drug. Deliv. Rev. 2018, 132, 296-332. 5 271. Simeonov, K. P.; Uppal, H., Direct reprogramming of human fibroblasts to hepatocyte-like 6 cells by synthetic modified mRNAs. PLoS One 2014, 9 (6), e100134.

7 272. Van Pham, P.; Vu, N. B.; Dao, T. T.; Le, H. T.; Phi, L. T.; Phan, N. K., Production of 8 endothelial progenitor cells from skin fibroblasts by direct reprogramming for clinical usages. In Vitro 9 Cell. Dev. Biol. Anim. 2017, 53 (3), 207-216.

10 273. Baek, S.; Oh, J.; Song, J.; Choi, H.; Yoo, J.; Park, G. Y.; Han, J.; Chang, Y.; 11 Park, H.; Kim, H.; Cho, S. G.; Kim, B. S.; Kim, J., Generation of Integration-Free Induced Neurons 12 Using Graphene Oxide-Polyethylenimine. Small 2017, 13 (5).

13 274. Connor, B.; Firmin, E.; McCaughey-Chapman, A.; Monk, R.; Lee, K.; Liot, S.; 14 Geiger, J.; Rudolph, C.; Jones, K., Conversion of adult human fibroblasts into neural precursor cells 15 using chemically modified mRNA. Heliyon 2018, 4 (11), e00918.

16 275. Koblas, T.; Leontovyc, I.; Loukotova, S.; Kosinova, L.; Saudek, F., Reprogramming of 17 Pancreatic Exocrine Cells AR42J Into Insulin-producing Cells Using mRNAs for Pdx1, Ngn3, and MafA 18 Transcription Factors. Mol Ther Nucleic Acids 2016, 5, e320.

19 276. Kim, B. E.; Choi, S. W.; Shin, J. H.; Kim, J. J.; Kang, I.; Lee, B. C.; Lee, J. Y.; 20 Kook, M. G.; Kang, K. S., Single-Factor SOX2 Mediates Direct Neural Reprogramming of Human 21 Mesenchymal Stem Cells via Transfection of In Vitro Transcribed mRNA. Cell Transplant. 2018, 27 22 (7), 1154-1167.

23 277. Moffett, H. F.; Coon, M. E.; Radtke, S.; Stephan, S. B.; McKnight, L.; Lambert, A.; 24 Stoddard, B. L.; Kiem, H. P.; Stephan, M. T., Hit-and-run programming of therapeutic cytoreagents 
1 using mRNA nanocarriers. Nature Commun. 2017, 8 (1), 389.

2 278. Kudinov, A. E.; Karanicolas, J.; Golemis, E. A.; Boumber, Y., Musashi RNA-Binding 3 Proteins as Cancer Drivers and Novel Therapeutic Targets. Clin. Cancer Res. 2017, 23 (9), 2143-2153. 4 279. Xu, Y.; Huang, L.; Kirschman, J. L.; Vanover, D. A.; Tiwari, P. M.; Santangelo, P. 5 J.; Shen, X.; Russell, D. G., Exploitation of Synthetic mRNA To Drive Immune Effector Cell 6 Recruitment and Functional Reprogramming In Vivo. J. Immunol. 2019, 202 (2), 608-617.

$7 \quad$ 280. Zhang, F.; Parayath, N. N.; Ene, C. I.; Stephan, S. B.; Koehne, A. L.; Coon, M. E.; 8 Holland, E. C.; Stephan, M. T., Genetic programming of macrophages to perform anti-tumor functions 9 using targeted mRNA nanocarriers. Nature Commun. 2019, 10 (1), 3974. 281. Hou, X.; Zhang, X.; Zhao, W.; Zeng, C.; Deng, B.; McComb, D. W.; Du, S.; 11 Zhang, C.; Li, W.; Dong, Y., Vitamin lipid nanoparticles enable adoptive macrophage transfer for the 12 treatment of multidrug-resistant bacterial sepsis. Nat Nanotechnol 2020, 15 (1), 41-46.

13 282. Gaj, T.; Guo, J.; Kato, Y.; Sirk, S. J.; Barbas, C. F., 3rd, Targeted gene knockout by direct 14 delivery of zinc-finger nuclease proteins. Nat Methods 2012, 9 (8), 805-7.

$15 \quad$ 283. Miller, J. B.; Zhang, S.; Kos, P.; Xiong, H.; Zhou, K.; Perelman, S. S.; Zhu, H.; 16 Siegwart, D. J., Non-Viral CRISPR/Cas Gene Editing In Vitro and In Vivo Enabled by Synthetic 17 Nanoparticle Co-Delivery of Cas9 mRNA and sgRNA. Angew Chem Int Ed Engl 2017, 56 (4), 1059181063.

19 284. Hendel, A.; Bak, R. O.; Clark, J. T.; Kennedy, A. B.; Ryan, D. E.; Roy, S.; 20 Steinfeld, I.; Lunstad, B. D.; Kaiser, R. J.; Wilkens, A. B.; Bacchetta, R.; Tsalenko, A.; 21 Dellinger, D.; Bruhn, L.; Porteus, M. H., Chemically modified guide RNAs enhance CRISPR-Cas 22 genome editing in human primary cells. Nature Biotechnol. 2015, 33 (9), 985-989.

23 285. Liu, J.; Chang, J.; Jiang, Y.; Meng, X.; Sun, T.; Mao, L.; Xu, Q.; Wang, M., Fast 24 and Efficient CRISPR/Cas9 Genome Editing In Vivo Enabled by Bioreducible Lipid and Messenger 
1 RNA Nanoparticles. Adv. Mater. 2019, 31 (33), e1902575.

2 286. Cheng, Q.; Wei, T.; Farbiak, L.; Johnson, L. T.; Dilliard, S. A.; Siegwart, D. J., 3 Selective organ targeting (SORT) nanoparticles for tissue-specific mRNA delivery and CRISPR-Cas 4 gene editing. Nat Nanotechnol 2020, 15 (4), 313-320.

5 287. Finn, J. D.; Smith, A. R.; Patel, M. C.; Shaw, L.; Youniss, M. R.; van Heteren, J.; 6 Dirstine, T.; Ciullo, C.; Lescarbeau, R.; Seitzer, J.; Shah, R. R.; Shah, A.; Ling, D.; Growe, $7 \quad$ J.; Pink, M.; Rohde, E.; Wood, K. M.; Salomon, W. E.; Harrington, W. F.; Dombrowski, C.; 8 Strapps, W. R.; Chang, Y.; Morrissey, D. V., A Single Administration of CRISPR/Cas9 Lipid 9 Nanoparticles Achieves Robust and Persistent In Vivo Genome Editing. Cell Rep. 2018, 22 (9), 2227 102235.

11 288. Jiang, C.; Mei, M.; Li, B.; Zhu, X.; Zu, W.; Tian, Y.; Wang, Q.; Guo, Y.; Dong, 12 Y.; Tan, X., A non-viral CRISPR/Cas9 delivery system for therapeutically targeting HBV DNA and 13 pcsk9 in vivo. Cell Res. 2017, 27 (3), 440-443.

14 289. Yin, H.; Xue, W.; Chen, S.; Bogorad, R. L.; Benedetti, E.; Grompe, M.; 15 Koteliansky, V.; Sharp, P. A.; Jacks, T.; Anderson, D. G., Genome editing with Cas9 in adult mice 16 corrects a disease mutation and phenotype. Nature Biotechnol. 2014, 32 (6), 551-3.

17 290. Van Lint, S.; Goyvaerts, C.; Maenhout, S.; Goethals, L.; Disy, A.; Benteyn, D.;

18 Pen, J.; Bonehill, A.; Heirman, C.; Breckpot, K.; Thielemans, K., Preclinical evaluation of TriMix 19 and antigen mRNA-based antitumor therapy. Cancer Res. 2012, 72 (7), 1661-71.

20 291. Scheel, B.; Aulwurm, S.; Probst, J.; Stitz, L.; Hoerr, I.; Rammensee, H. G.; Weller, 21 M.; Pascolo, S., Therapeutic anti-tumor immunity triggered by injections of immunostimulating single22 stranded RNA. Eur. J. Immunol. 2006, 36 (10), 2807-16.

23 292. Rausch, S.; Schwentner, C.; Stenzl, A.; Bedke, J., mRNA vaccine CV9103 and CV9104 24 for the treatment of prostate cancer. Hum. Vaccin. Immunother. 2014, 10 (11), 3146-52. 
1 293. Circelli, L.; Petrizzo, A.; Tagliamonte, M.; Heidenreich, R.; Tornesello, M. L.; 2 Buonaguro, F. M.; Buonaguro, L., Immunological effects of a novel RNA-based adjuvant in liver cancer 3 patients. Cancer Immunol. Immunother. 2017, 66 (1), 103-112.

4 294. Midoux, P.; Pichon, C., Lipid-based mRNA vaccine delivery systems. Expert Rev Vaccines $5 \quad \mathbf{2 0 1 5}, 14(2), 221-34$.

6 295. Castle, J. C.; Kreiter, S.; Diekmann, J.; Lower, M.; van de Roemer, N.; de Graaf, J.; $7 \quad$ Selmi, A.; $\quad$ Diken, M.; $\quad$ Boegel, S.; Paret, C.; Koslowski, M.; Kuhn, A. N.; Britten, C. M.; 8 Huber, C.; Tureci, O.; Sahin, U., Exploiting the mutanome for tumor vaccination. Cancer Res. 2012, $9 \quad 72(5), 1081-91$.

10 296. Kreiter, S.; Vormehr, M.; van de Roemer, N.; Diken, M.; Lower, M.; Diekmann, J.; 11 Boegel, S.; Schrors, B.; Vascotto, F.; Castle, J. C.; $\quad$ Tadmor, A. D.; $\quad$ Schoenberger, S. P.; 12 Huber, C.; Tureci, O.; Sahin, U., Mutant MHC class II epitopes drive therapeutic immune responses to 13 cancer. Nature 2015, 520 (7549), 692-6.

14 297. Sahin, U.; Derhovanessian, E.; Miller, M.; Kloke, B. P.; Simon, P.; Lower, M.; 15 Bukur, V.; Tadmor, A. D.; Luxemburger, U.; Schrors, B.; Omokoko, T.; Vormehr, M.; 16 Albrecht, C.; Paruzynski, A.; Kuhn, A. N.; Buck, J.; Heesch, S.; Schreeb, K. H.; Muller, F.; 17 Ortseifer, I.; Vogler, I.; Godehardt, E.; Attig, S.; Rae, R.; Breitkreuz, A.; Tolliver, C.; 18 Suchan, M.; Martic, G.; Hohberger, A.; Sorn, P.; Diekmann, J.; Ciesla, J.; Waksmann, O.; 19 Bruck, A. K.; Witt, M.; Zillgen, M.; Rothermel, A.; Kasemann, B.; Langer, D.; Bolte, S.; 20 Diken, M.; Kreiter, S.; Nemecek, R.; Gebhardt, C.; Grabbe, S.; Holler, C.; Utikal, J.; Huber, 21 C.; Loquai, C.; Tureci, O., Personalized RNA mutanome vaccines mobilize poly-specific therapeutic 22 immunity against cancer. Nature 2017, 547 (7662), 222-226.

23 298. Islam, M. A.; Xu, Y.; Tao, W.; Ubellacker, J. M.; Lim, M.; Aum, D.; Lee, G. Y.; 55

Zhou, K.; Zope, H.; Yu, M.; Cao, W.; Oswald, J. T.; $\quad$ Dinarvand, M.; $\quad$ Mahmoudi, M.; 
1 Langer, R.; Kantoff, P. W.; Farokhzad, O. C.; Zetter, B. R.; Shi, J., Restoration of tumour-growth 2 suppression in vivo via systemic nanoparticle-mediated delivery of PTEN mRNA. Nat Biomed Eng 2018, $32(11), 850-864$.

4 299. Kong, N.; Tao, W.; Ling, X.; Wang, J.; Xiao, Y.; Shi, S.; Ji, X.; Shajii, A.; Gan, 5 S. T.; Kim, N. Y.; Duda, D. G.; Xie, T.; Farokhzad, O. C.; Shi, J., Synthetic mRNA nanoparticle6 mediated restoration of p53 tumor suppressor sensitizes p53-deficient cancers to mTOR inhibition. Sci. 7 Transl. Med. 2019, 11 (523), eaaw1565.

$8 \quad$ 300. Song, E.; Mao, T.; Dong, H.; Boisserand, L. S. B.; Antila, S.; Bosenberg, M.; 9 Alitalo, K.; Thomas, J. L.; Iwasaki, A., VEGF-C-driven lymphatic drainage enables 10 immunosurveillance of brain tumours. Nature 2020, 577 (7792), 689-694.

11 301. Heiser, A.; Coleman, D.; Dannull, J.; Yancey, D.; Maurice, M. A.; Lallas, C. D.; 12 Dahm, P.; Niedzwiecki, D.; Gilboa, E.; Vieweg, J., Autologous dendritic cells transfected with 13 prostate-specific antigen RNA stimulate CTL responses against metastatic prostate tumors. J. Clin. Invest. $14 \quad 2002,109(3), 409-17$.

15 302. Bahl, K.; Senn, J. J.; Yuzhakov, O.; Bulychev, A.; Brito, L. A.; Hassett, K. J.; 16 Laska, M. E.; Smith, M.; Almarsson, O.; Thompson, J.; Ribeiro, A. M.; Watson, M.; Zaks, 17 T.; Ciaramella, G., Preclinical and Clinical Demonstration of Immunogenicity by mRNA Vaccines 18 against H10N8 and H7N9 Influenza Viruses. Mol. Ther. 2017, 25 (6), 1316-1327.

19 303. Pardi, N.; Hogan, M. J.; Pelc, R. S.; Muramatsu, H.; Andersen, H.; DeMaso, C. R.; 20 Dowd, K. A.; Sutherland, L. L.; Scearce, R. M.; Parks, R.; Wagner, W.; Granados, A.; 21 Greenhouse, J.; Walker, M.; Willis, E.; Yu, J. S.; McGee, C. E.; Sempowski, G. D.; Mui, B. 22 L.; Tam, Y. K.; Huang, Y. J.; Vanlandingham, D.; Holmes, V. M.; Balachandran, H.; Sahu, 23 S.; Lifton, M.; Higgs, S.; Hensley, S. E.; Madden, T. D.; Hope, M. J.; Kariko, K.; Santra, 24 S.; Graham, B. S.; Lewis, M. G.; Pierson, T. C.; Haynes, B. F.; Weissman, D., Zika virus 
1 protection by a single low-dose nucleoside-modified mRNA vaccination. Nature 2017, 543 (7644), 248251.

3 304. Richner, J. M.; Himansu, S.; Dowd, K. A.; Butler, S. L.; Salazar, V.; Fox, J. M.; 4 Julander, J. G.; Tang, W. W.; Shresta, S.; Pierson, T. C.; Ciaramella, G.; Diamond, M. S., 5 Modified mRNA Vaccines Protect against Zika Virus Infection. Cell 2017, 168 (6), 1114-1125 e10.

$6 \quad$ 305. Pardi, N.; Parkhouse, K.; Kirkpatrick, E.; McMahon, M.; Zost, S. J.; Mui, B. L.; 7 Tam, Y. K.; Kariko, K.; $\quad$ Barbosa, C. J.; $\quad$ Madden, T. D.; Hope, M. J.; Krammer, F.; Hensley, 8 S. E.; Weissman, D., Nucleoside-modified mRNA immunization elicits influenza virus hemagglutinin 9 stalk-specific antibodies. Nature Commun. 2018, 9 (1), 3361.

$10 \quad 306 . \quad$ Smith, T. R. F.; Patel, A.; Ramos, S.; Elwood, D.; Zhu, X.; Yan, J.; Gary, E. N.; 11 Walker, S. N.; Schultheis, K.; Purwar, M.; Xu, Z.; Walters, J.; Bhojnagarwala, P.; Yang, M.; 12 Chokkalingam, N.; Pezzoli, P.; Parzych, E.; Reuschel, E. L.; Doan, A.; Tursi, N.; Vasquez, 13 M.; Choi, J.; Tello-Ruiz, E.; Maricic, I.; Bah, M. A.; Wu, Y.; Amante, D.; Park, D. H.; 14 Dia, Y.; Ali, A. R.; Zaidi, F. I.; Generotti, A.; Kim, K. Y.; Herring, T. A.; Reeder, S.; 15 Andrade, V. M.; Buttigieg, K.; Zhao, G.; Wu, J. M.; Li, D.; Bao, L.; Liu, J.; Deng, W.; 16 Qin, C.; Brown, A. S.; Khoshnejad, M.; Wang, N.; Chu, J.; Wrapp, D.; McLellan, J. S.; 17 Muthumani, K.; Wang, B.; Carroll, M. W.; Kim, J. J.; Boyer, J.; Kulp, D. W.; Humeau, L.; 18 Weiner, D. B.; Broderick, K. E., Immunogenicity of a DNA vaccine candidate for COVID-19. Nature 19 Commun. 2020, $11(1), 2601$.

20 307. Zhu, F.-C.; Li, Y.-H.; Guan, X.-H.; Hou, L.-H.; Wang, W.-J.; Li, J.-X.; Wu, S.-P.; 21 Wang, B.-S.; $\quad$ Wang, Z.; Wang, L.; Jia, S.-Y.; Jiang, H.-D.; Wang, L.; Jiang, T.; Hu, Y.; 22 Gou, J.-B.; Xu, S.-B.; Xu, J.-J.; Wang, X.-W.; Wang, W.; Chen, W., Safety, tolerability, and 23 immunogenicity of a recombinant adenovirus type-5 vectored COVID-19 vaccine: a dose-escalation, 24 open-label, non-randomised, first-in-human trial. The Lancet 2020. 
1 308. Kowalski, P. S.; Rudra, A.; Miao, L.; Anderson, D. G., Delivering the Messenger: 2 Advances in Technologies for Therapeutic mRNA Delivery. Mol. Ther. 2019, 27 (4), 710-728.

3 309. Weng, Y.; Li, C.; Yang, T.; Hu, B.; Zhang, M.; Guo, S.; Xiao, H.; Liang, X. J.;

4 Huang, Y., The challenge and prospect of mRNA therapeutics landscape. Biotechnol. Adv. 2020, 40, 5107534.

6310 . Herzog, R. W., Hepatic AAV gene transfer and the immune system: friends or foes? Molecular 7 therapy: the journal of the American Society of Gene Therapy 2010, 18 (6), 1063-1066.

8 311. Schwanhausser, B.; Busse, D.; Li, N.; Dittmar, G.; Schuchhardt, J.; Wolf, J.; Chen, 9 W.; Selbach, M., Global quantification of mammalian gene expression control. Nature 2011, 473 (7347), $10 \quad 337-42$.

11 312. Urquhart, L., Top companies and drugs by sales in 2019. Nat. Rev. Drug Discov. 2020, 19 (4), 12228.

14 Table of Contents (TOC) 